\title{
ESTUDO COMPARATIVO DE DESAJUSTE CERVICAL, INFILTRAÇÃO MARGINAL E RESISTÊNCIA À TRAÇÃO DE COPI NGS METÁLICOS CIMENTADOS SOBRE ABUTMENTS TIPO UCLA PREPARADOS COM DIFERENTES DESENHOS DE MARGENS
}

\section{MARIANA RIBEIRO DE MORAES REGO}

Dissertação apresentada à Faculdade de Odontologia de Bauru da Universidade de São Paulo, como parte dos requisitos para obtenção do título de Mestre em Odontologia - área de Reabilitação Oral.

(Edição Revisada) 


\section{ESTUDO COMPARATIVO DO DESAJUSTE CERVICAL, INFILTRAÇÃO MARGINAL E RESISTÊNCIA À TRAÇÃO DE COPINGS METÁLICOS CIMENTADOS SOBRE ABUTMENTS TIPO UCLA PREPARADOS COM DIFERENTES DESENHOS DE MARGENS}

\section{MARIANA RIBEIRO DE MORAES REGO}

Dissertação apresentada à Faculdade de Odontologia de Bauru da Universidade de São Paulo, como parte dos requisitos para obtenção do título de Mestre em Odontologia - área de Reabilitação Oral.

Orientador: Profo Dr. Wellington Cardoso Bonachela

(Edição Revisada) 
R265e $\begin{aligned} & \text { Rego, Mariana Ribeiro de Moraes } \\ & \text { Estudo comparativo do desajuste cervical, infiltração }\end{aligned}$ marginal e resistência à tração de copings metálicos cimentados sobre abutments tipo UCLA preparados com diferentes desenhos de margens / Mariana Ribeiro de Moraes Rego. -- Bauru, 2005.

$x x, 139$ p. : il. ; $30 \mathrm{~cm}$.

Dissertação (Mestrado) -- Faculdade de Odontologia de Bauru. Universidade de São Paulo.

Orientador: Prof. Dr. Wellington Cardoso Bonachela

Autorizo, exclusivamente pra fins acadêmicos e científicos, a reprodução total ou parcial desta tese, por processos fotocopiadores e/ou meios eletrônicos.

Assinatura do autor:

Data: 25 de setembro de 2005 


\section{MARIANA RIBEIRO DE MORAES REGO}

11 de janeiro de 1978

Rio de Janeiro - RJ

Filiação

1997-2001

$2000-2003$

2001-2003

2003-2005

Associações
Nascimento

Luis César de Moraes Rego

Célia Maria Ribeiro de Moraes Rego

Curso de Graduação realizado na Faculdade de Odontologia da Universidade Federal do Rio de Janeiro

Estágio no Departamento de Prótese e Materiais Dentários da Faculdade de Odontologia da Universidade Federal do Rio de Janeiro na Disciplina de Prótese Fixa II

Curso de Especialização em Prótese Dentária na Universidade do Grande Rio - RJ

Curso de Pós-Graduação em Reabilitação Oral (Prótese), em nível de Mestrado, na Faculdade de Odontologia de Bauru USP

Associação Brasileira de Odontologia (ABO)

Sociedade Brasileira de Pesquisa Odontológica (SBPqO) 


\section{DEDICATÓRIA}

A Deus, por ser minha maior fonte de força, por estar ao meu lado em todos os momentos, por iluminar meus caminhos, por tornar tudo possível.

Aos meus pais, Célia e Luis, por apoiarem meus sonhos, por me amarem incondicionalmente, por acreditarem que eu chegaria até aqui e especialmente à minha Mãe, que mesmo distante, esteve ao meu lado nos momentos em que eu mais precisei.

Ao Luiz, enquanto Mestre, pela dedicação, competência, honestidade e incentivo, tornando-se o exemplo que escolhi para seguir e motivo maior que me trouxe até aqui, e enquanto namorado, pelo amor, carinho, por apoiar meu sonho, por aceitar a minha ausência e por esperar a minha volta.

Dedico a vocês este trabalho. 
"De tudo ficaram três coisas:

a certeza de que estamos sempre começando...

a certeza de que é preciso continuar...

a certeza de que seremos interrompidos antes de terminar...

\section{PORTANTO DEVEMOS}

Fazer da interrupção um caminho novo...

da queda um passo de dança...

do medo, uma escada...

do sonho, uma ponte...

da procura... um encontro." 


\section{AGRADECIMENTOS ESPECIAIS}

A Deus por nunca me abandonar e nos momentos mais difíceis, me carregar nos braços.

Aos meus pais Célia e Luis pela vida, pelo amor infinito, pelo apoio e por plantar em mim a vontade de chegar cada dia mais longe, para ser motivo de orgulho.

Ao meu namorado Luiz, pelo amor, compreensão e companheirismo, por toda ajuda durante a execução deste trabalho, por sonhar o meu sonho e se alegrar com as minhas conquistas.

Ao meu irmão Bruno, pelos dias de amizade e por estar ao lado da minha mãe durante a minha ausência.

Aos meus avós Carmy e Ribeiro, Augusta (in memorian) e Luiz Augusto (in memorian), pelo amor infinito, pelo carinho, pelos cuidados, pela presença.

Aos meus tios Antônio, Carmem, Cenira, Cleide, J oão Carlos e José Roberto e primos Alejandro, Joshua, Liana, Sábata, Stella e Stella Maris por completarem a família que eu amo e sem a qual não seria feliz. 
À tia Alcina por ser também minha avó, e assim, por todo carinho e apoio que tem me dedicado.

Aos meus padrinhos, Emília e Maximino, por todo o carinho sempre que estão ao meu lado.

Aos meus amigos, Ana Beatriz, Ana Rita, Bianca, Carlos, Felipe, Flávia, J oão César, Kate, Karine, Ludimilla, Marcelo, Márcio, Mayra, Natália, Rossana e Vinícius por todo o carinho, pela alegria que trazem à minha vida, por estarem sempre presentes (mesmo quando distantes), por aceitarem minha ausência e mesmo assim... Continuarem GRANDES AMIGOS!

À Thayana que me aceitou em sua vida com muito carinho, me apoiou e consolou e soube compreender minhas necessidades, mesmo quando isso afetava diretamente seus prazeres e compromissos.

À Tia Maria Helena, que participou deste sonho desde o início, me ajudando e torcendo por mim sempre.

À Eleuza, por ser mais que paciente, por ter sido amiga além de ter-me "adotado" e ter sido um pouco mãe, quando a minha estava distante. 
Aos colegas de Mestrado Valdey e Lucas que souberam ser diferentes quando todos foram iguais, tornando-se mais do que colegas, grandes amigos.

Aos amigos da turma de Doutorado, Eduardo Ayub, Marli, Paulo Fukashi, Paulo Rosseti, Ricardo e Tatiany, por serem amigos quando podiam apenas ser colegas.

Aos funcionários Ana Cláudia Mattar, Cleusa Leite e Eduardo Covolan pela amizade conquistada, por me ouvirem quando eu precisava de alguém para me escutar, pela ajuda sempre necessária.

Muito obrigada por tudo! 


\section{AGRADECIMENTOS}

Ao meu orientador Prof. Dr. Wellington Cardoso Bonachela, pela orientação na realização deste trabalho, pela confiança em mim depositada e por todos os ensinamentos transmitidos.

Aos Professores Carlos dos Reis Pereira de Araújo, José Herique Rubo e Luiz Fernando Pegoraro, por transmitirem sempre a verdadeira essência de um Mestre.

Aos Professores do Departamento de Prótese, Accácio Lins do Valle, Gerson Bonfante, Lucimar Falavinha Vieira, Milton Carlos Gonçalves Salvador, Paulo César Rodrigues Conti, Paulo Martins Ferreira, Renato de Freitas e Vinícius Carvalho Porto, por todos os ensinamentos transmitidos a cada dia do curso.

Ao Prof. Dr. José Mondelli pelo grande exemplo de Profissional, Mestre e Ser Humano e por sua amizade verdadeira.

Ao Prof. Dr. Paulo Amarante pela dedicação com a qual me ajudou durante a etapa experimental e ao Departamento de 
Materiais Dentários por disponibilizar suas dependências e equipamentos.

Ao Departamento de Endodontia por disponibilizar suas dependências e equipamentos e ao funcionário Edimauro de Andrade por toda boa vontade e presteza com que me recebeu e me ajudou durante a etapa experimental deste trabalho.

Ao Prof. Dr. José Roberto Pereira Lauris pela ajuda na análise estatística deste trabalho.

Às secretárias do Departamento de Prótese, Ana Cláudia Mattar, Déborah Riêra Blasca, Edna Fabrini e Valquíria Nogueira pela presteza, amizade e dedicação.

Aos técnicos Marcelo Giatti, Nelson Queiroz e Reivanildo Viana por todo o apoio e ajuda sempre que precisei e acima disso, pela amizade.

Ao técnico Sidnei Martins e toda sua equipe por todo o apoio, dedicação e competência na execução deste trabalho.

Ao Laboratório de Prótese Adalberto Santo e toda sua equipe, especialmente ao Júnior, por todo o apoio e por todo tempo dispensado para me ajudar na execução deste trabalho. 
A todos os funcionários da Biblioteca, especialmente as bibliotecárias Rita de Cássia Paglione e Vera Regina Boccato, pela disponibilidade e presteza sempre que solicitados.

Aos funcionários da Central de Esterilização pela paciência com os atrasos, pela disponibilidade e presteza.

À Conexão Sistemas de Prótese pelo apoio e concessão de material para a execução deste trabalho.

À FAPESP, pelo apoio financeiro, sem o qual tornar-se-ia impossível concluir este trabalho.

\section{À Faculdade de Odontologia de Bauru - Universidade de} São Paulo, representada por sua Diretora Profa. Dra. Maria Fidela de Lima Navarro.

A todas as pessoas que de alguma forma contribuíram para a execução deste trabalho. 


\section{SUMÁRIO}

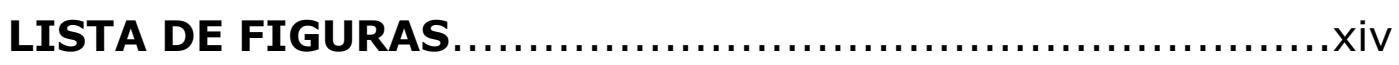

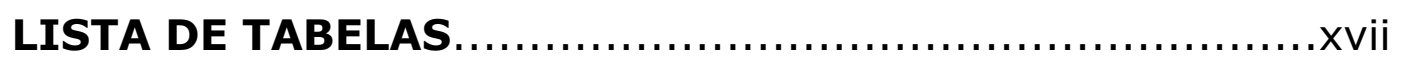

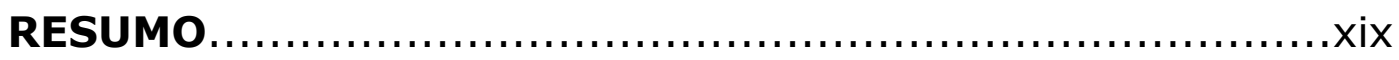

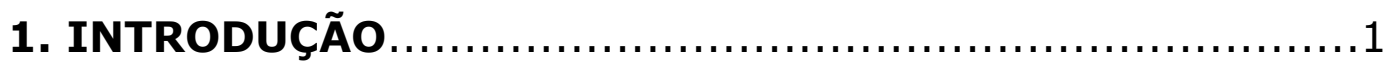

2. REVISÃO DE LITERATURA............................... 9

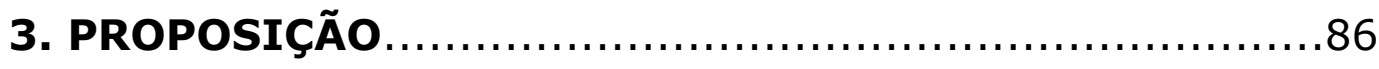

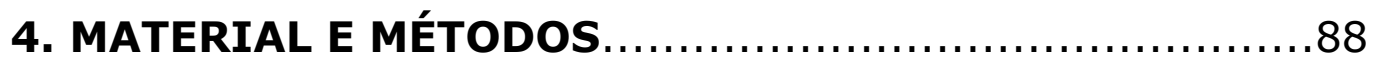

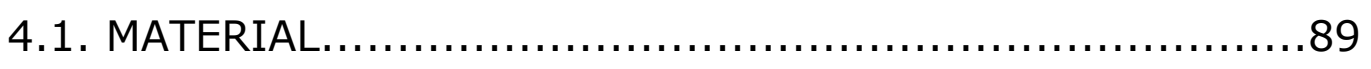

4.2. MÉTODOS .............................................. 90

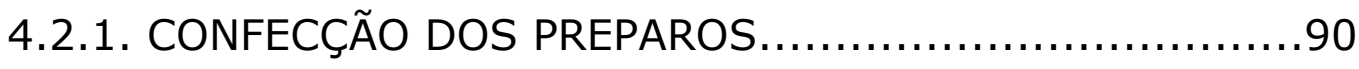

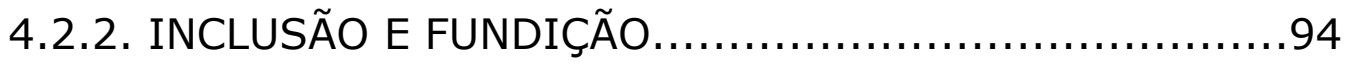

4.2.3. ACABAMENTO E POLIMENTO ...........................97

4.2.4. POSICIONAMENTO DOS ANÁLOGOS DE IMPLANTES.....99

4.2.5. ENCERAMENTO, INCLUSÃO E FUNDIÇÃO DOS COPINGS

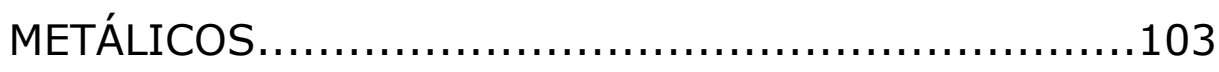


4.2.6. AVALIAÇÃO DO DESAJUSTE CERVICAL ANTES DA

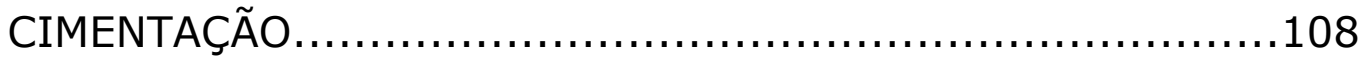

4.2.7. CIMENTAÇÃO

4.2.8. AVALIAÇÃO DO DESAJUSTE CERVICAL APÓS A CIMENTAÇÃO ................................................

4.2.9. CÁlCULO DO DESAJUSTE FINAL OBTIDO COM A CIMENTAÇÃO ................................................. 114

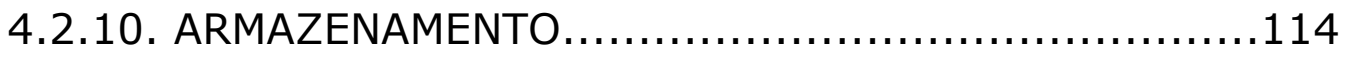

4.2.11. INFILTRAÇÃO MARGINAL..............................116

4.2.12. RESISTÊNCIA À TRAÇÃO .............................121

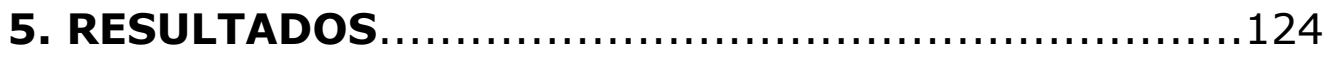

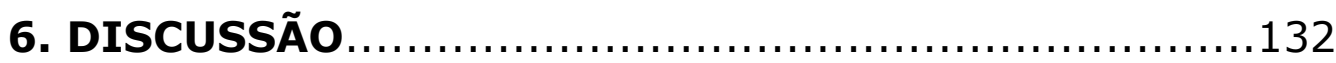

7. CONCLUSÃO ............................................ 144

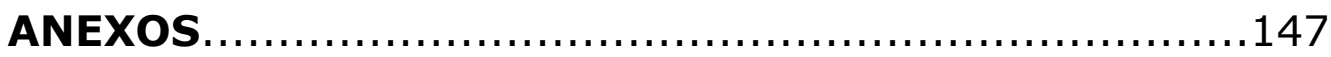

REFERÊNCIAS BIBLIOGRÁFICAS......................154

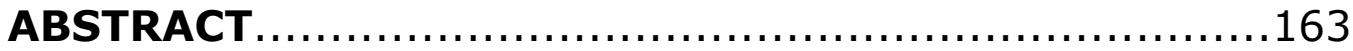




\section{Lista de Figuras}

FIGURA 1 - Fresadeira utilizada na confecção dos preparos........91

FIGURA 2 - Confecção dos preparos (A-C) $.92-93$

FIGURA 3 - Abutments com condutos de alimentação................95

FIGURA 4 - Abutments em anel para fundição........................95

FIGURA 5 - Liga de Ni-Cr...................................... 96

FIGURA 6 - Alteração na forma das borrachas abrasivas (A-B)...98

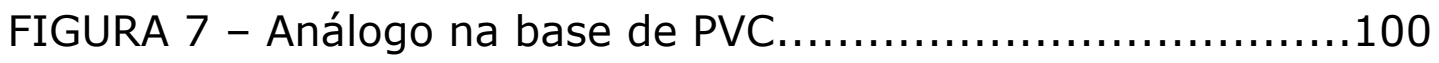

FIGURA 8 - Análogo na base de resina............................101

FIGURA 9 - Delineador usado na inclusão dos análogos (A-B).101

FIGURA 10 - Enceramento do coping..............................103

FIGURA 11 - Matriz para duplicação do enceramento (A-C)104-105

FIGURA 12 - Injeção da cera plastificada (A-B)....................106

FIGURA 13 - Coping com alça para tração........................107

FIGURA 14 - Encaixe macho-fêmea para correto posicionamento do coping. 108 
FIGURA 15 - Marcações esféricas para avaliação do desajuste cervical 10

9

$\begin{array}{lllll}\text { FIGURA } & 16 & - & \text { Prensa } & \text { para }\end{array}$ cimentação. 110

FIGURA 17 - Microscópio comparador (A-B)..... $110-111$

FIGURA 18 - Esquema de avaliação do desajuste cervical. 111

FIGURA 19 - Seringa utilizada na cimentação (A-B). $112-113$

FIGURA 20 - Espécime corado em fuccina.... 115

FIGURA 21 - Inclusão do espécime em resina acrílica $(A-B) \ldots . .116$

FIGURA

22

$-\quad$ Disco

de

corte

Isocut 118

FIGURA 23 - Máquina de corte Isomet (A-C) 118-119

FIGURA 24

Fotomicroscópio 120

FIGURA 25 - Máquina Universal de Ensaios (A-B). 122

FIGURA 26 - Corte longitudinal do espécime para teste de infiltração marginal $(A-B)$.... 148 
FIGURA 27 - Fotomicrografia - pigmentação do cimento pela

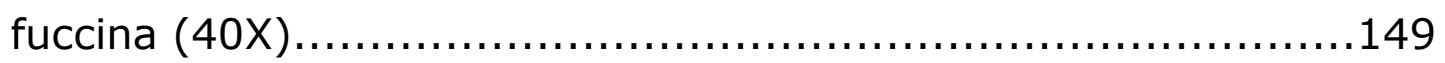

FIGURA 28 - Fotomicrografia - infiltração escore 1 (40X)........149

FIGURA 29 - Fotomicrografia - adaptação adequada (40X)......149

FIGURA 30 - Fotomicrografia - adaptação ótima (40X)...........149

FIGURA 31 - Fotomicrografia - infiltração escore 6 (A-C)(40X).149

FIGURA 32 - Fotomicrografia -chanfro profundo (40X)..........150

FIGURA 33 - Fotomicrografia - linha de cimento (40X)..........150

FIGURA 34 - Fotomicrografia - espécime com escore 3 (40X)..150

FIGURA 35 - Fotomicrografia - chanferete (40X)................150

FIGURA 36 - Fotomicrografia - espécime com escore 3 (80X)..150

FIGURA 37 - Fotomicrografia - linha de cimento (40X)..........150

FIGURA 38 - Fotomicrografia - infiltração escore 1 (160X).....150 


\section{Lista de Tabelas}

TABELA 1: Material de consumo utilizado. .89

TABELA 2: Mediana, média, desvio padrão, valores mínimo e máximo para desajuste cervical 126

TABELA 3: Análise de variância a um critério aplicado aos valores de desajuste vertical

TABELA 4: Mediana, média, desvio padrão, valores mínimo e máximo para infiltração marginal.

TABELA 5: Teste de Kruskal Wallis aplicado aos valores de desajuste cervical. 128

TABELA 6: Mediana, média, desvio padrão, valores mínimo e máximo para resistência à tração.

TABELA 7: Análise de variância a um critério aplicado aos valores de resistência à tração 130

TABELA 8: Teste de Tukey aplicado aos valores de resistência à tração para comparação individual entre os grupos. 
TABELA 9 - Valores absolutos para o desajuste cervical obtidos com a cimentação temporária. 151

TABELA 10 - Escores para infiltração marginal obtidos para cada

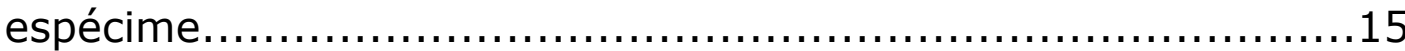

2

TABELA 11 - Valores absolutos para resistência à tração obtidos para cada espécime............................................ 153 


\section{Resumo}

O objetivo desse estudo foi comparar o desajuste cervical, a infiltração marginal e a resistência à tração de copings metálicos cimentados sobre abutments tipo UCLA preparados com três diferentes desenhos de margens: ombro, chanfro profundo e chanferete. Para isso, três abutments UCLA calcináveis receberam preparos padronizados, variando apenas os desenhos de término cervical. Réplicas desses abutments foram industrialmente confeccionadas, sendo 20 de cada desenho de margem, formando assim, os três grupos experimentais. Esses abutments foram fundidos e sobre eles, encerados e fundidos copings metálicos para coroas metalo-cerâmicas. O desajuste cervical foi avaliado em um microscópio comparador Mitutoyo, antes e após a cimentação provisória com TempBond NE. Pela subtração desses valores, foram obtidos os valores de desajuste cervical final para cada espécime. Os espécimes foram então redivididos em dois grupos de 30, com 10 espécimes de cada desenho de margem, sendo que um foi submetido a testes de tração e outro a testes de infiltração marginal após um período de 30 dias. Os valores obtidos foram submetidos aos testes estatísticos. Com relação ao desajuste cervical o teste ANOVA mostrou não haver diferença estatisticamente significante $(p>0.05)$ entre os grupos avaliados. 0 
mesmo foi comprovado pelo teste de Kruskall-Walis com relação à infiltração marginal. Sobre a resistência à tração, ficou comprovado pelo teste ANOVA, haver diferença estatisticamente significante entre os grupos $(p<0.05)$. Assim, o teste de Tukey mostrou que essa diferença foi encontrada apenas quando comparados os desenhos em chanferete e chanfro profundo, sendo que o último apresentou maiores valores retentivos. Testes de correlação foram conduzidos para avaliar se houve influência do desajuste cervical na infiltração e na retenção dos copings metálicos, porém, esta correlação não foi estatisticamente significante $(p>0.05)$. Dessa forma, pôde-se concluir que os diferentes desenhos de margem não influenciaram o desajuste cervical ou a infiltração marginal dos copings metálicos, entretanto, em relação à resistência à tração o desenho em chanfro profundo mostrou valores maiores que 0 desenho em chanferete, sem apresentar diferenças quando comparado ao desenho em ombro. Pôde-se concluir ainda que não há correlação entre desajuste cervical e infiltração marginal ou retenção dentro das variáveis avaliadas nesse estudo.

Palavras chave: desajuste cervical, infiltração marginal, resistência à tração, implantes, coroas totais. 
1 INTRODUÇÃO 


\section{Introdução}

A restauração de dentes perdidos para uma reconstrução funcional e estética e que também mantenha a saúde das estruturas orais existentes, é o objetivo do tratamento para clínicos e pacientes. ${ }^{30} \mathrm{O}$ uso de implantes osseointegrados para alcançar este objetivo tem ajudado a contornar muitas limitações encontradas com as próteses fixas e removíveis convencionais e tem-se mostrado bem sucedido em longo prazo, para o tratamento de pacientes total e parcialmente edentados. ${ }^{30,31,57} \mathrm{O}$ sucesso em longo prazo dos implantes osseointegrados está na integração com as estruturas ósseas e tecidos gengivais. Apenas recentemente a importância das estruturas gengivais peri-implantares e sua participação na longevidade do tratamento com implantes receberam maior atenção. A relação tanto com os tecidos duros quanto com os tecidos moles deve ser uma união estável e duradoura para ser biologicamente saudável. ${ }^{30}$

Sendo assim, o sucesso da reabilitação oral de pacientes tratados com implantes osseointegrados depende não somente da osseointegração, mas também, da manutenção da integridade da conexão da supra-estrutura protética aos implantes. ${ }^{7}$ 
A reabilitação de arcadas edêntulas com implantes osseointegrados cilíndricos foi concebida, inicialmente, para o uso exclusivo na mandíbula, com a instalação de 5 ou 6 implantes entre os forames mentuais e com a confecção de próteses fixas que eram unidas aos implantes por meio de parafusos, sem manter uma relação íntima com os tecidos moles subjacentes por se tratarem de próteses com conexões aos abutments totalmente supragengivais. ${ }^{51}$ Entretanto, desde que inicialmente introduzidos por Brånemark em 1985 e restaurados com uma coroa artificial por Jemt em 1986, o uso de implantes osseointegrados para a reposição de elementos unitários tem aumentado significativamente ${ }^{9}$ uma vez que com o aumento da demanda de pacientes, as próteses removíveis tornaram-se menos aceitáveis e muitos pacientes opõem-se ao preparo de dentes hígidos para a instalação de uma prótese fixa. ${ }^{5}$

Contudo, apesar do sucesso em longo prazo e da previsibilidade das restaurações implanto-suportadas confirmados por estudos longitudinais como o de ZARB e SCHMITT ${ }^{64}$ em 1990, investigações clínicas de restaurações parafusadas mostraram que a perda do parafuso de retenção que fixa a prótese ao abutment é um problema comum. ${ }^{10,31,37,64}$ Isso levou ao desenvolvimento das próteses sobre implantes cimentadas. ${ }^{10}$ Além da vantagem da 
eliminação do parafuso que fixa a prótese ao abutment, as próteses cimentadas apresentam várias outras vantagens sobre as próteses parafusadas, como a semelhança ao tratamento protético fixo sobre dentes, uso de menos componentes protéticos e com isso mais simples, menor custo, melhor estética e carregamento oclusal, adaptação passiva das restaurações, menos fraturas da resina acrílica ou porcelana, menos consultas, além de que o agente cimentante é considerado por muitos autores como um amortecedor de impactos causados durante a função. 3,7,16,25,31,37,45,57 Além disso, com o advento dos abutments preparáveis como o UCLA, a aplicação de técnicas e conceitos já fundamentados na Odontologia, torna-se cada vez mais freqüente. A grande desvantagem da prótese cimentada citada por vários autores é a falta de reversibilidade que pode tornar-se necessária no caso de restaurações implanto-suportadas para manutenção ou verificação da higiene oral do paciente, para reparos na restauração ou para apertos no parafuso do abutment que podem ser realizados sem que a prótese seja danificada. ${ }^{3}$ No caso da prótese parafusada, essa reversibilidade é garantida pelo parafuso que fixa a prótese ao abutment. ${ }^{3,7,37,57}$ Entretanto, vários autores mostram que essa mesma reversibilidade pode ser alcançada nas próteses cimentadas com 0 uso de cimentos temporários. ${ }^{2-}$ 
Desta forma, com a maior utilização das próteses implantosuportadas cimentadas, a adaptação cervical entre o abutment e a restauração assume grande importância para a manutenção da saúde dos tecidos ao redor do implante, já que em sua maioria, a junção entre esses componentes está localizada mais subgengivalmente do que aquelas suportadas por dentes. Assim, torna-se imprescindível o cuidado com as variáveis protéticas que influenciam nesta adaptação cervical, uma vez que ela determinará a espessura da linha de cimento exposta ao meio bucal, que por sua vez poderá contribuir para a instabilidade dos tecidos periodontais. $^{20,55}$ Este cimento marginal exposto, com sua superfície rugosa está sujeito à dissolução e aderência de placa bacteriana, que é a causa primária na etiologia da doença periodontal e cáries. . $^{84,20,23,27,38,52}$ No caso das restaurações implanto-suportadas, não há incidência de cáries, entretanto, GUALINI e BERGLUNDH ${ }^{21}$ em 2003 afirmaram que o acúmulo de placa em implantes resulta no desenvolvimento de uma lesão inflamatória na mucosa peri-implantar associada e que os sinais clínicos da inflamação aumentam tanto nos implantes quanto nos dentes durante o período de formação de placa.

Desta forma, podemos observar que a adaptação cervical de uma restauração fundida, tanto sobre dentes quanto sobre 
implantes osseointegrados, é muito importante para o sucesso da mesma. $26,27,39,41,54,61$

Entretanto, quando próteses fixas são cimentadas a dentes e a abutments de implantes, uma preocupação deve existir não apenas quanto à linha de cimento formada, mas também quanto à retenção desta restauração, ${ }^{12}$ uma vez que a discrepância cervical e a retenção são fatores cruciais na longevidade das restaurações fundidas. ${ }^{44}$

Desta forma, conicidade, altura, rugosidade do preparo, desenho das margens cervicais, fundição, cimento e técnica de cimentação utilizada, são as variáveis mais comumente citadas na literatura como determinantes do grau de retenção e desajuste cervical das restaurações fundidas. $8,11,20,23,35,44,56$

A forma geométrica do preparo influenciará no grau de retenção e este indiretamente no assentamento total da restauração fundida. Logo, quanto mais alto, paralelo e rugoso o preparo, mais dificuldades teremos para o assentamento antes e principalmente após a cimentação da prótese, aumentando assim, o desajuste cervical. 
Outro fator que deve ser observado durante a confecção da forma geométrica de um preparo para coroa total é o desenho da margem cervical, pois segundo DEDMON,${ }^{11}$ o desenho da margem afeta a espessura da linha de cimento quando coroas totais fundidas são cimentadas. Ainda, segundo GARDNER, ${ }^{17}$ o desenho da margem cervical é o elo mais importante e também o mais fraco no sucesso das restaurações fundidas, uma vez que representam um dos componentes mais susceptíveis a falhas, tanto mecânicas quando biológicas.

Vários são os desenhos de margem sugeridos na literatura: ${ }^{6}$ ombro, chanferete, chanfro profundo ou lâmina de faca linha zero, em 1350, dentre outros, sendo que alguns ainda podem ser biselados a critério do profissional. ${ }^{42}$ Vários estudos ${ }^{6,8,11,13,16-}$ $18,23,24,27,42,43,49,50,54,56$ ao longo dos anos, vêm avaliando os diferentes tipos de desenho de margens quanto à adaptação, distorção e assentamento oclusal, sem contudo, que uma conclusão quanto ao melhor tipo de desenho de margem seja alcançada. Sabe-se apenas que o desenho adequado é aquele que permite o melhor assentamento da restauração antes e após a cimentação, uma vez que durante este procedimento, o agente cimentante deve escoar de forma contínua sobre o preparo, o que 
torna importante uma seleção adequada, visando também um menor desajuste cervical.

Uma vez confeccionado o preparo com todos os seus detalhes, outro fator determinante para a quantidade de desajuste cervical é a seleção do agente cimentante e da técnica de cimentação.

Como já discutido anteriormente, é preconizada na literatura a utilização de cimentos temporários para a cimentação definitiva das próteses implanto-suportadas cimentadas, a fim de que seja mantido o princípio da reversibilidade.

Diante do exposto, torna-se óbvia a necessidade da revisão de conceitos já estabelecidos na Odontologia Restauradora como desenhos de margens, desajuste e infiltração marginal e retenção, para sua aplicação no atual campo da Implantodontia. 
2 REVISÃO DE LITERATURA 


\section{Revisão de Literatura}

A cimentação de um trabalho protético, seja sobre dentes preparados ou implantes osseointegrados, sempre foi objeto de muito estudo.

Inúmeros fatores podem influenciar nos resultados dessa importante etapa de uma prótese fixa.

Nesse estudo, foram avaliados três desses fatores: desajuste cervical, infiltração marginal e resistência à tração. Dessa forma, uma revisão da literatura será agora apresentada levando-se em consideração esses aspectos.

Em 1964, o alívio da resistência promovida pelo cimento em coroas totais metálicas foi avaliado por FUSAYAMA T., IDE K. e HOSODA H. ${ }^{15}$ Para isso, molares humanos receberam preparos para coroa total. Durante os preparos, alguns espécimes apresentaram uma conicidade onde o diâmetro do preparo era reduzido em $1 \mathrm{~mm}$ a cada $4 \mathrm{~mm}$ de altura e outros uma conicidade onde o diâmetro do preparo era reduzido em $1 \mathrm{~mm}$ a cada $2 \mathrm{~mm}$. Além disso, alguns espécimes apresentaram altura de preparo de 5 
a $6 \mathrm{~mm}$, enquanto em outros essa altura variou entre 3 e $4 \mathrm{~mm}$. Os desenhos de término utilizados também variaram, sendo utilizado o ombro em uma face do preparo e o chanfro na outra face. Os preparos foram moldados com hidrocolóide irreversível. Alguns troquéis receberam uma camada de esmalte de unha em todo o preparo, exceto na margem, outros receberam uma folha de estanho de $40 \mu \mathrm{m}$ de espessura fixada por vaselina que foi espalhada pelo preparo, exceto na margem e outros não receberam qualquer tipo de tratamento. Padrões de cera foram confeccionados e fundidos em uma liga de cobre. Para a cimentação das restaurações foi utilizado o cimento fosfato de zinco e em seguida, uma carga estática de 15 ou $50 \mathrm{Kg}$ foi aplicada às coroas até a presa do cimento. Os espécimes foram seccionados no sentido vestíbulo-lingual e as superfícies seccionadas receberam acabamento com uma pedra. A espessura de cimento foi mensurada em um microscópio com uma precisão de $0.001 \mathrm{~mm}$. Os resultados mostraram que nenhuma diferença estatisticamente significante foi encontrada quando cargas estáticas de 15 ou 50 KG foram aplicadas, sendo a carga de $15 \mathrm{Kg}$ suficiente mesmo quando não há alívio interno da coroa. Um aumento na conicidade do preparo gerou uma redução na linha de cimento, exceto para aqueles espécimes onde um alívio interno da coroa foi realizado. Entretanto, um aumento da conicidade reduz as capacidades 
retentivas do preparo. Preparos mais baixos produziram coroas mais bem adaptadas quando comparados a preparos mais altos, entretanto, essa diferença não foi estatisticamente significante. A presença de alívio interno também foi significativa para a redução da linha de cimento, mas nenhuma diferença foi encontrada com relação ao tipo de alívio utilizado. Os autores encontraram que a espessura da linha de cimento exposta em coroas cimentadas sobre términos em ombro é maior do que aquelas cimentadas sobre chanfros. Com base nos resultados obtidos, os autores puderam concluir que (i) uma quantidade de pressão excessiva durante a cimentação não produziu diferença na linha de cimento, (ii) um aumento na conicidade dos preparos resultou em um decréscimo acentuado da linha de cimento, (iii) a redução na altura dos preparos reduziu levemente a linha de cimento, (iv) o alívio interno reduziu significativamente a linha de cimento, (v) a exposição de cimento na margem foi maior nos preparos em ombro que em chanfro.

Em 1973, SHILlingBURG H.T., HOBO S. e FISHER D.W. ${ }^{50}$ avaliaram o desenho do preparo e a distorção de margem em restaurações metalo-cerâmicas. Quatro desenhos de margem foram avaliados: chanfro, chanfro profundo com bisel, ombro biselado e ombro. Um modelo-mestre representando um preparo 
para coroa total metalo-cerâmica com desenho de margem em chanfro foi confeccionado em cera e depois fundido em uma liga de cromo-cobalto. Esse modelo foi moldado com polissulfeto e cinco modelos em gesso foram obtidos. O modelo mestre teve então seu término modificado para chanfro com bisel, em seguida em ombro biselado e ombro, e entre cada alteração de desenho, novas moldagens foram realizadas e cinco troquéis de gesso obtidos para cada grupo. Sobre os troquéis foram enceradas infra-estruturas metálicas. Para garantir a padronização dessas estruturas, um molde dividido foi utilizado. Após o enceramento, as infraestruturas foram então incluídas e fundidas. A aplicação da porcelana seguiu 5 etapas: (i) desgaseificação, (ii) opaco, (iii) porcelana de dentina e incisal, (iv) queima de correção para dentina e esmalte e (v) glaze. Entre cada etapa e antes de qualquer procedimento de queima, mensurações da distorção marginal foram realizadas, avaliando-se a distância da linha do término de cada coroa às marcas de referência posicionadas nos troquéis. Os resultados mostraram que todos os desenhos de margem apresentaram aumentos sucessivos de abertura marginal na primeira aplicação de porcelana e que, com exceção do ombro biselado, todos os outros desenhos continuaram a abrir após a segunda aplicação da porcelana. Diferenças estatisticamente significantes foram encontradas entre o ombro biselado $(5.8 \mu \mathrm{m}) \mathrm{e}$ 
as duas configurações de chanfro e também entre o ombro $(10.7 \mu \mathrm{m})$ e as duas configurações de chanfro. Nenhuma diferença foi encontrada entre o chanfro $(47.1 \mu \mathrm{m})$ e o chanfro profundo com bisel $(29.3 \mu \mathrm{m})$ ou entre o ombro e o ombro biselado. Assim, os autores concluíram que os desenhos de término em ombro, com ou sem bisel, produziram menores distorções nas margens vestibulares de coroas metalo-cerâmicas quando comparados aos desenhos em chanfro, com ou sem bisel.

Em 1978, a infiltração marginal de coroas totais cimentadas foi avaliada por MONDELLI J., ISHIKIRIAMA A. e GALAN JÚNIOR J. ${ }^{38}$ Molares humanos foram preparados para coroa total e diretamente sobre os preparos as coroas foram enceradas e posteriormente fundidas em ouro. As coroas foram cimentadas sobre os dentes com o cimento fosfato de zinco como controle e com o cimento fosfato de zinco associado a algum tipo de agente protetor. Esses agentes - verniz de cavidade, base, hidróxido de cálcio e agente bactericida - foram aplicados em todas as superfícies preparadas incluindo a margem e também em todas as superfícies $1 \mathrm{~mm}$ acima da margem. A exceção foi o agente bactericida que foi aplicado em todas as superfícies incluindo a margem. Uma hora após a cimentação, 5 espécimes de cada grupo foram imersos em ${ }^{131} \mathrm{INa}$, enquanto os outros espécimes só foram 
imersos nessa solução após o período de imersão de 21 dias em água destilada. Os espécimes foram seccionados e escores atribuídos ao grau de infiltração marginal encontrado. Assim, os autores concluíram que coroas totais cimentadas com fosfato de zinco mostraram diferenças na infiltração marginal de ${ }^{131} \mathrm{INa}$ dependendo do material de proteção utilizado, e que o melhor desses materiais contra a infiltração marginal foi o verniz de cavidades aplicado em duas camadas em todas as superfícies, incluindo a margem. Concluíram também que a quantidade de infiltração marginal pode ser influenciada pela adaptação da coroa e da espessura do filme de cimento e que não foram encontradas diferenças entre os dois períodos de teste.

KOYANO E., IWAKU M. e FUSAYAMA T. ${ }^{33}$ avaliaram, em 1978, as técnicas de pressão e a espessura de cimento em restaurações fundidas. Foram utilizados nesse estudo, dois tipos experimentais de cavidades, uma representando uma inlay e outra representando uma coroa total. Após o enceramento do padrão de cera, este foi fundido em uma liga de cobre. O cimento utilizado nesse estudo foi o cimento fosfato de zinco aplicado no interior da cavidade. Após a cimentação, as restaurações foram submetidas à pressão de acordo com diferentes técnicas: (i) pressão estática (1, 2, 3 ou $4 \mathrm{Kg}$ ); (ii) martelo gravitacional (após a cimentação, a 
pressão foi primeiramente aplicada por dois golpes de martelo repetido 10 vezes por 20 segundos e então mantido sob pressão estática de $1 \mathrm{~kg}$ por 15 minutos); (iii) martelo de mola (a pressão foi primeiramente aplicada por dois golpes de martelo de um conjunto dentário automático de martelo no nível "forte" por 10 vezes em 20 segundos e então a pressão estática de $1 \mathrm{~kg}$ foi aplicada por 15 minutos); (iv) vibração vertical (foi utilizado um vibrador vertical para condensação de amálgama por 5 segundos a 2300 rpm por 3 vezes em 20 segundos e depois a carga estática de $1 \mathrm{~kg}$ aplicada por 15 minutos); (v) vibração horizontal (um vibrador horizontal para condensação de amálgama foi utilizado. A pressão foi aplicada por 15 segundos e uma carga estática de $1 \mathrm{~kg}$ foi aplicada por 15 minutos); (vi) combinação das pressões estática e dinâmica (para os espécimes maiores, a pressão foi primeiramente aplicada por carga estática de $4 \mathrm{~kg}$ por 10 segundos e então pelo martelo gravitacional, o vibrador vertical ou o vibrador horizontal. Uma carga estática de $1 \mathrm{~kg}$ para o grupo do martelo e de $2 \mathrm{~kg}$ para os outros grupos foi mantida por 15 minutos). A espessura da linha de cimento foi determinada antes e após a cimentação. Os resultados mostraram que a linha de cimento mais delgada foi obtida pela vibração vertical, seguida daquela obtida pela vibração horizontal e que a técnica de pressão estática foi a que gerou a maior linha de cimento. Além disso, um aumento da carga gerou 
menores linhas de cimento quando aplicada a pressão estática, e para os espécimes maiores, quando aplicadas as técnicas vibratórias. Assim, os autores concluíram que (i) a pressão dinâmica produziu menores linhas de cimento que a pressão estática; (ii) que a combinação da pressão estática seguida de pressão dinâmica produziu menores linhas de cimento que qualquer técnica individual; (iii) a melhor técnica para uso clínico é o assentamento da restauração por pressão digital seguida por aplicação de vibração horizontal sob pressão manual.

Em 1979, OLIVEIRA J.F., ISHIKIRIAMA A., VIEIRA D.F. e MONDELLI J.4 ${ }^{40}$ avaliaram a influência da pressão e vibração durante a cimentação. Para esse estudo foi utilizado um modelo tipo typodont com dentes Ivorine. Uma armação metálica retangular adaptada ao ramo superior do typodont permitiu a aplicação de carga. O primeiro molar inferior direito recebeu um preparo para inlay, enquanto o primeiro molar inferior esquerdo recebeu um preparo para coroa total. Os dentes preparados foram incluídos e fundidos em uma liga de cromo-cobalto, tornando-se então troquéis. Sobre estes, padrões de cera foram confeccionados, fundidos em ouro tipo III e adaptados aos troquéis. Uma carga estática de $9 \mathrm{~kg}$ foi aplicada e a adaptação das restaurações aos troquéis mensurada. Os troquéis retornaram ao 
typodont e as restaurações foram cimentadas com cimento fosfato de zinco. Estas foram inicialmente assentadas com pressão digital e em seguida, um dos aparatos de pressão (madeira de laranjeira; rolo de algodão; disco de borracha; e aplicador de pressão Medart) foi posicionado entre a restauração e o dente antagonista. Uma carga estática de $9 \mathrm{~kg}$ foi então aplicada. Para a cimentação sob vibração, o aparelho Electromallet foi aplicado por 10 segundos antes da aplicação da carga estática. Novas mensurações da adaptação foram realizadas e a diferença entre as medidas iniciais e finais representou a perda de adaptação provocada pela cimentação. Os resultados mostraram que as discrepâncias para as inlays foram menores do que aquelas obtidas pelas coroas totais e que a vibração diminuiu a discrepância encontrada na cimentação dos dois tipos de restauração. O aplicador de pressão Medart foi o dispositivo mais efetivo usado para assentar as restaurações durante a cimentação, enquanto o rolo de algodão foi o que permitiu o pior assentamento. Assim, os autores concluíram que a vibração aplicada no início da cimentação, melhora a adaptação de inlays e coroas quando comparada à cimentação sem vibração e que o dispositivo Medart produziu melhor adaptação.

Em 1980, a distorção relacionada ao desenho da margem em restaurações metalo-cerâmicas foi avaliada por FAUCHER R.R. e 
NICHOLLS J.I. ${ }^{13}$ Três desenhos de margem foram avaliados: chanfro, ombro e ombro biselado. Um modelo mestre foi confeccionado, simulando um preparo para coroa total metalocerâmica em um incisivo central. Esse modelo foi inicialmente preparado com uma margem vestibular em chanfro, que foi depois convertida em ombro e então em ombro biselado. Para cada preparo, cinco coroas foram enceradas a partir de um molde dividido, e fundidas em uma liga para cerâmica. Elas apresentavam um braço pela lingual, que permitia sua montagem no aparato de observação. As coroas foram montadas em um jig e observadas pelo aspecto gengival, sob um projetor de perfil, zerado nas marcas de referência. Essas marcas eram localizadas no braço lingual, orientadas diagonalmente, para garantir vários pontos de registro na superfície vestibular. A superfície externa das margens foi então traçada em séries de $1 \mathrm{em} 1 \mathrm{~mm}$. Esse procedimento foi repetido após as seguintes etapas: desgaseificação, opaco, primeira camada de porcelana, segunda camada e glaze. Os resultados mostraram que houve uma tendência à redução do diâmetro vestíbulo-lingual, com um aumento no diâmetro mesiodistal. O tipo de margem em chanfro apresentou maiores distorções, com diferença estatisticamente significante, do que os tipos em ombro e ombro biselado, que não apresentaram diferenças estatísticas entre si. As distorções para os desenhos de 
margem testados continuaram ao longo dos estágios de queima da porcelana. Com base nos resultados obtidos, os autores concluíram que os desenhos de margem em ombro e ombro biselado apresentam menor distorção de margem do que o desenho em chanfro e que a margem vestibular se distorce lingualmente, o que corresponde à tensão induzida pela porcelana na vestibular.

Em 1981, GAVELIS J.R., MORENCY J.D., RILEY E.D. e SOZIO R.B. ${ }^{18}$ avaliaram o efeito de vários desenhos de término cervical no selamento marginal e no assentamento oclusal de coroas totais. Coroas metálicas foram confeccionadas e cimentadas sobre preparos com diferentes desenhos de término cervical lâmina de faca, ombro $90^{\circ}$, ombro $45^{\circ}$, ombro $90^{\circ}$ com bisel paralelo, chanfro com bisel paralelo, ombro $90^{\circ}$ com bisel $45^{\circ} \mathrm{e}$ ombro $90^{\circ}$ com bisel $30^{\circ}$. Após a cimentação, os espécimes foram incluídos em resina, seccionados em sua porção média e observados em microscópio com micrômetro adaptado para avaliação do selamento marginal e do assentamento oclusal das coroas. Os resultados mostraram que, em relação ao selamento marginal, os melhores resultados foram obtidos pelo término em lâmina de faca, seguido pelos términos com biséis paralelos (ombro $90^{\circ}$ e chanfro), sendo que entre esses dois não foi encontrada diferença estatística. Os piores resultados foram encontrados pelos 
términos em ombro $45^{\circ}$, ombro $90^{\circ}$ com bisel $30^{\circ}$ e $45^{\circ}$. Com relação ao assentamento oclusal, os melhores resultados foram encontrados pelo término em ombro $90^{\circ}$ e os piores, atribuídos ao término em ombro $90^{\circ} \mathrm{com}$ bisel paralelo.

VAN NORTWICK W.T. e GETTLEMAN L. ${ }^{59}$ avaliaram, em 1981, o efeito do alívio interno, da vibração e da perfuração no assentamento vertical das coroas cimentadas. Dez troquéis de uma liga de cobalto-níquel-cromo foram fabricados, simulando um preparo para coroa total de pré-molar e para cada troquel, duas coroas em ouro foram confeccionadas. A primeira foi confeccionada sem qualquer tipo de alívio, intimamente adaptada ao troquel. Para a confecção da segunda, duas camadas de die spacer foram aplicadas ao troquel, exceto na margem. Para a cimentação foi utilizado o cimento fosfato de zinco. Uma carga estática de $7.2 \mathrm{Kg}$ foi aplicada sobre as coroas e a vibração foi aplicada horizontalmente contra um lado da coroa por 10 segundos, enquanto a força estática era aplicada. Na união troquel-coroa, foram confeccionados cinco pares de marcas de referência, que foram utilizadas para a mensuração do assentamento vertical em um microscópio, que foi realizada antes e após a cimentação. Para este estudo, foram então formados oito grupos de dez espécimes cada, pela combinação da presença ou ausência dos fatores: alívio 
interno, vibração e perfuração da coroa. Após a mensuração do assentamento vertical, os espécimes foram submetidos aos testes de tração. Os resultados mostraram que os grupos sem alívio interno e sem perfuração falharam quanto ao assentamento, independente da presença ou ausência de vibração. Quando o alívio ou a perfuração foram incluídos, as coroas assentaram até 6 vezes mais. Diferença estatisticamente significante foi encontrada para os fatores alívio (isoladamente), perfuração (isoladamente) e para a combinação de alívio e perfuração. A vibração não apresentou efeito significativo isoladamente e não apresentou efeito na interação com alívio e perfuração ou a combinação de ambos. Assim, os autores puderam concluir que (i) a vibração, aplicada lateralmente, não apresentou efeito nem interação com outros fatores para um melhor assentamento da coroa, (ii) o alívio e a perfuração isoladamente alcançaram efetivamente, um bom assentamento, (iii) a combinação entre alívio e perfuração foi a mais efetiva, (iv) quando as coroas estão bem assentadas, tendem a pender menos.

Uma avaliação da integridade marginal de restaurações metalo-cerâmicas foi realizada por STRATING H., PAMEIJER C.H. e GILDENHUYS R.R. ${ }^{54}$ em 1981. Um incisivo central superior Ivorine foi preparado para coroa total metalo-cerâmica, sendo que 
na face lingual foi utilizado um término em lâmina de faca, enquanto na vestibular, um término côncavo. Seis duplicatas desse preparo foram confeccionadas em resina epóxica e sobre elas foram enceradas infra-estruturas com diferentes desenhos: (i) 30 estruturas com um colar cervical de $0.5 \mathrm{~mm}$ (sendo 15 controles), (ii) 15 estruturas sem colar cevical, e (iii) 15 estruturas para coroas colar-less. Para a fundição das estruturas, três diferentes tipos de metal foram utilizados para cada tipo de desenho: uma liga preciosa, uma semipreciosa e uma não preciosa. Após a fundição foram realizadas etapas de aplicação de porcelana: desgaseificação, opaco, primeira queima de cerâmica, segunda queima e glaze. Os espécimes do grupo controle, não participaram de nenhum estágio de queima. Para a cimentação, um cimento de policarboxilato foi utilizado e uma carga padronizada foi aplicada aos espécimes por 10 minutos. Os espécimes foram seccionados inciso-apicalmente e observados em microscópio para avaliação da espessura da linha de cimento em 6 diferentes localizações em cada amostra. Com base nos resultados obtidos, os autores concluíram que (i) o término côncavo fornece um preparo adequado para restaurações metalo-cerâmicas, (ii) que ligas nãopreciosas podem ser fundidas com a mesma precisão de ligas semi-preciosas e preciosas, (iii) a distorção do metal não é significante em um desenho com colar cervical de $0.5 \mathrm{~mm}$ ou sem 
colar, se uma espessura de metal de $0.4 \mathrm{~mm}$ for usada, (iv) coroas tipo colar-less são inaceitáveis clinicamente.

Em 1982, PARDO G.I. ${ }^{42}$ demonstrou um desenho para coroa total que oferece melhores características marginais. Segundo o autor, são cinco os desenhos de margens gengivais comumente aceitos para coroas totais: ombro, chanfro, lâmina de faca, ombro biselado e chanfro biselado, sendo que os dois primeiros representam desenhos horizontais de margem e os três últimos, desenhos verticais. PARDO enfatiza a importância do tamanho da coroa, citando que quando este é reduzido, interferências podem ocorrer ao longo das paredes axiais durante o posicionamento da coroa, evitando assim, um completo assentamento da mesma. Uma solução seria a confecção de uma coroa de tamanho aumentado. Isso levaria a um maior assentamento na região do ombro, entretanto, uma abertura na região do bisel persistiria, proporcional ao aumento da coroa. O autor propõe então a confecção de uma restauração expandida internamente para evitar contatos prematuros e ao mesmo tempo adaptada no local da margem gengival; um contato íntimo ocorre apenas na margem. Assim, o autor conclui que um preparo para coroa total com um desenho de margem biselado associado com uma coroa expandida internamente e adaptada na margem seria capaz de oferecer um 
potencial para (i) minimizar as discrepâncias marginais, (ii) reduzir a incidência de sobre-contornos, e (iii) minimizar os efeitos da variação no tamanho da coroa.

Uma revisão da literatura sobre margens de coroas totais foi realizada em 1982 por GARDNER F.M. ${ }^{17}$ Segundo o autor, a maioria dos investigadores mostrou que as margens supragengivais são melhores para o periodonto que as margens intra-sulculares, no entanto, mostraram também que as margens supra-gengivais nem sempre são viáveis e que existe alguma indicação que a qualidade da margem pode ter tanta importância para a saúde periodontal quanto a sua localização. A maioria dos pesquisadores concordou que margens em lâmina de faca não são as mais aceitáveis. Segundo eles, margens amplas com ângulos internos são melhores. Métodos para fornecer espaço para o cimento são adequados para melhorar o assentamento e assim, a adaptação marginal das fundições.

HAMAgUCHI H., CACCIATORE A. e TUELleR V.M. ${ }^{24}$ avaliaram, em 1982, a distorção marginal de coroas totais metalocerâmicas a partir de um estudo com microscopia eletrônica de varredura. Para isso, quatro troquéis metálicos foram confeccionados com preparos para metalo-cerâmica apresentando diferentes términos cervicais: chanfro, chanfro com bisel, ombro e 
ombro biselado. Os casquetes metálicos foram fundidos com dois tipos diferentes de ligas metálicas: ouro e ouro branco. Mensurações quanto à adaptação marginal na face vestibular foram realizadas antes da aplicação da cerâmica, após o glaze e após a porcelana ser removida do casquete por ação de ácidos. As mensurações das desadaptações marginais foram obtidas a partir de microscopia eletrônica de varredura. Os resultados mostraram que as comparações das três micrografias mostrando a margem vestibular antes da porcelana, após o glaze e após a remoção da porcelana revelaram pequenas alterações na abertura marginal. No término em ombro biselado, não foram encontradas alterações após a aplicação da porcelana assim como o término em chanfro biselado. Os mesmos resultados foram obtidos para o ombro e chanfro sem bisel. Com base nos resultados obtidos, os autores concluíram que independente do desenho de margem utilizado, a aplicação e queima da porcelana não distorcem mecanicamente a margem.

PASCOE D.F., ${ }^{43}$ em 1983, avaliou a adaptação cervical de restaurações extracoronárias durante a cimentação. Para isso, perfis bi-dimensionais de preparos para coroa total com diferentes desenhos de término - ombro e ombro biselado - foram confeccionados e sobre eles, coroas metálicas com a mesma 
espessura dos perfis. Dois tipos de coroas foram confeccionados justa e frouxa. O conjunto foi confinado entre dois blocos de vidro posicionado em uma máquina universal de testes. Fotografias foram obtidas durante o processo de cimentação das coroas que foi realizado com cimento fosfato de zinco. Os autores concluíram que um assentamento assimétrico não pôde ser demonstrado em um perfil bidimensional, e que as margens biseladas reduziram as aberturas marginais, mas não permitiram um completo assentamento das coroas.

\section{Em 1984, ISHIKIRIAMA A., BUSATO A.L.S., NAVARRO}

M.F.L. e MONDELLI J.. ${ }^{28}$ avaliaram a cimentação temporária de coroas totais metálicas e de resina acrílica. Para isso, 48 molares humanos receberam preparos para coroa total com desenho de margem em chanfro. As coroas de resina acrílica foram confeccionadas com pincel diretamente sobre os preparos. Para a confecção das coroas metálicas, os padrões de cera foram confeccionados diretamente sobre os preparos e então fundidos em uma liga de ouro tipo IV. Uma carga estática de $5 \mathrm{Kg}$ foi aplicada sobre as coroas posicionadas nos preparos e a distância da base ao topo do espécime foi calculada para cada espécime, representando a medida inicial. A cimentação das coroas foi realizada com 6 cimentos temporários diferentes (MPC, Dycal, Temp Bond, 
Lysanda, Life e ZOE) que foram manipulados de acordo com as indicações do fabricante e aplicadas à superfície interna das coroas com o auxílio de um pincel. Novamente uma carga estática de $5 \mathrm{Kg}$ foi aplicada sobre as coroas e novas medidas foram realizadas. Após o registro das medidas os espécimes foram então submetidos aos testes de tração após termociclagem. Os resultados mostraram que os diferentes cimentos causaram diferenças quanto a adaptação, que foram similares para as coroas de resina e as metálicas. Os menores resultados foram obtidos pelos cimentos MPC, Lyfe e Dycal, e os maiores, pelos cimentos Lysanda e ZOE. Os resultados obtidos pelo cimento Temp Bond foi comparável aos cimentos MPC, Lyfe e Dycal. Quanto à resistência à remoção, o tipo de coroa foi um fator significante. Para a remoção das coroas de resina acrílica foi necessária apenas $1 / 3$ da força para a remoção das coroas metálicas. Os cimentos temporários também influenciaram a resistência à remoção. Os cimentos Life, Dycal e ZOE apresentaram os maiores valores retentivos enquanto os cimentos MPC, Temp Bond e Lysanda apresentaram os menores valores. Assim, os autores concluíram que não houve diferença na adaptação primária das coroas de resina e metálicas, mas que os cimentos Life e Dycal promoveram uma melhor adaptação enquanto os cimentos ZOE e Lysanda geraram maiores aberturas marginais. Concluíram ainda que coroas metálicas requerem maior 
força para remoção independente do agente cimentante, e que os cimentos Life, Dycal e ZOE apresentam a maior resistência à remoção.

Em 1985, a adaptação cervical de três desenhos de margem foi avaliada in vivo, por meio de microscopia eletrônica de varredura, por BELSER U.C., MacENTEE M.I. e RITCHER W.A. ${ }^{6}$ Três desenhos de margem foram avaliados - margem biselada em metal, margem em chanfro em metal e margem em chanfro em porcelana. Coroas metalo-cerâmicas foram confeccionadas e cimentadas in vivo em preparos com os diferentes desenhos. Antes da cimentação (com as coroas em posição) e após, moldagens das margens foram realizadas e modelos obtidos em resina epóxica. Os modelos foram avaliados em microscópio eletrônico de varredura e os resultados mostraram que não há diferença significativa entre os três desenhos de margem, antes ou após a cimentação, em relação à adaptação cervical das restaurações.

A relação entre margens abertas e desenhos de margens em coroas totais metálicas confeccionadas por laboratórios comerciais foi avaliada, em 1985, por DEDMON H.W. ${ }^{11}$ Troquéis de gesso com diferentes desenhos de término cervical - chanfro regular, chanfro profundo, chanfro com bisel, ombro, ombro com bisel e lâmina de faca - foram enviados para laboratórios comerciais para 
a confeç̧ão de coroas totais. A desadaptação das margens dessas coroas foi avaliada sob microscópio com aumento de $2 \mathrm{X}$ e classificada como fechada ou aberta se fosse menor ou maior que $39 \mu \mathrm{m}$ respectivamente. Com base nos resultados obtidos, os autores concluíram que restaurações fundidas confeccionadas em laboratórios comerciais, com margens preparadas em chanfro profundo e ombro, ambas sem bisel, tendem a apresentar aberturas que excedem $39 \mu \mathrm{m}$ nos troquéis e que os términos em lâmina de faca e os términos biselados têm menor tendência a apresentarem essa abertura.

TJAN A.H., MILLER G.D. e SARKISSIAN R. ${ }^{56}$ realizaram em 1985 um estudo para avaliar o uso de canais internos de escape com o objetivo de melhorar o assentamento de coroas totais metálicas com diferentes configurações de margens. Trinta molares superiores receberam preparos padronizados para coroa total com uma convergência de $6^{\circ}$. Os desenhos de margem utilizados neste estudo foram: chanferete, ombro e ombro biselado. Os padrões de cera foram confeccionados diretamente sobre os preparos e então fundidos em ouro tipo III. Nenhum tipo de alívio interno foi confeccionado, exceto a remoção de bolhas positivas e as coroas não foram polidas. Uma broca diamantada com a ponta arredondada foi utilizada para a confecção do canal de 
escape com a profundidade equivalente ao diâmetro da broca utilizada. Para o término cervical em chanferete, o sulco de escape terminou $0.5 \mathrm{~mm}$ antes da margem gengival. Para os términos em ombro e ombro biselado, o sulco terminou exatamente na união entre a parede axial e os ombros. O cimento utilizado para a cimentação das coroas metálicas foi o cimento fosfato de zinco tipo I que foi aplicado com o auxílio de uma seringa de insulina de $1 \mathrm{cc}$. A coroa foi preenchida com o cimento e assentada sob pressão digital seguida por uma carga estática de $5,5 \mathrm{Kg}$ por 10 minutos. As discrepâncias marginais após a cimentação foram obtidas e comparadas com a discrepância encontrada em uma coroa não cimentada posicionada sobre o preparo após sofrer a mesma carga de 12 pounds por 10 minutos. O grupo representado pelo término cervical em chanferete apresentou os menores valores para as discrepâncias marginais, sem diferença estatística entre o grupo do término em ombro. Por outro lado, o grupo representado pelo término em obro biselado apresentou os maiores valores de discrepância marginal, com diferença estatisticamente significante quando comparado aos outros grupos. Assim, os autores concluíram que o término em ombro produz uma discrepância marginal comparável ao término em chanferete e que o término em ombro biselado produz discrepâncias maiores que os outros grupos. 
A distorção marginal de restaurações fundidas induzidas pela cimentação foi avaliada por MOORE J.A., BARGHI N., BRUKL C.E. e KAISER D.A. ${ }^{39}$ em 1985. Para isso, onze troquéis foram torneados a partir núcleos maciços de latão até um diâmetro de $9 \mathrm{~mm}$, com uma convergência de 5 graus e um término em lâmina de faca. Duas camadas de die-spacer foram aplicadas e coroas totais foram enceradas diretamente sobre os troquéis e então fundidas em ouro. As aberturas marginais foram determinadas em 5 diferentes pontos para a obtenção da abertura marginal média. Cada coroa foi então preenchida com cimento fosfato de zinco e assentadas sobre os troquéis com pressão digital. Em seguida os espécimes foram levados à uma máquina Instron para 0 assentamento final $e$ as aberturas marginais novamente mensuradas. Os resultados mostraram uma abertura marginal média pré-cimentação de $9.5 \pm 9.2 \mu \mathrm{m}$ e uma abertura marginal média pós-cimentação de $35.6 \pm 18.5 \mu \mathrm{m} \quad(\mathrm{p}<0.001)$. Com base nesses resultados, os autores concluíram que (i) a abertura marginal de coroas de ouro aumentou durante a cimentação; (ii) a altura vertical de coroas bem adaptadas também aumentou após a cimentação (estudo paralelo).

OSTLUND L.E. ${ }^{41}$ avaliou, em 1985, o efeito do desenho do preparo dentário e da matemática, nas aberturas nas margens de 
restaurações fundidas. Em seu trabalho, o autor enfatiza a importância da adaptação marginal e que, embora se acredite que quanto menor a desadaptação entre a coroa e o dente antes da cimentação melhor a adaptação após a cimentação, isso nem sempre acontece. Apesar da evolução das técnicas, ceras, revestimentos e materiais de moldagem, as fundições continuam não se adaptando tão bem após a cimentação quanto se adaptavam antes de serem cimentadas. Segundo o autor, o cimento exerce influência negativa na adaptação das margens e isso deve ser explicado pelo tamanho da partícula e da linha do cimento e por problemas durante o procedimento de cimentação. Ainda, segundo o princípio da junta deslizante, à medida que a coroa desliza no preparo buscando o assentamento, o plano oclusal e a parede cervical estão eqüidistantes do dente preparado. Entretanto, a distância entre o bisel cervical e o preparo é menor, e quanto mais angulado for o bisel mais a coroa se aproxima do preparo. Ainda assim, a abertura na margem corresponde à distância entre o plano oclusal e a parede cervical do preparo. Isso é explicado a partir da utilização da regra matemática do co-seno para os triângulos retângulos. Entretanto, essa regra se aplica para coroas não cimentadas. Quando o agente cimentante é introduzido, o controle da adaptação é uma função direta da espessura da linha do cimento utilizado. Então, quanto mais o ângulo do bisel se 
aproxima do plano do eixo de inserção da restauração, maior será a abertura preenchida por cimento entre a margem da coroa e do preparo. Assim, uma abertura pós-cimentação de $50 \mu \mathrm{m}$ é obtida quando um cimento com espessura de $25 \mu \mathrm{m}$ é utilizado. Segundo o autor, se a restauração for corretamente aliviada internamente, exceto pelo bisel da parede cervical, quanto mais a angulação do plano do bisel cervical se aproximar do paralelismo com o plano do eixo de inserção, maior será a abertura na margem. Então, o bisel na cervical deve se aproximar o máximo possível do plano horizontal ao invés do plano vertical. Assim, considerando o alívio interno para a linha de cimento, um ombro de $90^{\circ}$ pode se aproximar, pelo menos teoricamente, do menor limite possível uma abertura marginal de $25 \mu \mathrm{m}$. Assim, o autor conclui que uma restauração fundida, a menos que completamente aliviada, será sempre uma restauração que não assentará completamente.

Um estudo sobre margens de preparos foi realizado por GULKER I., ${ }^{23}$ em 1985. Segundo o autor, atenção aos detalhes da localização e desenho do preparo, impressão, fabricação e adaptação das restaurações e cimentação são necessárias para garantir adaptação marginal adequada, estética e saúde periodontal. Com relação à configuração da margem, o autor enfatiza que o operador deve buscar (i) forma adequada de 
retenção e resistência no preparo e (ii) reduzir uma quantidade suficiente de estrutura dentária para permitir a confecção de uma restauração bem contornada, uma vez que uma redução inadequada traz problemas para o laboratório, resultando em uma coroa antiestética e mal contornada, sendo o primeiro passo para a doença periodontal. Assim, um término em slice não fornece espaço suficiente para uma restauração estética onde um chanfro ou ombro é mais indicado, devendo estar reservado para restaurações metálicas. Quanto à localização da margem, o autor afirma que a localização da margem deve estar relacionada primeiramente à retenção e aos requisitos estéticos e que a melhor localização é aquela que permite controle da adaptação por parte do dentista e controle de placa por parte do paciente. Sobre os materiais, o autor cita que a formação de placa é reduzida em superfícies altamente polidas e que a porcelana é o material mais "auto-limpante" e que menos distorce as margens. Com relação à estética, o autor enfatiza que apesar de muitas margens serem localizadas intra-sulcularmente por motivos estéticos, uma grande porcentagem dessas margens se tornará supragengival em um período de 5 anos devido à recessões gengivais nas faces vestibulares. Quanto aos biseis, o autor apresenta dúvidas quanto à relevância dos biseis para as restaurações de coroa total. Para ele, esse tipo de término contribui para a recessão gengival e para 
a desadaptação da coroa após a cimentação, pela interposição da linha de cimento. Sobre a adaptação, o autor relata que provavelmente, os efeitos em longo prazo da adaptação são os mais importantes, uma vez que uma adaptação pobre torna-se uma falha séria posteriormente. O autor cita que um bisel não é capaz de reduzir uma linha de cimento e que a melhor adaptação é obtida com o ombro e uma restauração aliviada internamente. Assim, o autor conclui que as margens das restaurações devem ser tratadas cuidadosamente, pois um dos maiores problemas a ser resolvido é a adaptação marginal, pois é um fator que o dentista geralmente ignora ou não é capaz de avaliar devido à natureza microscópica do problema ou ao fato de a margem estar geralmente recoberta pelo tecido gengival.

Em 1986, SORENSEN S.E., LARSEN I.B. e JÖRGENSEN K.D. ${ }^{53}$ avaliaram a reação da gengiva e do osso alveolar à adaptação marginal de coroas cujas margens localizavam-se subgengivalmente. A inflamação gengival, o volume do fluido crevicular e a absorção óssea foram avaliados. A mensuração da discrepância marginal foi medida a partir de moldagem. Os resultados mostraram um aumento da severidade da doença periodontal com o aumento da discrepância marginal subgengival. Um aumento da perda óssea, do sangramento gengival e do 
volume do fluido crevicular foi observado sem, entretanto, ser detectada presença de bolsa periodontal.

Os fatores que afetam o assentamento e a adaptação de coroas totais foram avaliados por KAY G.W., JABLONSKI D.A. e DOGON I.L. ${ }^{29}$ em 1986, a partir de um estudo de simulação por computador. Um modelo de computador foi desenvolvido e executado. A cimentação para cada experimento envolveu os seguintes elementos: geometria do troquel (convergência de $10^{\circ}$, ombro $90^{\circ}$, altura de $6 \mathrm{~mm}$ ), alívio do troquel, força de assentamento e tempo (45Kg em um intervalo de 120 a 140 segundos), consistência do cimento, tamanho da partícula do cimento $(25 \mu \mathrm{m})$, posição inicial do casquete $(0.5 \mathrm{~mm}$ acima do troquel). Alguns experimentos foram simulados pelo modelo. Inicialmente, a influência do desenho da margem gengival foi avaliada. As diferenças na adaptação e no assentamento final de dois desenhos de lâmina de faca ( 8 ou 10 mm de diâmetro no término), dois ombros (45 e 90) e três ombros biselados $(5,30$ e 450) foram avaliadas e comparadas. Então, as localizações iniciais dos troquéis foram centralizadas e alinhadas, mas variaram quanto à altura acima do troquel $(0.3,0.5$ e $0.7 \mathrm{~mm})$. A influência da magnitude da força no assentamento e adaptação foi também avaliada. Cargas de 11, 22 e $45 \mathrm{Kg}$ foram aplicadas. Quanto a 
aplicação de alívio interno, seus efeitos foram testados no ombro $90^{\circ}$ e no ombro com bisel de 50, variando as espessuras de alívio entre 0 e $20 \mu \mathrm{m}$. A localização do alívio também foi testada, com um espaço de $10 \mu \mathrm{m}$ criado na superfície oclusal, parede axial e ombro isoladamente ou em combinação. O efeito do atraso na aplicação da carga foi registrado e o tempo gasto entre a manipulação do cimento e a mensuração da carga variou entre 100 e 180 segundos. Finalmente, o índice de presa na cimentação também foi registrado e índices correspondentes à metade e ao dobro dos valores de controle foram comparados. Com relação ao efeito do desenho do término, os resultados mostraram que o desenho de ombro $45^{\circ}$ apresentou menor falta de assentamento $(126.4 \mu \mathrm{m})$, enquanto que a lâmina de faca apresentou a maior falta de assentamento $(170.0 \mu \mathrm{m})$. Quanto ao efeito da posição inicial no assentamento, foi encontrado que a distância do casquete ao troquel não influenciou significativamente o assentamento final. Um aumento na carga aplicada promoveu um maior assentamento, sendo que uma carga de $11 \mathrm{Kg}$ promoveu uma falta de assentamento de $244 \mu \mathrm{m}$, enquanto a carga de $45 \mathrm{KG}$ uma falta de assentamento de $141 \mu \mathrm{m}$. Da mesma forma, um aumento da quantidade de alívio interno também promoveu um melhor assentamento e menores aberturas marginais, com valores de $132.7 \mu \mathrm{m}$ para nenhum alívio e de $7.0 \mu \mathrm{m}$ para um alívio de $15 \mu \mathrm{m}$ 
no ombro $90^{\circ}$. Para o ombro com bisel de $5^{\circ} 0$ mesmo padrão foi observado, mas a redução na falta de assentamento não foi tão dramática. Foi encontrado também que a aplicação do alívio interno nas paredes axiais apresentou melhores resultados isoladamente ou em combinação quando comparada ao controle ou à localização na oclusal apenas. Quanto ao atraso da aplicação de carga, os dados mostraram que o tempo teve papel importante na determinação do assentamento completo. Quando o tempo para a aplicação de carga foi de 100 segundos os resultados para falta de assentamento e abertura marginal foram de 124.7 e $12.9 \mu \mathrm{m}$, contra 205.3 e $19.9 \mu \mathrm{m}$ para um tempo de 180 segundos respectivamente. Finalmente, a relação do índice de presa do cimento determinado pela viscosidade do cimento mostrou que quando o índice de presa é dobrado, a discrepância de assentamento é aumentada em $250 \%$ em relação ao controle e que quando o índice é reduzido à metade, o assentamento é melhorado em $45 \%$.

Em 1987, MARKeR V.A., MILleR A.W., MILLER B.H. e SWEPSTON J.H. ${ }^{35}$ avaliaram os fatores que afetam a retenção e a adaptação de coroas de ouro. Foram utilizados para este estudo, preparos padronizados para coroa total em dentes Ivorine. Foram confeccionados 13 modelos idênticos de um quadrante $\left(3^{\circ}\right)$ no qual 
o 10 molar era o dente que continha o preparo. Cada modelo foi distribuído a um participante do estudo. Duas impressões foram feitas de cada modelo, utilizando materiais e técnicas normalmente utilizadas pelos clínicos. Um único clínico aplicou quatro camadas de die spacer a um preparo de cada par obtido pelas moldagens, nas paredes axiais e na oclusal. As coroas foram enceradas e fundidas em ouro. Os procedimentos de inclusão e fundição foram realizados por cada investigador, utilizando os materiais de preferência. Após o assentamento das coroas sobre os preparos, a retenção friccional pré-cimentação foi determinada em uma máquina universal de testes. Cada coroa foi cimentada com cimento fosfato de zinco, sob pressão estática vertical de $5 \mathrm{~kg}$. Os espécimes foram mantidos sob pressão e $100 \%$ de umidade por 24h. A adaptação cervical foi avaliada visualmente e uma escala de 1 a 4 foi atribuída, sendo 1 a menor desadaptação e 4 a maior. Testes de tração foram então realizados. Os preparos foram então polidos e as coroas limpas e recimentadas. Os testes de adaptação e retenção foram então repetidos. Em seguida, novos testes foram conduzidos, desta vez após a asperização dos preparos. Com base nos resultados obtidos, os autores concluíram que (i) o completo assentamento das coroas após a cimentação foi melhorado pela aplicação do die spacer; (ii) as coroas confeccionadas sobre modelos com die spacer apresentaram maior retenção do que 
aquelas sem o espaçador; (iii) uma rugosidade moderada das paredes axiais aumenta a retenção quando o cimento fosfato de zinco é utilizado; (iv) as propriedades físicas dos materiais restauradores são importantes, mas a técnica individual e o cuidado de cada operador têm um efeito maior na adaptação final e na retenção das coroas fundidas.

A alteração na adaptação marginal relacionada ao desenho da margem, tipo de liga e proximidade da porcelana em restaurações metalo-cerâmicas foi avaliada por RITCHER-SNAPP K., AQUilino S.A., SVARE C.W. e URNER K.A. ${ }^{49}$ em 1988. Coroas metalo-cerâmicas foram confeccionadas em ligas nobres e não-nobres e cimentadas sobre troquéis metálicos com preparos para coroa total com dois desenhos de término cervical - ombro biselado e término em $45^{\circ}$. A porcelana foi aplicada sobre os casquetes metálicos, criando dois tipos de situação: (1) a porcelana indo até o término do casquete e (2) deixando a cinta metálica. A adaptação cervical foi avaliada a partir de observação ao microscópio e por um programa de análise de imagens. Os autores concluíram que nenhuma das variáveis investigadas ou combinação dessas variáveis afetaram a adaptação final de uma restauração metalo-cerâmica. 


\section{Em 1989, LEWIS S., AVERA S., ENGLEMAN M. e BAUMER}

J. $^{34}$ discutiram a restauração de implantes inadequadamente angulados. Segundo o autor, quando implantes são posicionados com uma angulação moderada para vestibular, a restauração final poderá estar comprometida, devido ao posicionamento do orifício de acesso ao parafuso. Se a restauração for conectada diretamente ao implante ao invés do abutment transmucoso, pelo menos $3 \mathrm{~mm}$ de espaço interoclusal adicional é alcançado. Este espaço permite o desenho de um orifício de acesso maior verticalmente, fornecendo melhor acesso ao parafuso de titânio que conecta a restauração ao implante. Essa solução, entretanto, só é possível em dentes anteriores, pois em dentes posteriores a cúspide lingual seria sacrificada. Nesses casos, a solução seria a mesma que aquela encontrada para casos de implantes muito angulados onde o orifício de acesso poderia interferir com a estética e/ou função: copings telescópicos e sobre-fundições.

HOLMES J.R., BAYNE S.C., HOLLAND G.A. e SULLIK W.D. ${ }^{26}$ traçaram considerações sobre a mensuração da adaptação marginal em 1989. Os autores sugerem a utilização de uma terminologia única para a descrição das desadaptações cervicais de coroas - abertura interna, abertura cervical, margem sobreextendida, margem sub-extendida, discrepância marginal vertical, 
discrepância marginal horizontal, discrepância marginal absoluta e discrepância de assentamento - para que seja possível traçar comparações sobre estudos que avaliam as desadaptações cervicais, uma vez que a confusão na terminologia pode fazer com que autores estejam mensurando diferentes tipos de desadaptações e dando a elas o mesmo nome. Assim, os autores propõem que, com base na terminologia sugerida, apenas seis tipos de desadaptação marginal existem - (1) nenhuma abertura marginal e nenhuma sobre ou sub-extensão; (2) abertura marginal e nenhuma sobre ou sub-extensão; (3) abertura marginal e sobreextensão; (4) abertura marginal e sub-extensão; (5) nenhuma abertura marginal e sobre-extensão; e (6) nenhuma abertura marginal e sub-extensão.

Em 1990, HUNTER A.J. e HUNTER A.R. ${ }^{27}$ realizaram uma revisão da literatura sobre as margens gengivais para coroas em relação às discrepâncias e suas configurações. Os autores concluíram que margens localizadas profundamente no sulco gengival podem trazer problemas para o periodonto e que esse problema é composto com grandes discrepâncias no assentamento da coroa e linhas de cimento. A redução das discrepâncias pela diminuição do ângulo de fechamento entre o preparo e a coroa implica em biséis longos e bem angulados, o que pode criar 
significantes problemas técnicos e clínicos. A solução para esses problemas seria a utilização de margens horizontais, combinadas com procedimentos que melhorem o assentamento da coroa.

A deformação apresentada por coroas durante a cimentação foi avaliada por WILSON P.R., GOODKIND R.J. e SAKAGUCHI $\mathbf{R}^{63}$ em 1990. Um troquel foi torneado em aço inoxidável com $5^{\circ}$ de conicidade, altura de $6 \mathrm{~mm}$ e término cervical em ombro. Cinco padrões de resina acrílica foram confeccionados diretamente sobre o troquel, e fundidos em ouro tipo III. Um aparato foi confeccionado para permitir a avaliação da deformação das coroas durante um processo de cimentação, variando-se a viscosidade do fluido interposto entre o troquel e a coroa (representando o agente cimentante), a presença de um orifício de escape e o espaço disponível para o fluido entre o troquel e a coroa (representando o alívio interno). Os resultados mostraram que a deformação aumentou com a viscosidade do fluido, não sendo afetada pela presença ou não de alívio interno. O tempo de assentamento das coroas também aumentou com a viscosidade de fluido e reduziu com presença de alívio interno. Foi encontrado ainda, que a presença de um orifício de escape do cimento reduziu significantemente a deformação nas coroas além de reduzir o tempo de assentamento. 
ZARB G.A. e SCHMITT A. ${ }^{64}$ avaliaram, em 1990, a efetividade clínica longitudinal dos implantes dentários osseointegrados, ressaltando os problemas e as complicações encontradas. Para isso, foram selecionados 46 pacientes edêntulos que não se adaptaram a terapia com prótese total removível convencional e que foram tratados com próteses fixas e overdentures retidas por implantes osseointegrados. Cada paciente era chamado anualmente para controle e coleta de dados. Em cada consulta foi realizado exame extra e intra-oral associados a radiografias para avaliação dos implantes individualmente. Os resultados mostraram que 274 implantes foram colocados para suportar as 49 próteses. O índice de sucesso para osseointegração para os implantes individualmente, foi de $89 \%$, enquanto que 0 índice de sucesso para as próteses em função foi de $100 \%$. Alguns problemas e complicações clínicas foram encontrados e enumerados pelos autores como problemas no estágio cirúrgico I, problemas após o estágio cirúrgico I, problemas no estágio cirúrgico II e problemas/complicações protéticas. Nesse último caso, foram encontrados problemas nos abutments, nos parafusos centrais, nos parafusos do abutment, em infra-estruturas, problemas estéticos e funcionais e problemas relacionados a fraturas nos parafusos de ouro, que retinham a prótese sobre implantes. Foram observadas 53 fraturas de parafusos de ouro, 
sendo que os autores ressaltam que este é o elo fraco das próteses parafusadas. É preciso ressaltar, que das 53 fraturas encontradas, $38(71 \%)$ ocorreram em apenas 2 pacientes. Diante dos resultados obtidos, os autores concluíram que a maioria dos problemas tinha origem iatrogênica, mas que alguns são inerentes ao método propriamente dito. Concluíram também que a técnica e a manutenção do tratamento com osseointegração são exigentes, mas que os resultados obtidos são atraentes e que novos estudos não devem considerar apenas os benefícios terapêuticos da osseointegração, mas o custo-benefício desta técnica quando comparada às convencionais.

Um método padronizado para a determinação da fidelidade marginal em coroas foi demonstrado por SORENSEN J.A., ${ }^{52}$ em 1990. Um dente Ivorine recebeu preparo para coroa total com um término em ombro $90^{\circ}$. A partir desse preparo, dez troquéis chapeados em prata foram confeccionados para cada sistema de coroa. Dez coroas de cada tipo foram confeccionadas de acordo com as recomendações do fabricante e cimentadas de forma padronizada, com aplicação de uma carga estática de 2,7Kg por 10 minutos. Os espécimes foram então embebidos em resina epóxica e após 24 horas, seccionados nos sentidos vestíbulo-lingual e mesio-distal permitindo a avaliação em 8 diferentes pontos da 
coroa. As coroas seccionadas foram então fotografadas em um microscópio. Uma retícula com escala dividida em incrementos de $5 \mu \mathrm{m}$ foi sobreposta, o que permitiu a padronização e os cálculos. Em seguida, uma película plástica foi sobreposta às fotografias, apresentando uma linha vertical correspondente à raiz do dente e ao perfil de emergência. Uma segunda linha vertical era coincidente com o término do preparo e se estendia axialmente ao longo do término do preparo e para fora do dente. Com o auxílio de uma régua dividida em incrementos de $5 \mu \mathrm{m}$, as discrepâncias marginais foram mensuradas, a partir do alinhamento dessa régua com as linhas-guia da película plástica e a mensuração das distâncias em pontos pré-determinados. Três diferentes avaliadores participaram deste estudo. Os resultados mostram uma variação intraavaliadores de $9 \mu \mathrm{m}$ para as discrepâncias verticais e de $10 \mu \mathrm{m}$ para as discrepâncias horizontais com a utilização da metodologia sugerida pelo autor.

O efeito da discrepância marginal de coroas foi avaliado in vivo em 1991 por FELTON D.A., KANOY B.E., BAYNE S.C. e WIRTHMAN G.P. ${ }^{12}$ Para isso, moldagens de coroas totais com términos localizados intra-sulcularmente foram obtidas e os modelos avaliados em microscópio eletrônico de varredura. Além disso, avaliações da profundidade de bolsa, índice gengival e 
volume do fluido crevicular também foram realizadas. Os autores concluíram que o aumento da discrepância marginal provocou um aumento da inflamação gengival, do índice gengival e do volume do fluido crevicular, sem afetar, entretanto, a profundidade de bolsa.

Em 1992, o uso de agentes cimentantes com um sistema de implantes foi avaliado por BREEDING L.C., DIXON D.L., BOGACKI M.T. e TIETGE J.D. ${ }^{7}$ Dois cimentos resinosos - Core Paste e Resiment - e um cimento ionomérico - Ketac Cem - foram utilizados para a cimentação de abutments sobre implantes. Os testes de tração foram realizados em dois tempos, uma hora após a cimentação em temperatura ambiente e 30 dias após a cimentação com manutenção dos espécimes em meio aquoso. Além disso, coroas totais metálicas foram confeccionadas sobre abutments e sobre um pré-molar extraído e cimentadas sobre estes com três diferentes cimentos temporários - IRM, Dycal e Temp Bond. Uma hora após a cimentação os testes de tração foram realizados. Os autores concluíram que sobre-estruturas implanto-suportadas cimentadas com qualquer um dos três agentes cimentantes temporários podem ser removidas sem alterar a união entre o abutment e o implante promovida pelo cimento definitivo e que a força retentiva de uma coroa de liga nobre 
cimentada temporariamente sobre um abutment de titânio foi similar àquela da mesma coroa cimentada temporariamente sobre um dente humano preparado, quando os mesmos cimentos são utilizados. Os autores concluíram ainda que os abutments cimentados sobre os implantes com o cimento ionomérico Ketac Cem apresentaram maiores valores retentivos após o periodo de armazenamento de 30 dias em solução salina do que aqueles cimentados com os cimentos resinosos Core Paste ou Resiment.

BYRNE G., 8 em 1992, avaliou a influência da forma do término cervical na cimentação de coroas. Para isso, um dente de plástico recebeu preparo para coroa total, sendo que em sua face vestibular recebeu preparo para obro biselado e na palatina, preparo em chanfro. Um molde foi obtido e vazado em resina epóxica obtendo-se 15 espécimes. No mesmo dente de plástico o término da face vestibular foi alterado para chanfro e os procedimentos repetidos. Mais uma vez o término do dente plástico foi alterado, dessa vez para ombro e novos modelos em resina epóxica foram obtidos. Para cada término cervical, cinco modelos de gesso foram obtidos a partir dos modelos em resina. Coroas metalocerâmicas foram confeccionadas e assentadas sobre os preparos da seguinte forma: diretamente sobre o modelo de gesso sem cimento, diretamente sobre o modelo de resina sem cimento e 
sobre o modelo de resina utilizando cimento fosfato de zinco. Os conjuntos coroa/preparo foram seccionado vestíbulo-lingualmente e as discrepâncias axiais e marginais observadas em microscópio eletrônico de varredura. Com base nos resultados encontrados, os autores concluíram que um espaço axial de 20 a $30 \mu \mathrm{m}$ foi criado utilizando-se procedimentos indiretos comuns e técnicas de fundição de rotina; não houve diferença na adaptação marginal ou axial entre as coroas confeccionadas pela técnica direta (sobre o modelo de resina) ou indireta (sobre o modelo de gesso); as coroas cimentadas não sofreram um assentamento total independente do desenho do término cervical; e que o desenho do término cervical não afetou a adaptação das coroas.

Os efeitos do cimento, do espaço para o cimento, do desenho da margem, dos materiais para assentamento e da força de assentamento na cimentação de coroas foram avaliados em 1992, por WANG C-J., MILLSTein P.L. e NATHANSON D. ${ }^{61}$ Dois troquéis metálicos com preparos para coroa total foram confecionados, sendo que um apresentava término em ombro e o outro em ombro biselado. Moldagens e troquéis de gesso foram obtidos, e antes da confecção das coroas, esses troquéis receberam diferentes tratamentos - nenhum espaçador aplicado ou quatro camadas de die spacer. No momento da cimentação das coroas, 
mais três variáveis foram incluídas, o cimento utilizado - fosfato ou ionômero de vidro, a carga de cimentação $-2,26 \mathrm{Kg}$ ou $13,6 \mathrm{Kg}$, e o material utilizado para auxiliar no assentamento - madeira de laranjeira ou o E-Z bite (um material de três camadas e com consistência variada). Mensurações do assentamento cervical foram realizadas antes e após a cimentação. Com base nos resultados, os autores concluíram que a aplicação do die spacer melhorou significativamente o assentamento das coroas durante a cimentação assim como um aumento da força de assentamento de 2,26 Kg para $13,6 \mathrm{Kg}$. Concluíram também que o assentamento foi melhor quando o cimento ionômero de vidro foi utilizado. A combinação die spacer, ombro com bisel, maior força e cimento ionômero de vidro resultou em maior assentamento da coroa quando comparada a ao uso do die spacer com o término em ombro. Ainda, a madeira de laranjeira e o Z-B bite foram igualmente efetivos durante a cimentação da coroa.

Em 1992, GORODOVSKY S. e ZIDAN O.. ${ }^{19}$ avaliaram a força retentiva, a desintegração e a qualidade marginal dos agentes cimentantes. Para avaliação da força retentiva da qualidade marginal, coroas metálicas foram confeccionadas e cimentadas sobre dentes naturais com diferentes agentes cimentantes - cimento fosfato de zinco, cimento ionômero de vidro 
(Ketac-Cem), cimento resinoso (Comspan), cimento resinoso com agente de união Prima Bond e cimento resinoso adesivo (Superbond C\&B). Testes de tração foram realizados e a qualidade marginal avaliada a partir de microscopia eletrônica de varredura. Para avaliação da desintegração, discos de cimentos foram confeccionados e mantidos em água destilada por 23 horas e o peso perdido foi calculado. Os autores concluíram nesse estudo, que os menores valores de força retentiva foram encontrados para o cimento fosfato de zinco, sem diferença estatística em relação ao cimento ionômero de vidro. Os maiores valores foram encontrados para o cimento resinoso adesivo. Na microscopia eletrônica de varredura, foi observado que os cimentos resinosos e fosfato de zinco permaneceram intactos, porém o cimento ionomérico desapareceu das margens da restauração. Com relação à desintegração os maiores valores foram encontrados para 0 cimento fosfato de zinco enquanto que os menores valores foram atribuídos aos cimentos resinosos.

DIXON D.L., BREEDING L.C. e LILLY K.R. ${ }^{12}$ avaliaram, em 1992, o uso de agentes cimentantes com um sistema de implantes. Para isso, coroas metálicas foram confeccionadas com diferentes alívios internos - nenhum alívio, alívios de 0,0254 cm, 0,0508 cm e 0,0762 cm - e cimentadas sobre os abutments com diferentes 
agentes cimentantes - um cimento fosfato de zinco e dois cimentos resinosos (Resiment e Core Paste). As discrepâncias marginais foram mensuradas antes e após a cimentação com auxílio de um microscópio comparador e então testes de tração foram realizados. Com base nos resultados obtidos, os autores concluíram que os alívios não reduziram os valores retentivos para nenhum dos grupos testados e que os grupos cimentados com os cimentos resinosos apresentaram valores retentivos significativamente maiores do que o grupo cimentado com o cimento fosfato de zinco. Concluíram ainda que os cimentos fosfato de zinco e Resiment apresentaram valores de discrepâncias marginais inferiores a 25 $\mu \mathrm{m}$ com um alívio de 0,0254 cm e que o cimento Core Paste precisou de um alívio de 0,0762 cm para alcançar a mesma discrepância de 25 нm.

O efeito do aumento do espaço para o cimento na cimentação de coroas artificiais foi avaliada em 1994 por WILSON P.R. ${ }^{62}$ Coroas foram confeccionadas e cimentadas sobre troquéis metálicos torneados com alturas e diâmetros variados em incrementos de $10 \mu \mathrm{m}$. Após a realização dos testes de tração, e com base nos resultados obtidos, os autores concluíram que um espaço menor que $40 \mu \mathrm{m}$ não permitiu que a coroa alcançasse o melhor assentamento que foi atingido com o aumento do espaço. 
KOKA S., EWOLDSEN N.O., DANA C.L. e BEATTY M.W. ${ }^{32}$ avaliaram o efeito do agente cimentante e da técnica na retenção de cilindro de ouro do sistema CeraOne em 1995. Para isso, o cilindro de ouro foi cimentado sobre o abutment com dois diferentes cimentos - Temp Bond NE (temporário) e Fosfato de Zinco (definitivo) - com duas diferentes técnicas - deixando o orifício de acesso ao parafuso do abutment aberto ou fechando-o com resina acrílica autopolimerizável. Após a cimentação, os testes de tração foram conduzidos e com base nos resultados obtidos, os autores concluíram que o preenchimento do orifício de acesso ao parafuso do abutment produziu valores significativamente mais altos de separação quando comparados aos orifícios não preenchidos, e que o uso do cimento fosfato de zinco produziu valores mais altos de separação quando comparado ao cimento temporário Temp Bond NE.

Em 1996, a discrepância marginal de coroas cerâmicas com componentes de implantes redesenhados foi avaliada por SUTHERLAND J.K., LONEY R.W. e JAROTSKIC T.J. ${ }^{55}$ Os componentes de implantes fabricados pela Nobelpharma Canada utilizados nesse estudo sofreram modificações em seu desenho devido aos resultados de outros estudos que mostravam discrepâncias marginais de 169 um. A partir da utilização de um 
microscópio acoplado a uma câmera e um computador, a discrepância marginal entre os abutments e as cápsulas de cerâmica do sistema CeraOne foi avaliada em diferentes etapas com a cápsula de cerâmica antes da queima, após a queima, com aplicação de cerâmica sobre a cápsula simulando uma coroa (a mesma sofreu dois ciclos de queima e um ciclo para o glaze), e após a cimentação com cimento fosfato de zinco. Os resultados mostraram que nenhuma diferença estatística foi encontrada entre as discrepâncias marginais das cápsulas, das cápsulas após a queima e das coroas não cimentadas. Entretanto, as coroas cimentadas exibiram uma discrepância marginal média estatisticamente maior do que a encontrada nos outros grupos. Os resultados mostraram ainda que os componentes redesenhados do sistema CeraOne exibiram discrepâncias marginais substancialmente menores para todas as etapas quando comparados com as discrepâncias obtidas em outro estudo semelhante, realizado antes da alteração do desenho dos componentes.

SINGER A. e SERFATY V., ${ }^{51}$ em 1996, reportaram um acompanhamento de 6 meses a 3 anos de próteses parciais fixas implanto-suportadas cimentadas. Setenta pacientes foram tratados com 92 próteses fixas (35 - maxila; 57 - mandíbula) suportadas 
por 225 implantes (86 - maxila; 139 - mandíbula). Os implantes utilizados tinham o mesmo desenho de abutments que foram preparados para obtenção de espaço interoclusal adequado, conicidade $\left(6^{\circ}\right.$ a $\left.8^{\circ}\right)$ e desenho de margem desejado. As restaurações metalo-cerâmicas confeccionadas foram cimentadas sobre esses abutments com o cimento temporário Temp Bond. $\mathrm{O}$ cimento IRM foi utilizado nos casos onde a solubilização do cimento foi observada. As seguintes complicações e falhas foram avaliadas: solubilização do cimento, fratura da porcelana, mobilidade da restauração causada por perda do parafuso central, falha nos implantes, complicações de tecido mole. Os resultados mostraram que após o período de observação, a falha mais comum foi a solubilização do cimento, em $9.8 \%$ dos casos, sendo que quatro casos ocorreram nos primeiros 6 meses e cinco casos entre 7 e 12 meses. Outras falhas encontradas foram fratura da porcelana $(2.2 \%)$, mobilidade da restauração devido à perda do parafuso central $(2.2 \%)$ e falha no implante $(1.1 \%)$. Nenhuma falha foi observada em relação a complicações no tecido mole em torno do implante. Com base nos resultados encontrados, os autores concluíram que o princípio da reversibilidade é mantido com o uso de um cimento temporário e que cada vantagem da prótese parcial fixa parafusada pode ser aplicada também à prótese cimentada, 
evitando problemas estéticos, de perda do parafuso centra, de custo elevado, entre outros.

Os fatores que influenciam a retenção do cilindro de ouro do sistema CeraOne foram avaliados em 1996, por KENT D.K., KOKA S., BANKS S.B. e BEATTY M.W. ${ }^{31}$ Cilindros de ouro do sistema CeraOne foram cimentados sobre abutments de diferentes alturas - 3,7 e 5,0 mm. Para a cimentação das peças, diferentes cimentos - Temp Bond, Temp Bond NE e Fosfato de Zinco - foram utilizados em diferentes volumes - 0,01 e 0,02 ml. Após a cimentação, testes de tração foram realizados, e os resultados mostraram que os cimentos temporários apresentaram carga de falha semelhante e muito inferior daquela apresentada pelo cimento fosfato de zinco. Ainda, abutments mais altos produziram maiores cargas de falha. Com base nos resultados, os autores concluíram que 0,01 e 0,02 $\mathrm{ml}$ de cimento produziram cargas de falha comparáveis e que a escolha do agente cimentante pode afetar essas cargas. Concluíram ainda, que o uso de um sistema com 5,0 mm de altura pode afetar as cargas de falha e que a combinação de um abutment de 5,0 $\mathrm{mm}$ de altura com o cimento fosfato de zinco aumenta significativamente as cargas de falha do cimento.

GANOR Y., INDIG B. e GROSS M. ${ }^{15}$ apresentaram um caso de coroa cimentada reversível sobre abutments angulados 
implanto-suportados em 1996. Um implante foi instalado na região do primeiro pré-molar superior direito. Após a moldagem, um modelo de trabalho foi confeccionado com o posicionamento dos análogos. Um enceramento diagnóstico mostrou a necessidade da utilização de um abutment angulado em $15^{\circ}$ para vestibular. Uma coroa metalo-cerâmica foi confeccionada com uma cavidade de acesso de apenas $3 \mathrm{~mm}$ de diâmetro na vertente triturante vestibular para permitir somente 0 acesso da chave de apertamento. Para isso, durante todo o processo de enceramento e aplicação da coroa a chave ficou posicionada sobre o abutment. Assim, um orifício de menor diâmetro foi confeccionado, sem comprometer a resistência ou a estética da restauração. A restauração foi cimentada com o orifício preenchido por cera. Após a cimentação, resina composta foi utilizada para fechar a abertura na porcelana. Diante da necessidade de reversibilidade, o complexo coroa/abutment pode ser removido. Após a remoção da resina composta, a chave é introduzida através da cera que preenche o orifício e o parafuso é solto.

Em 1997, Hebel K.S. e GAIJAR R.C. ${ }^{24}$ compararam restaurações implanto-suportadas cimentadas e parafusadas, buscando uma ótima oclusão e estética na implantodontia. Os autores enumeram as vantagens das próteses cimentadas sobre as 
parafusadas em relação à estética, oclusão e transmissão de forças além de permitir um melhor acesso às regiões posteriores, terem menor custo, menor complexidade de componentes e procedimentos laboratoriais e levarem a um menor tempo nas consultas. Assim, concluem que a oclusão e a estética não devem ser arbitrariamente descartadas pelo uso das próteses parafusadas na busca por reversibilidade, uma vez que uma manipulação adequada das próteses cimentadas fornece essa reversibilidade, com o uso dos cimentos temporários, sem, contudo, afetar a oclusão, a estética e a distribuição de estresses aos componentes protéticos e à interface osso-implante.

CLAYTON G.H., DRISCOLL C.F. e HONDRUM S.0. ${ }^{9}$ avaliaram, em 1997, o efeito dos agentes cimentantes na retenção e adaptação marginal do sistema de implantes CeraOne. Para isso, cilindros de ouro do sistema CeraOne foram cimentados sobre abutments com cinco diferentes tipos de agentes cimentantes: cimento de ionômero de vidro modificado (Vitremer), cimento de ionômero de vidro (Fuji One), cimento temporário à base de óxido de zinco e eugenol (Temp Bond), cimento fosfato de zinco e cimento resinoso (Panavia). Os espécimes sofreram termociclagem após 24 horas de armazenagem em água destilada. Após os testes de tração, os resultados mostraram que o cimento fosfato de zinco 
produziu uma força retentiva $164 \%$ mais forte que o cimento ionômero de vidro e $49 \%$ maior que o cimento resinoso. A microscopia eletrônica de varredura mostrou que o cimento fosfato de zinco apresentou a maior abertura marginal mas seu valor médio de $62 \mu \mathrm{m}$ não deve ser clinicamente significante. Os autores concluíram também, que devido ao fato de o cimento fosfato de zinco não ser um cimento adesivo, a configuração geométrica do sistema CeraOne (conicidade, extensão, área de superfície e espaço para o cimento) deve ser a mais adequada para o uso desse cimento.

Em 1998, PREISKel H.W. e TSOLKA P. ${ }^{45}$ avaliaram as próteses telescópicas para implantes em um estudo retrospectivo. Nesse estudo, 238 implantes foram posicionados em 41 pacientes completa ou parcialmente edentados e um total de 73 próteses telescópicas foram instaladas. Moldagens foram confeccionadas e os análogos posicionados. Abutments de titânio foram preparados no modelo mestre e modificações nas paredes axiais, altura e término foram realizadas, se necessárias. As infra-estruturas foram fundidas em uma liga de ouro platinizada e a porcelana foi aplicada. Os abutments foram posicionados sobre os implantes. Para a cimentação das próteses foi utilizado o cimento temporário Temp Bond e as próteses foram assentadas manualmente. Os 
pacientes foram reavaliados nos períodos pós-cimentação de 1 dia, 1 e 2 semanas, 1 e 3 meses, e então em intervalos de 6 meses. Exames radiográficos foram feitos na instalação da prótese e anualmente. Os resultados mostraram que 19 abutments apresentaram perda de parafuso após um período de 547 dias. Problemas de retenção ocorreram em 4 próteses. Em duas delas, a remoção da prótese não foi conseguida quando desejada, e as outras duas sofreram deslocamento acidental. Uma desadaptação da prótese ocorreu apenas 3 vezes, sendo necessárias novas fundições e próteses adicionais para a obtenção de dentes menores. Os autores concluíram então, que o princípio das coroas telescópicas, usado nas restaurações suportadas por dentes parece ter um mérito considerável na prótese sobre implantes e merece mais desenvolvimento. Nesse estudo, próteses telescópicas implanto-suportadas cimentadas apresentaram-se como um método versátil e confiável de tratamento.

Os resultados de um estudo prospectivo de 5 anos sobre coroas unitárias cimentadas sobre implantes com o sistema CeraOne foram demonstrados em 1998 por ANDERSSON B., ÖDMAN P., LINDVALL A-M e BRÅnemARK P-I. ${ }^{5}$ Foram selecionados 57 pacientes e este grupo correspondeu ao primeiro grupo de pacientes tratados com CeraOne. Os abutments foram 
fixados aos implantes com parafusos de titânio (para os três primeiros pacientes) e de ouro (para os outros pacientes). As coroas (62 metal-free e 3 metalo-cerâmicas) foram cimentadas sobre os abutments. O exame clínico incluiu avaliação da mucosa peri-implantar, gengiva, profundidade de bolsa nos dentes adjacentes, mobilidade do dente/implante, oclusão, posicionamento margem da coroa no sulco peri-implantar e estética. Todas as complicações notadas pelo paciente ou pelo dentista foram registradas. As visitas de reavaliação ocorreram em 2 semanas, 1, 3 e 6 meses, 1, 2, 3, 4 e 5 anos após a cimentação. Exames radiográficos também foram realizados. Dos 57 pacientes tratados, 49 completaram os 5 anos de avaliação. O índice de sucesso dos implantes foi de $98.5 \%$. Com relação às coroas, quatro falhas foram registradas, todas na maxila. Dessas, duas devido à fratura após um trauma e duas devido à necessidade de mudança do abutment (as coroas apresentavam-se intactas). $O$ índice de sucesso para as coroas foi de $93.7 \%$. O sangramento foi mais comumente encontrado em volta dos dentes adjacentes do que em volta dos implantes. O nível da mucosa peri-implantar apresentouse relativamente estável em relação ao nível do abutment/coroa. 0 resultado estético foi considerado bom para todas as coroas para os pacientes e dentistas. Uma perda óssea média de $1.3 \mathrm{~mm}$ foi encontrada no primeiro ano. Após esse período os implantes 
exibiram uma menor perda óssea e um nível ósseo estável foi registrado após 2 anos. Com base nesses dados, os autores concluíram que um alto índice cumulativo de sucesso foi obtido para os implantes $(98.5 \%)$ e coroas $(93.7 \%)$. Uma perda óssea mínima foi encontrada em volta dos dentes adjacentes e dos implantes e após 2 anos um nível ósseo estável foi obtido. Os tecidos moles em torno dos dentes e implantes estavam saudáveis e não foi encontrada recessão da mucosa peri-implantar. Assim, o sistema CeraOne mostrou-se um conceito protético altamente previsível e seguro, eliminando problemas de perda de parafusos dos abutments e criando uma plataforma para bons resultados estéticos.

Em 1999, KeITH S.E., MILleR B.H., WOODY R.D. e HIGGINBOTTOM F.L. ${ }^{30}$ avaliaram a discrepância marginal de coroas metalo-cerâmicas parafusadas e cimentadas sobre abutments de implantes. Para isso, 20 implantes foram utilizados, 10 para as restaurações cimentadas e 10 para as parafusadas. Os abutments apropriados para cada grupo foram posicionados aos implantes com um torque de $35 \mathrm{~N} / \mathrm{cm}$. Coroas metalo-cerâmicas foram então confeccionadas para cada grupo de acordo com os protocolos padrão de laboratório. A aplicação da porcelana apresentou cinco estágios: desgaseificação, opaco, $1^{a}$ queima, $2^{a}$ 
queima e glaze. O grupo das restaurações cimentadas foi dividido para a avaliação de dois agentes cimentantes diferentes: cimento ionômero de vidro e cimento fosfato de zinco. As coroas foram assentadas com pressão digital e então uma carga estática de $10 \mathrm{Kg}$ foi aplicada por 10 minutos. No grupo das restaurações parafusadas, as coroas foram assentadas e um torque de $15 \mathrm{~N} / \mathrm{cm}$ foi aplicado ao parafuso de titânio. As discrepâncias marginais foram mensuradas em estágios selecionados da confecção da coroa: nos cilindros de ouro antes da confecção das coroas parafusadas, após a confecção das infra-estruturas para as coroas cimentadas e parafusadas, após a aplicação da cerâmica e polimento marginal e finalmente após a cimentação com os dois cimentos testados. Os resultados mostraram que a menor discrepância marginal foi encontrada para os cilindros de ouro antes da fundição. As discrepâncias após a fundição e após a aplicação da cerâmica, entretanto, apresentaram valores similares, no grupo das coroas parafusadas. Para as coroas cimentadas, a infra-estrutura mostrou a melhor adaptação ao conjunto implante/abutment. Após a aplicação da cerâmica, antes da cimentação, a discrepância aumentou e após a cimentação esses valores apresentaram um pequeno aumento para 0 cimento ionômero de vidro e a maior discrepância marginal foi então apresentada após a cimentação das coroas com o cimento fosfato 
de zinco. Com base nos resultados encontrados, os autores concluíram que a discrepância marginal média apresentada pelas coroas parafusadas foi significativamente menor do que aquela apresentada pelas coroas cimentadas e que esses valores de discrepância marginal para coroas cimentadas são menores para o cimento ionômero de vidro quando comparado ao cimento fosfato de zinco.

A resistência à tração de agentes cimentantes provisórios utilizados com um sistema de implantes foi avaliada em 1999 por RAMP M.H., DIXON D.L., RAMP L.C., BREEDING L.C. e BARBER L.L. ${ }^{47}$ Casquetes metálicos foram cimentados sobre abutments com cinco diferentes cimentos temporários - Temp Bond, IRM, Provilink, Neo-Temp e um cimento à base de poliuretano (SteriOss). Após um período de imersão de 48 horas, os testes de tração foram realizados. Com base nos resultados obtidos, os autores concluíram que os cimentos temporários Temp Bond e Provilink exibiram os menores valores de resistência à tração e que o cimento temporário Neo-Temp apresentou os maiores valores, chegando a ser 3 vezes mais retentivo que o cimento Temp Bond.

Em 2000, COVEY D.A., KENT D.K., GERMAIN JR. H.A.S. e KOKA S.,${ }^{10}$ avaliaram os efeitos do tamanho do abutment e do tipo 
de agente cimentante na força de retenção uniaxial de coroas implanto-suportadas. Foram testados três diferentes tamanhos de abutment - padrão, largo e experimental - e dois tipos de agentes cimentantes - temporário (à base de Óxido de Zinco e Eugenol) e definitivo (Fosfato de Zinco). Testes de tração foram realizados e os resultados mostraram que o cimento definitivo produziu forças uniaxiais de retenção 2.5 a 4.7 vezes maiores que o cimento temporário e que o aumento na área de superfície produzido pelo abutment largo não resultou em aumento nas forças retentivas. Os autores concluíram ainda que a altura do abutment e a proporção da altura para a largura estavam positivamente relacionadas à força de retenção, enquanto uma área de superfície total do abutment e a largura não mostraram essa relação.

MICHALAKIS K.X., PISSIOTIS A.L. e HIRAYAMA H., ${ }^{37} \mathrm{em}$ 2000, avaliaram as cargas de falha de quatro agentes cimentantes temporários utilizados na cimentação de próteses parciais fixas implanto-suportadas. Para isso, estruturas de PPF suportadas por dois e quatro implantes foram confeccionadas e cimentadas com quatro diferentes cimentos temporários - ImProv, Nogenol, Temp Bond e Temp Bond NE. Os testes de tração foram realizados e os resultados mostraram que 24 horas após a cimentação, o cimento temporário ImProv apresentou os maiores valores de resistência à 
tração tanto para as PPFs suportadas por 2 implantes quanto para aquelas suportadas por 4 implantes. O cimento Nogenol apresentou os menores valores de resistência à tração e por isso, deve ser o cimento de escolha quando a reversibilidade é importante.

A passividade do assentamento e a abertura marginal de próteses parciais fixas parafusadas ou cimentadas retidas por implantes foram avaliadas por GUICHET D.L., CAPUTO A.A., CHOI, H. e SORENSEN, J.A., ${ }^{22}$ em 2000. Para isso, foi realizada uma simulação de tratamento de um quadrante mandibular posterior esquerdo restaurado com três implantes, posicionados nos locais correspondentes aos primeiro e segundo pré-molares e primeiro molar. Foram confeccionadas cinco próteses parciais fixas com desenho para prótese parafusada e cinco com desenho para prótese cimentada. Uma forma esqueletal anatomicamente correta foi usada para criar um modelo mestre, um molde e um modelo do paciente em resina fotoelástica. Essa resina simulava um osso saudável. Moldagens foram confeccionadas e os análogos dos implantes posicionados. O gesso foi vazado e então um modelo de trabalho criado. Os dentes da PPF foram encerados e duplicados em silicone para permitir uma posterior padronização das PPFs confeccionadas. Para as próteses parafusadas, os abutments e os cilindros de ouro foram posicionados sobre o modelo de trabalho e 
uma infra-esturura confeccionada em resina. Essa infra-estrutura foi inserida no molde de silicone e a cera foi então injetada. Para as próteses cimentadas, os abutments foram posicionados e preparados de forma padronizada. Casquetes de resina foram preparados, posicionados sobre os abutments e incluídos no molde de silicone para a injeção da cera. Os padrões foram então fundidos em uma liga de ouro-paládio. As PPFs foram então posicionadas sobre os implantes no modelo mestre, e a discrepância marginal medida com um microscópio comparador para os dois grupos. Em seguida, para as próteses parafusadas foi utilizado o torque de $20 \mathrm{~N} / \mathrm{cm}$ para os parafusos do abutment e de $10 \mathrm{~N} / \mathrm{cm}$ para os parafusos de ouro. Para as próteses cimentadas foi utilizado o cimento temporário Temp Bond sob uma carga de $4.5 \mathrm{Kg}$ por 1 minuto seguida de uma carga de $0.9 \mathrm{Kg}$ por 2 minutos. As discrepâncias marginais foram então novamente mensuradas. Posteriormente, os espécimes foram avaliados quanto à geração de estresses pelo apertamento do parafuso ou pela cimentação. As próteses e os modelos de osso fotoelástico foram imersos em óleo mineral e fotografados sob luz polarizada. Os dados fotográficos foram analisados e classificados em ordem de aumento de estresse para comparação. Os resultados mostraram que antes do apertamento do parafuso ou da cimentação, as aberturas marginais médias foram semelhantes para os dois grupos. Entretanto, para 
as próteses parafusadas, essa abertura foi significativamente reduzida após o apertamento do parafuso, o que não aconteceu com as próteses cimentadas após a cimentação. Quanto a avaliação do estresse gerado pelo assentamento, foi encontrado que com o apertamento do parafuso de ouro, uma transferência de estresses ao modelo de osso foi encontrada em 4 das 5 PPFs testadas, variando quanto à localização e intensidade. No grupo das próteses cimentadas, apenas uma das cinco PPFs apresentou um nível moderado de estresse. Assim, os autores concluíram que as aberturas marginais para as próteses parafusadas e cimentadas não foram diferentes antes do assentamento. Entretanto, após o assentamento, as próteses parafusadas apresentaram aberturas de margem significativamente menores do que as próteses cimentadas. Os autores concluíram ainda que diferenças foram encontradas na geração de estresses para os dois grupos. As próteses parafusadas apresentaram variação na localização e intensidade de estresse, com alguns casos de grande concentração apical. Já as próteses cimentadas apresentaram um baixo nível de estresse, com uma tendência à localização coronária. A abertura marginal significativamente reduzida nas próteses parafusadas foi associada a um maior estresse, enquanto o aumento na abertura marginal das próteses cimentadas está relacionado a uma menor geração de estresse. 
O efeito da força de assentamento, do desenho da margem e do cimento no selamento marginal e na retenção de coroas totais metálicas foi avaliado por PIEMJAI M.. ${ }^{44}$ em 2001. Para isso, modelos metálicos de preparos para coroa total foram confeccionados com as mesmas formas e dimensões, alterando-se apenas os desenhos do término cervical que variaram em chanfro, ombro e ombro biselado. Coroas metálicas foram confeccionadas e cimentadas com dois tipos de cimentos - fosfato de zinco (Phosphacap) e ionômero de vidro (Fuji Cap 1), sob três diferentes forças de assentamento - 25, 100 e 300 N. A desadaptação marginal foi definida pela diferença na altura da coroa antes e após a cimentação e essa diferença obtida a partir de microscópio comparador. Após essa avaliação, testes de tração foram realizados. Os autores concluíram que o aumento na força de compressão promove um aumento na adaptação marginal, sem interferir, entretanto, na retenção das coroas. Os términos em ombro e ombro biselado não apresentaram diferenças significativas entre si, mas foram melhores que o chanfro no que diz respeito à resistência à tração. O cimento de ionômero de vidro apresentouse mais retentivo que o cimento fosfato de zinco e não foi encontrada relação entre a adaptação e a retenção das coroas. 
VALBAO F.P.B., PEREZ E.G. e BREDA M. ${ }^{58}$ apresentaram, em 2001, um método alternativo para a retenção e remoção de próteses sobre implantes cimentadas. Segundo esta técnica, uma moldagem é confeccionada do implante unitário e o modelo de gesso obtido montado em articulador semi-ajustável. O abutment é ajustado, preparado e encerado, deixando uma parede palatina espessa para facilitar a técnica. A inclinação e o alinhamento do abutment são verificados e este é fundido em uma liga semi-nobre e galvanizadas em ouro. Uma infra-estrutura para metalo-cerâmica é encerada e fundida com uma ampla exposição de metal na parede palatina. Então, um orifício de acesso é confeccionado nesta região palatina com uma broca carbide esférica No.4. Com uma outra broca carbide esférica No.2, um outro orifício é preparado no abutment através do primeiro orifício confeccionado. O abutment é posicionado e após a confirmação da adaptação por meio de radiogarfias, o parafuso é apertado com um torque de $32 \mathrm{~N} / \mathrm{cm}$. A restauração é cimentada com um cimento temporário sem eugenol e o orifício da restauração é preenchido com resina composta após a remoção do cimento temporário de seu interior. Segundo os autores, esta técnica facilita o alinhamento no arco, a retenção, estabilidade e reversibilidade. 
AKASHI A.E., FRANCISCHONE C.E., TOKUTSUNE E. $\mathrm{e}$ SILVA JR. W. , ${ }^{2}$ avaliaram em 2002, o efeito de diferentes tipos de cimentos temporários na resistência à tração e adaptação marginal de coroas sobre implantes. Casquetes metálicos foram confeccionados e cimentados sobre abutments do sistema CeraOne com um dos quatro cimentos temporários avaliados - Temp Bond, Temp Bond NE, Dycal e Improv. Antes e após a cimentação, os conjuntos espécime/casquete foram observados em microscópio comparador para avaliação da desadaptação marginal obtida após a cimentação e testes de tração foram realizados. Com base nos resultados encontrados, os autores concluíram que não houve diferença na adaptação marginal dos casquetes metálicos quando qualquer um dos quatro cimentos temporários foi utilizado. Em relação à resistência à tração, o cimento temporário Dycal apresentou os maiores valores, enquanto os menores valores foram atribuídos ao Temp Bond NE.

Uma comparação das forças de resistência uniaxiais dos cimentos utilizados em coroas implanto-suportadas foi realizada por AKCA K., İPLIKÇIOĞLU H. e ÇEHRELI M.C., ${ }^{3}$ em 2002. Para isso, 21 implantes padrão e 7 implantes de base larga foram utilizados. Os implantes de tamanho padrão foram divididos em 3 grupos, de acordo com a altura do abutment utilizado: 4.0mm - 
amarelos, $5.5 \mathrm{~mm}$ - cinzas, $7.0 \mathrm{~mm}$ azuis. Já para os implantes de base larga, abutments com $4.0 \mathrm{~mm}$ de altura foram utilizados. Todos os abutments apresentavam convergência oclusal de $6^{\circ} \mathrm{e}$ foram assentados sobre os implantes com um torque de $35 \mathrm{~N} / \mathrm{cm}$. Os padrões de cera das restaurações foram confeccionados e fundidos em uma liga contendo ouro (77.3\%), platina $(9.8 \%)$ e paládio (8.9\%). Para a cimentação 10 diferentes cimentos foram utilizados: 3 cimentos policarboxilato de zinco (Aqualox, Durelon e Poly-F), dois cimentos ionômero de vidro (Meron e Vitremer), um cimento ionômero de vidro híbrido (ProTec-Cem), dois cimentos temporários à base de óxido de zinco sem eugenol (Sinegol e Procem), um cimento temporário à base de óxido de zinco e eugenol (Temp Bond) e um cimento fosfato de zinco (Poscal). Os cimentos foram aplicados e as restaurações assentadas com pressão digital seguida de uma carga estática de $50 \mathrm{~N}$. Os espécimes foram mantidos em saliva artificial em temperatura ambiente por 24 horas e os testes de tração foram realizados. Os resultados mostraram que dentre todos os cimentos, o Poly- $F$ apresentou os maiores valores para todos os abutments seguido por Vitremer, Durelon e Aqualox. Os menores valores foram apresentados por Sinegol. Os cimentos temporários apresentaram menores valores retentivos que os outros cimentos testados. Os autores concluíram que a composição química dos cimentos 
utilizados para coroas implanto-suportadas afeta a resistência uniaxial quanto esses cimentos são utilizados sobre abutments e que a altura desses abutments apresentam um impacto maior do que seu diâmetro na força retentiva axial dos cimentos. Os autores concluíram ainda que os cimentos temporários apresentam retenção axial baixa quando utilizados com coroas implantosuportadas, podendo haver a necessidade de freqüentes recimentações. O uso do cimento fosfato de zinco ou ionômero de vidro poderia reduzir as falhas do cimento.

Em 2003, as características imuno-histoquímicas das lesões inflamatórias em implantes foram avaliadas por GUALINI F. e BERGLUNDH T. ${ }^{21} \mathrm{O}$ autor cita os achados obtidos em avaliações clínicas e em estudos animais que mostram o acúmulo de placa ao redor dos implantes resultam no desenvolvimento de uma lesão inflamatória na mucosa peri-implantar. Para determinar as características imuno-histoquímicas dessas lesões, dois grupos de indivíduos foram selecionados, sendo um deles formado por 10 pacientes parcialmente edentados restaurados com implantes que estavam em função por 2 a 5 anos e apresentavam sinais de mucosite peri-implantar (inflamação de tecido mole sem perda óssea). O outro grupo era formado por 6 indivíduos restaurados com implantes por 5 a 11 anos com a presença de sítios com sinais 
de peri-implantite (perda óssea marginal, inflamação de tecido mole, sem mobilidade no implante). Foram coletadas biópsias de tecido mole nos dois grupos e estas foram submetidas à análise imuno-histoquímica. Os resultados mostraram que as lesões de peri-implantite são maiores e contém maiores proporções de células B e de células elastase-positivas que as lesões de mucosite. Assim, os autores concluíram que as lesões de peri-implantite apresentam propriedades diferentes das lesões de mucosite.

A influência dos agentes cimentantes e das condições de tempo na discrepância e infiltração marginal de coroas puras de cerâmica foi avaliada em 2003 por GU X-H. e KERN M. ${ }^{20}$ Coroas de cerâmica pura e metalo-cerâmicas (controle) foram confeccionadas e cimentadas sobre molares extraídos com diferentes agentes cimentantes - cimento fosfato de zinco, cimento compômero e cimento resinoso. A avaliação da discrepância marginal foi realizada por observação em microscópio eletrônico de varredura. Para a avaliação da infiltração marginal, o método de penetração de corante foi utilizado. Os espécimes foram mantidos em fuccina básica, incluídos em resina, cortados e avaliados em um estereo-microscópio. Escores foram atribuídos para a penetração do corante na interface dente/restauração. Testes de fadiga foram realizados para simulação de passagem de tempo. Os resultados 
mostraram que as discrepâncias marginais das coroas de cerâmica pura foram significativamente menores do que aquelas das metalocerâmicas. Defeitos mais visíveis foram observados no cimento fosfato de zinco e estes aumentaram após os testes de fadiga. Esses defeitos não foram observados nos dois outros agentes cimentantes utilizados. Em relação à infiltração marginal, foram encontradas diferenças nos grupos de cerâmica pura cimentada com os diferentes agentes cimentantes. O cimento fosfato de zinco apresentou a maior infiltração marginal enquanto que o cimento resinoso apresentou a menor infiltração.

MICHALAKIS K.X, HIRAYAMA H. e GAREFIS P.D. ${ }^{35}$ realizaram, em 2003, uma revisão crítica sobre restaurações cimentadas versus parafusadas. Foram discutidas vantagens e desvantagens dos dois tipos de restauração e avaliados os fatores que podem interferir no sucesso dessas restaurações. Um dos fatores avaliados foi a facilidade de confecção e custo, onde o autor mostrou que as próteses cimentadas apresentam vantagens sobre as parafusadas devido às técnicas tradicionais, a falta de necessidade de treinamento especial e ao custo relativamente mais baixo dos componentes. Com relação à passividade da infraestrutura, foram citados dois tipos de complicações decorrentes de uma falta de passividade: complicações biológicas (excesso de 
carga transmitida ao osso, perda óssea e o desenvolvimento de microflora na abertura entre $\mathrm{o}$ implante e o abutment) e complicações protéticas (perda ou fratura do parafuso ou fratura do implante). Segundo o autor, quando nenhuma distorção ocorre na infra-estrutura, uma adaptação passiva é alcançada. Entretanto, essas distorções podem ocorrer em diversos estágios, como durante a moldagem, confecção do modelo, confecção do padrão de cera, procedimentos de inclusão e fundição, durante a queima da porcelana e durante a instalação da prótese. Assim, um somatório dessas distorções pode causar estresses internos significativos no complexo implante-prótese. $O$ autor relatou que até a época de seu estudo, nenhum trabalho obteve sucesso em demonstrar passividade em próteses parafusadas. As próteses cimentadas podem ser passivas devido ao espaço de 25 a $30 \mu \mathrm{m}$ do cimento. Quanto à retenção, os fatores que influenciam a prótese cimentada são: a convergência das paredes axiais, a área de superfície e altura, a rugosidade de superfície e o cimento. Para as restaurações parafusadas, a retenção é dada pelo parafuso que conecta a restauração com o abutment que são geralmente de ouro ou titânio. A oclusão é um outro fator que afeta a seleção entre próteses cimentadas ou parafusadas. Nas restaurações parafusadas a abertura de acesso ao parafuso ocupa cerca de $50 \%$ da mesa oclusal de molares e mais que $50 \%$ em pré-molares. Assim, o 
estabelecimento de uma oclusão ideal pode não ser possível já que para estabelecer contatos oclusais adequados, esses devem ser posicionados sobre a resina composta que veda o orifício e que é um material que sofre desgaste quando em oposição ao esmalte ou porcelana. No caso das próteses cimentadas, contatos ideais podem ser estabelecidos e permanecerem estáveis por um longo período de tempo. Com relação à estética, o problema encontrado nas próteses parafusadas está relacionado à resina utilizada para o vedamento do acesso ao parafuso que com o tempo sofre alterações de cor e desgastes. No momento da instalação da prótese, para as restaurações parafusadas é necessária somente uma verificação radiográfica da adaptação das próteses aos implantes antes do torque final do parafuso. Para as próteses cimentadas, entretanto, deve haver um cuidado com a remoção do excesso de cimento além da avaliação radiográfica, uma vez que isto é crítico para a saúde peri-implantar. A reversibilidade é uma das principais desvantagens da prótese cimentada. Por isso, cimentos temporários têm sido utilizados com o objetivo de garantir reversibilidade a essas restaurações. Entretanto, estudos mostram diferentes capacidades retentivas dos cimentos temporários, sendo necessário adequar seu uso ao tipo de restauração a ser cimentada (múltipla ou unitária). Diante disso, os autores concluem que o clínico deve estar atento às limitações e 
desvantagens de cada tipo de prótese de modo a selecionar o mais adequado à determinada situação clínica.

Em 2004, REGO M.R.M. e SANTIAGO L.C. ${ }^{48}$ avaliaram a retenção de coroas provisórias cimentadas com oito cimentos temporários. Para isso, pré-molares humanos receberam preparos padronizados para coroa total, com uma convergência oclusal de 60. Coroas provisórias foram então confeccionadas diretamente sobre os preparos com o auxílio de um pincel. Para a cimentação das restaurações provisórias, oito diferentes cimentos temporários foram utilizados: quatro à base de óxido de zinco sem eugenol (Temp Bond Ne, Rely X Temp, Freegenol e Nogenol), dois a base de óxido de zinco e eugenol (Temp Bond e Provy New) e dois à base de hidróxido de cálcio (Hydro $\mathrm{C}$ e Provicol). O cimento foi aplicado na região cervical das coroas que foram inicialmente assentadas com pressão digital. Em seguida uma carga estática de $5 \mathrm{Kg}$ foi aplicada até a presa do cimento (indicada pelo fabricante). Os espécimes foram então submetidos a testes de tração. Os resultados mostraram maiores valores para os cimentos Hydro C, Temp Bond e Rely X Temp, sem diferenças estatisticamente significantes. Por outro lado, os menores valores foram apresentados pelos cimentos Nogenol, Freegenol e Temp Bond NE, novamente sem diferenças estatísticas. Assim, com base nos 
resultados apresentados, os autores concluíram que coroas provisórias cimentadas com Hydro C apresentaram maiores valores retentivos quando comparado a outros cimentos, exceto Temp Bond e Rely X Temp e que as coroas cimentadas com Nogenol, Freegenol e Temp Bond NE apresentaram a menor resistência à tração.

Uma comparação da resistência à fratura de porcelanas em coroas metalo-cerâmicas parafusadas ou cimentadas retidas por implantes foi realizada por TORRADO E., ERCOLI C., MARDINI M.A., GRASER G.N., TALLENTS R.H. e CORDARO L., ${ }^{57}$ em 2004. Para isso, coroas metalo-cerâmicas foram confeccionadas de diferentes formas. Para o primeiro grupo, as coroas apresentavam uma mesa oclusal de $5 \mathrm{~mm}$ (vestíbulo-lingual) com uma perfuração de $2,5 \mathrm{~mm}$ no centro da mesa oclusal para que fosse parafusada sobre o abutment. O segundo grupo era semelhante ao primeiro, sendo que a perfuração foi localizada $1 \mathrm{~mm}$ mais para vestibular da coroa. As coroas do terceiro grupo apresentavam desenho para prótese cimentada, ou seja, não apresentaram perfuração oclusal e tinham uma mesa oclusal também de $5 \mathrm{~mm}(\mathrm{~V}-\mathrm{L})$. O grupo quatro apresentava coroas semelhantes às do grupo três, sendo que com uma mesa oclusal reduzida, de $4 \mathrm{~mm}$ (V-L). O espaço reservado para a cerâmica em todos os grupos foi de $1,2 \mathrm{~mm}$. Para o 
posicionamento das coroa sobre os abutments foi utilizada vaselina, para todos os grupos (cimentadas e parafusadas). Os espécimes foram submetidos a cargas compressivas. Os resultados mostraram que os grupos 1 e 2 necessitaram de menor força para a fratura das coroas quando comparados aos grupos 3 e 4 . Nenhuma diferença estatística foi encontrada entre os grupos 1 e 2 ou entre os grupos 3 e 4 . Assim, os autores concluíram que uma força significativamente mais baixa foi necessária para fraturar coroas parafusadas do que coroas cimentadas e que nenhuma diferença foi encontrada na resistência à fratura entre as coroas cimentadas com mesas oclusais de 4 ou $5 \mathrm{~mm}$. Os autores concluíram ainda que a localização da abertura de acesso ao parafuso não afetou a resistência à fratura da porcelana.

Alfaro M.A., PAPAZOglou E., Mcglumphy E.A. e HOLLOWAY J.A. ${ }^{4}$ avaliaram, em 2004, as propriedades retentivas em curto prazo de cimentos para próteses implanto-suportadas reversíveis. Abutments de titânio com uma convergência de $6^{\circ}$ foram utilizados e parafusados sobre os implantes com um torque de $35 \mathrm{~N} / \mathrm{cm}$. Foram feitas moldagens e então modelos de gesso tipo IV. Três camadas de die spacer foram aplicadas para a obtenção de uma linha de cimento de 30 a $45 \mu \mathrm{m}$. Padrões de cera foram confeccionados e fundidos em uma liga com alto teor de 
paládio. Onze materiais diferentes foram utilizados como agentes cimentantes: cimentos temporários à base de óxido de zinco e eugenol (Temp Bond, TempoCem), cimentos à base de óxido de zinco e eugenol modificado com polímero (Fynal), base de cavidade de hidróxido de cálcio (Dycal), materiais de moldagem à base de polivinilsiloxano (Reprosil) e de poliéter (Impregum), um adesivo de silicone médico (Silastic), um dimetacrilato diuretano (TNE), um polímero uretano acrílico (ImProv), vaselina e finalmente o cimento fosfato de zinco que foi utilizado como Gold Standard. Para avaliar o efeito da adição de modificadores, foi ainda adicionada vaselina ao cimento temporário Temp Bond na mesma proporção do catalisador (1:3). Os materiais foram então aplicados às partes internas das fundições que foram assentadas sobre os abutments com pressão digital seguida de carga estática de $5 \mathrm{Kg}$ por 10 minutos. Após 30 minutos, os espécimes foram submetidos a testes de tração. Com o objetivo de testar o efeito do tempo e da dissolução dos materiais nos valores retentivos, novos testes foram conduzidos após $72 \mathrm{~h}$ de imersão em solução salina a $37^{\circ} \mathrm{C}$. Os resultados mostraram que o tempo, assim como o tipo de material apresentaram efeitos significativos nos valores retentivos. Para o grupo de 30 minutos, os maiores valores retentivos foram apresentados por Fynal e ImProv e para o grupo de $72 \mathrm{~h}$, os maiores valores foram obtidos pelo fosfato de zinco, seguido dos 
materiais Fynal e ImProv. O cimento temporário Temp Bond apresentou menores valores retentivos que o Dycal que por sua vez foi menos retentivo que o Fynal. Comparando os resultados em 30 minutos e 72 horas, Temp Bond, Dycal e Fynal apresentaram uma redução nos valores retentivos, enquanto que o fosfato de zinco e o Silastic demonstraram um aumento significativo na resistência à tração. O Temp Bond com vaselina não sofreu alterações com o tempo, assim como o TempoCem. Com base nos resultados obtidos os autores puderam concluir que para o grupo de 30 minutos, os materiais podem ser divididos em grupos ascendentes de retenção: (i) Silastic e Temp Bond + vaselina, (ii) Reprosil, (iii) Impregum e TempoCem, (iv) Tempo Cem e Temp Bond, (v) TNE e Dycal e (vi) ImProv e Fynal. Para o grupo de 72h: (i) Temp Bond + vaselina e Reprosil, (ii) Temp Bond, Impregum, Silastic e TempoCem, (iii) TNE e Dycal, (iv) Fynal e Improv. O armazenamento dos espécimes por $72 \mathrm{~h}$ em solução salina causou uma redução significativa nos valores de Reprosil, Temp Bond, Fynal, ImProv e Dycal e um aumento nas forças retentivas de Silastic e cimento fosfato de zinco, quando comparado aos valores obtidos em 30 minutos.

Um acompanhamento de 10 anos de um novo desenho de prótese implanto-suportada retida por parafuso e cimento foi 
realizado em 2004 por PREISKeL H.W. e TSOLKA P.. ${ }^{45}$ Foram avaliadas 78 próteses. Esse novo desenho de retenção fazia com que cada prótese incorporasse pelo menos, 1 elemento retido por parafuso e 1 ou mais unidades telescópicas cimentadas. Foram realizadas moldagens e os abutments telescópicos foram preparados no modelo mestre com modificações necessárias em suas paredes axiais, altura e término. Os abutments parafusados foram posicionados sobre o modelo mestre e os cilindros de ouro posicionados. As infra-estruturas foram fundidas em ouro. As próteses foram cimentadas com o cimento temporário Temp Bond misturado à vaselina. Foi realizado um assentamento manual e os parafusos dos elementos parafusados foram apertados. Os pacientes foram reexaminados nos seguintes intervalos de tempo após a instalação das próteses: 1 dia, 1 e 2 semanas, 1 e 3 meses e então em intervalos de 6 meses. As próteses foram removidas nos intervalos de 2 semanas, 1 e 3 meses e então somente se fosse necessário algum reparo. Radiografias foram confeccionadas na instalação e anualmente. Os resultados mostraram que 5 dos 286 implantes instalados foram perdidos antes da instalação das próteses e 4 após a instalação (aprox. 14 meses). Dos 285 abutments que suportaram as próteses, 161 eram cimentados e 124 parafusados. Dos abutments utilizados, 8 (4 cimentados e 4 parafusados) apresentaram parafusos soltos nas visitas pós- 
cimentação. Um parafuso protético de ouro fraturou após 1372 dias e foi substituído. Com base nesses resultados, os autores concluíram que a combinação de retenções por parafusos e por cimento temporário mostrou-se uma abordagem válida para próteses fixas implanto-suportadas na população estudada.

Vigolo P., Givani A., MAJZOUB Z. e CORDIOLI G. ${ }^{60}$ realizaram, em 2004, um estudo clínico prospectivo de 4 anos avaliando coroas unitárias implanto-suportadas retidas por parafusos versus coroas unitárias implanto-suportadas cimentadas. Foram selecionados 12 pacientes que apresentassem sítios unitários edêntulos bilaterais nas regiões de caninos, pré-molares e molares. Vinte e quatro implantes foram então posicionados e moldagens realizadas 3 meses após o segundo estágio cirúrgico. Os análogos foram posicionados nas moldagens que foram vazadas com gesso tipo IV. Foram utilizados 24 abutments UCLA de ouro que foram adaptados aos implantes com um torque de $30 \mathrm{~N} / \mathrm{cm}$. Para as coroas cimentadas foi utilizado o cimento temporário Temp Bond NE. As coroas parafusadas foram posicionadas e os parafusos de ouro apertados $(30 \mathrm{~N} / \mathrm{cm})$. Os pacientes foram reavaliados em intervalos de 3 meses no primeiro ano e de 6 em 6 meses nos anos subseqüentes. Os critérios utilizados para a avaliação dos implantes foram: ausência de mobilidade, ausência de dor ou 
parestesia, ausência de radiolucidez peri-implantar na avaliação radiográfica e ausência de perda óssea marginal progressiva. No final de 4 anos, todos os pacientes foram avaliados e parâmetros periodontais foram utilizados para avaliação da mucosa periimplantar: placa supra-gengival, inflamação gengival, sangramento à sondagem, quantidade de gengiva inserida em torno do abutment e profundidade de sondagem a partir da margem gengival. Como resultado desse trabalho, nenhum paciente apresentou qualquer complicação protética como perda do parafuso do abutment ou da coroa, fratura da porcelana ou perda das coroas cimentadas. A avaliação clínica da mucosa peri-implantar revelou resultados satisfatórios semelhantes para as interfaces implantemucosa para os dois grupos avaliados. Uma profundidade de sondagem de $2.8 \mathrm{~mm}$ e uma absorção óssea marginal de $0.8 \mathrm{~mm}$ foram registradas para os dois grupos ao final de 4 anos. Nenhuma diferença estatisticamente significante foi encontrada entre os dois grupos. Os autores concluíram então, que todos os 24 implantes sobreviveram e que nenhuma complicação protética ocorreu e que a escolha entre próteses cimentadas ou parafusadas parece estar primeiramente relacionada à preferência do clínico, uma vez que não foi encontrada nenhuma evidência de que um método é melhor que o outro. 
3 PROPOSIÇÃO 


\section{Proposição}

O objetivo deste estudo foi comparar o desajuste cervical, a infiltração marginal e a resistência à tração de copings metálicos cimentados com cimento temporário TempBond NE sobre abutments tipo UCLA preparados e fundidos com três diferentes desenhos de margens - ombro, chanfro profundo e chanferete após um período de 30 dias de imersão em água destilada e suas possíveis interações ou correlações. 
4 MATERIAL E MÉTODOS 


\section{Material e Métodos}

\subsection{Material}

Para a realização deste trabalho foram utilizados os materiais descritos na Tabela 1.

Tabela 1: Material de consumo utilizado

\begin{tabular}{|c|c|l|}
\hline \multicolumn{1}{|c|}{ Material } & Nome Comercial & \multicolumn{1}{|c|}{ Fabricante } \\
\hline $\begin{array}{c}\text { Abutment calcinável } \\
\text { tipo UCLA }\end{array}$ & - & $\begin{array}{l}\text { Conexão Sistemas de } \\
\text { Prótese, São Paulo, } \\
\text { SP }\end{array}$ \\
\hline Análogos de implante & - & $\begin{array}{l}\text { Conexão Sistemas de } \\
\text { Prótese }\end{array}$ \\
\hline Pontas diamantadas & - & $\begin{array}{l}\text { KGSorensen Ind. } \\
\text { Com. LTDA, Barueri, } \\
\text { SP }\end{array}$ \\
\hline Revestimento & Heat Shock & Polidental, Cotia, SP \\
\hline Liga de Ni-Cr & Vera Bond II & $\begin{array}{l}\text { AlbaDent, Cordélia- } \\
\text { CA, USA }\end{array}$ \\
\hline Borrachas abrasivas & - & KGSorensen \\
\hline $\begin{array}{r}\text { Resina acrílica } \\
\text { autopolimerizável }\end{array}$ & Jet & $\begin{array}{l}\text { Artigos Odontológicos } \\
\text { Clássico, Lapa, SP }\end{array}$ \\
\hline $\begin{array}{r}\text { Gesso especial tipo } \\
\text { IV }\end{array}$ & Durone & $\begin{array}{l}\text { Denstply, Petrópolis, } \\
\text { RJ }\end{array}$ \\
\hline Silicone de adição & PolyPour & $\begin{array}{l}\text { Gcera Lab } \\
\text { Technologies Inc, } \\
\text { Alsip-IL, USA }\end{array}$ \\
\hline Cimento temporário & TempBond NE & $\begin{array}{l}\text { Kerr Corporation, } \\
\text { Orange-CA, USA }\end{array}$ \\
\hline
\end{tabular}




\subsection{Métodos}

\subsubsection{Confecção dos preparos}

Inicialmente, foram utilizados para esse trabalho três abutments UCLA plásticos com hexágono interno de $3.75 \mathrm{~mm}$ de diâmetro (Conexão Sistemas de Prótese, São Paulo, SP), que receberam modificações em suas formas quanto à altura, convergência e margem cervical de acordo com as pontas diamantadas utilizadas. Essas pontas foram acopladas a uma peça de mão de baixa rotação com o auxílio de um adaptador e esta, a uma fresadeira com braços articulados BioArt 1000 (BioArt Equipamentos Odontológicos Ltda, São Carlos, SP, Brazil), o que permitiu a confecção de preparos circulares (Fig.1).

Dessa forma, cada um dos três abutments recebeu um preparo com a mesma altura $(4,0 \mathrm{~mm})$, mesma conicidade $\left(6^{\circ}\right)$ e diferentes desenhos da margem cervical, a saber: (i) margem em ombro $90^{\circ}$ - para isso foi utilizada a ponta diamantada No. 3069 (KGSorensen Ind. Com. Ltda, Barueri, SP); (ii) margem em chanfro - ponta diamantada No. 3227 (KGSorensen); e (iii) margem em 
chanfro profundo - ponta diamantada No. 4138 (KGSorensen) (Fig.2).

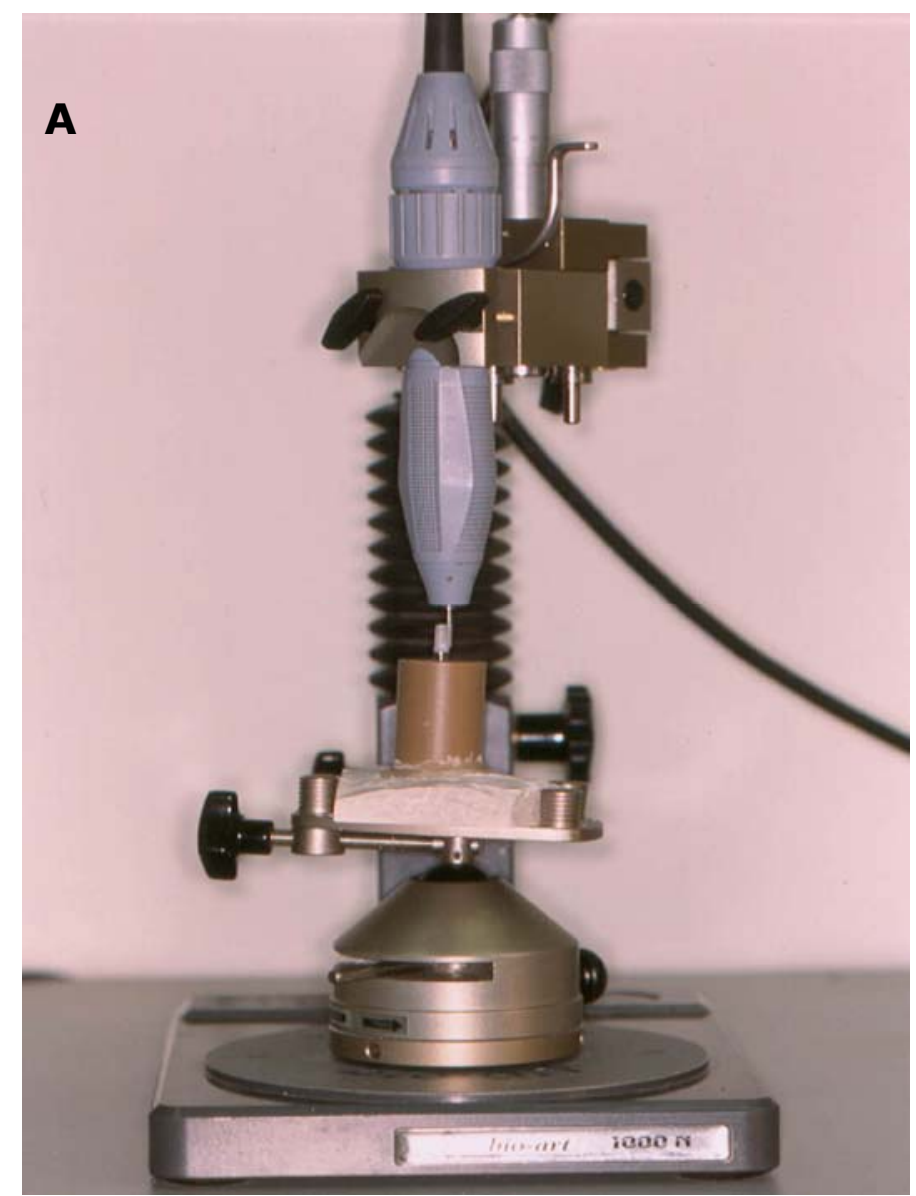

Fig.1 - A. Fresadeira BioArt 1000 vista frontal; B. Vista superior do braço articulado da fresadeira

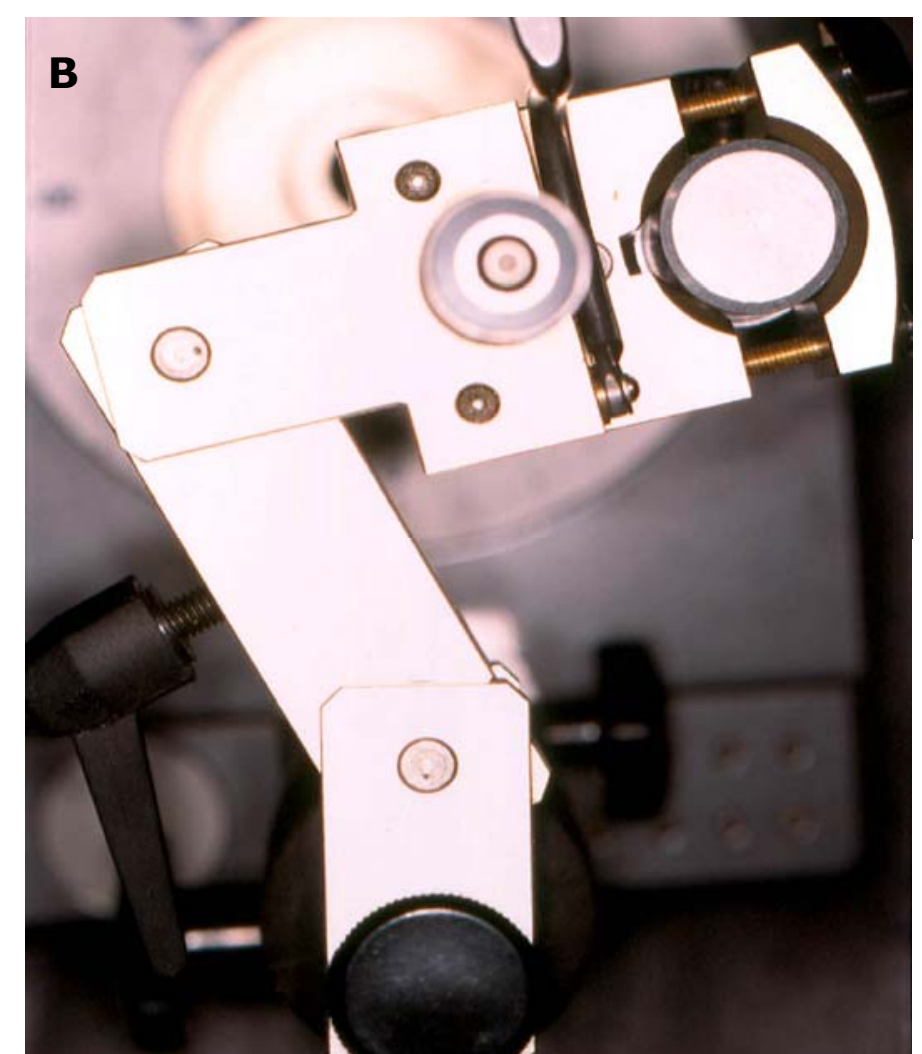




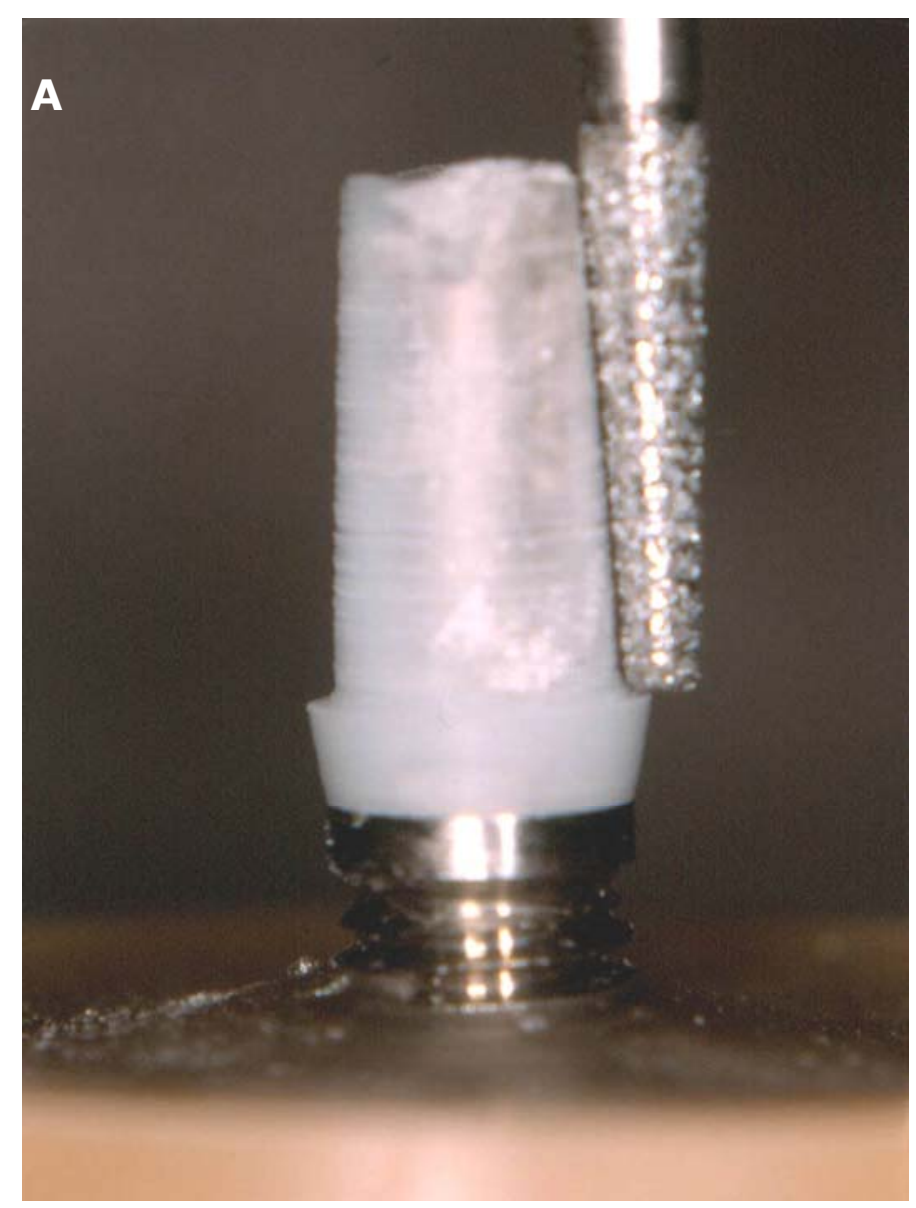

B

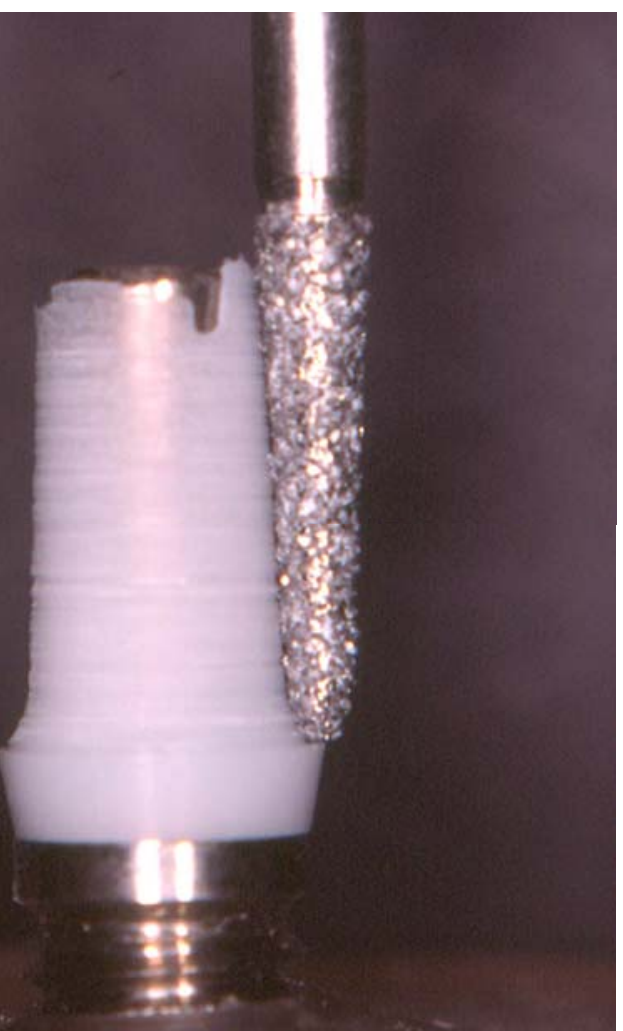




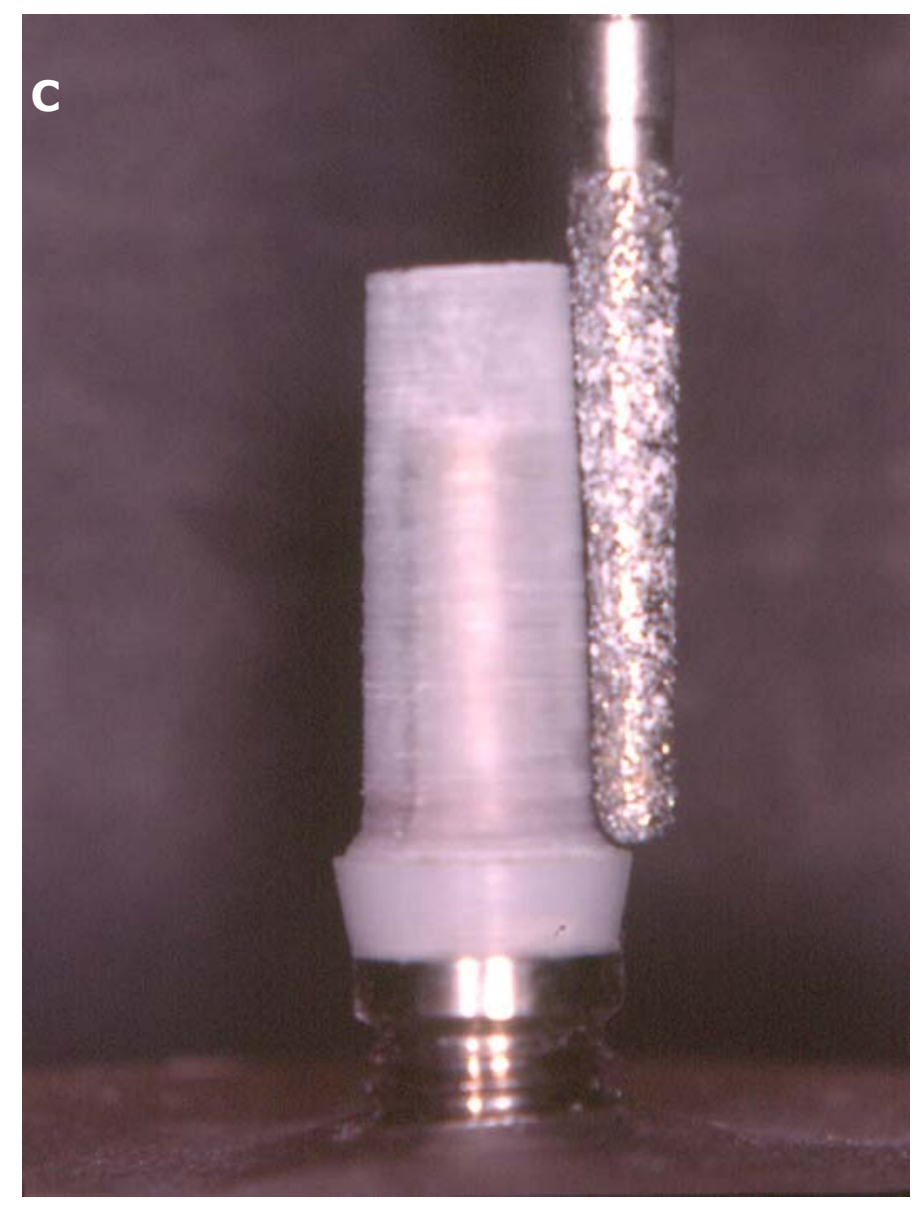

Fig.2 - A. Preparo em ombro realizado com a ponta diamantada 3069; B. Preparo em chanferete realizado com a ponta diamantada 3227; C. Preparo em chanfro profundo realizado com a ponta diamantada 4138.

A altura foi padronizada utilizando-se um paquímetro digital (Starret Indústria e Comércio LTDA, Itu, SP) e a conicidade, a partir das pontas diamantadas utilizadas. 
Após a confecção dos preparos, os abutments agora modificados foram enviados para a empresa Conexão Sistemas de Prótese para que 20 réplicas de cada tipo de preparo fossem industrialmente confeccionadas. Dessa forma, foram utilizados 60 abutments para a avaliação do desajuste cervical após a cimentação. Após essa primeira avaliação, os 60 abutments foram aleatoriamente divididos em dois grupos (por sorteio), onde 30 espécimes (10 de cada preparo) foram utilizados para o teste de resistência à tração e os outros 30 (10 de cada preparo) foram utilizados para o teste de infiltração marginal.

\subsubsection{I nclusão e fundição}

Os abutments foram então encaminhados ao laboratório de prótese para que fossem realizadas a inclusão e fundição dos mesmos.

Condutos de alimentação foram confeccionados sobre os abutments com fios de cera de $2.5 \mathrm{~mm}$ de diâmetro na parede axial, próximo à oclusal (Fig.3). 
Os abutments foram então fixados à base formadora de cadinho pelo vértice dos condutos de alimentação e sobre esta base, foi adaptado um anel de silicone para fundição. Foram incluídos 6 abutments em cada anel (Fig.4).

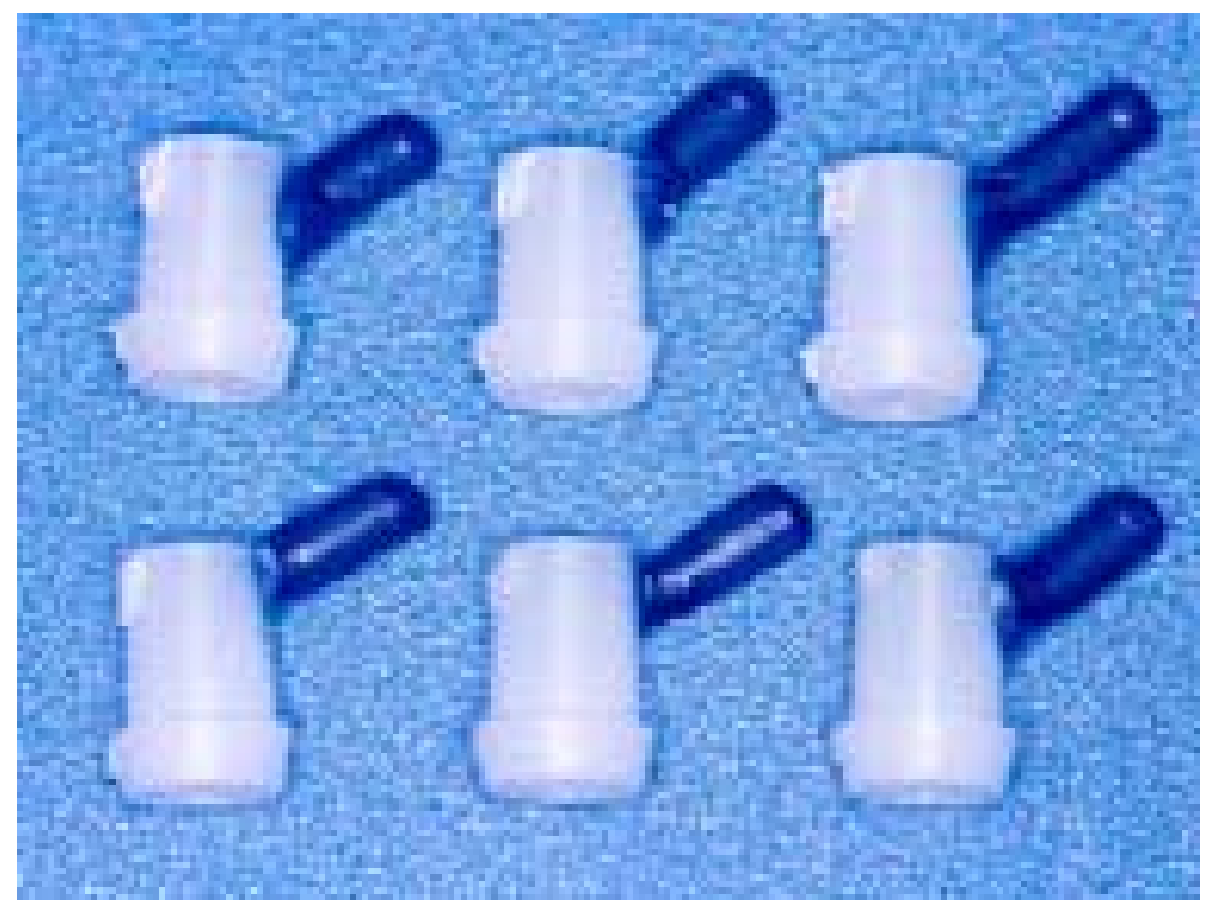

Fig. 3 - Condutos da alimentação unidos aos abutments

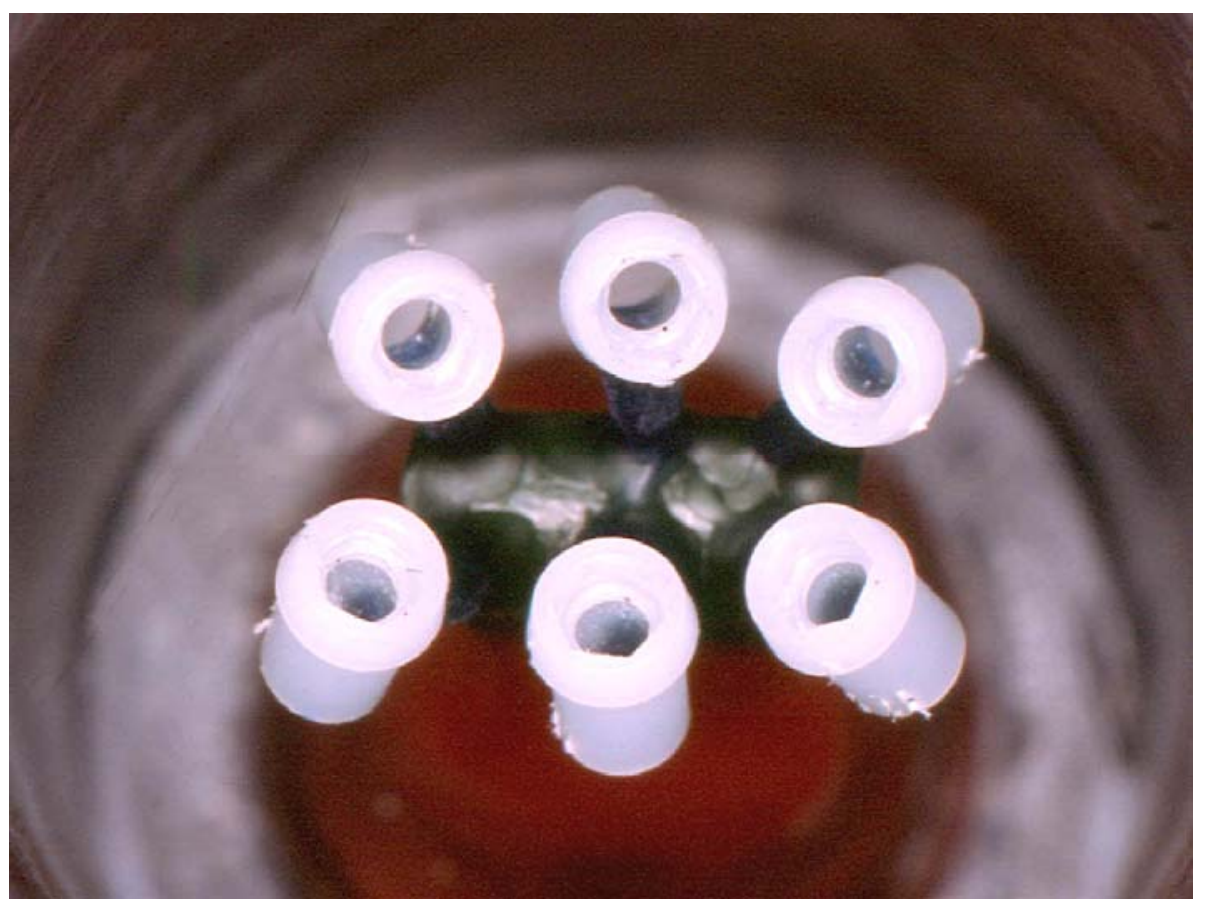


Fig.4 - Abutments no anel de silicone em grupos de seis

Para a inclusão foi utilizado revestimento Heat Shock (Polidental, Cotia, SP), numa proporção água/pó de $20 \mathrm{ml} / 98.4 \mathrm{~g}$, com espatulação a vácuo por 40s. Foi utilizada a técnica de expansão livre do revestimento.

Os anéis de silicone foram removidos após a presa do revestimento e este levado ao forno a $850^{\circ} \mathrm{C}$ e posteriormente a $950^{\circ} \mathrm{C}$ por $1 \mathrm{~h}$ para a eliminação dos padrões (abutments) plásticos.

Para a fundição foi utilizada a liga de níquel/cromo VeraBond II $^{\text {tm }}$ (AlbaDent, Cordelia-CA, USA) (Fig.5).

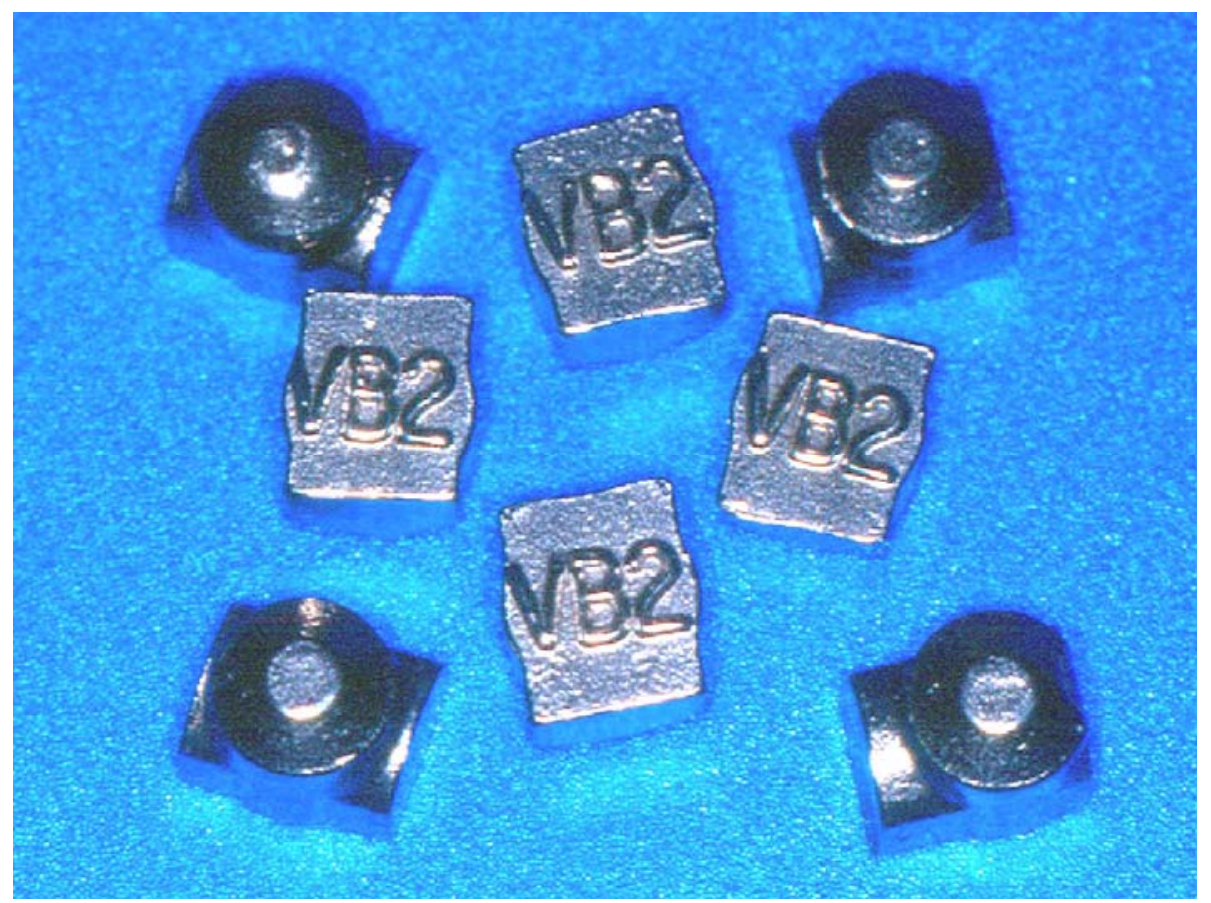


Fig.5 - Liga de Ni-Cr Vera Bond II utilizada neste estudo

Após a fundição os abutments foram removidos do revestimento, limpos com jato de micro-esferas de vidro (40 psi) e os condutos de alimentação removidos com o auxílio de discos de óxido de alumínio.

\subsubsection{Acabamento e polimento}

Para o acabamento dos abutments fundidos, foram utilizadas pontas diamantadas iguais às utilizadas anteriormente para os preparos e ainda, novas pontas de mesma numeração, porém com granulação mais fina (série FF - KGSorensen), adaptadas à fresadeira BioArt. Para melhor acabamento, novas pontas foram utilizadas para cada abutment.

Para o polimento, borrachas abrasivas para laboratório (KG Sorensen) com diferentes granulações foram utilizadas sendo também acopladas à fresadeira para garantir um polimento uniforme dos espécimes. Entretanto, como as borrachas apresentavam-se na forma cilíndrica, foi necessário dar a elas uma 
conformação cônica com um grau de convergência semelhante ao das pontas diamantadas utilizadas nos preparos. Para isso, as borrachas foram previamente desgastadas com pedras diamantadas posicionadas em uma mesa com a angulação desejada (Rotary Dental Instruments, Kahla, Germany) para assim conferir às borrachas uma conicidade de $6^{\circ}$ (Fig.6).
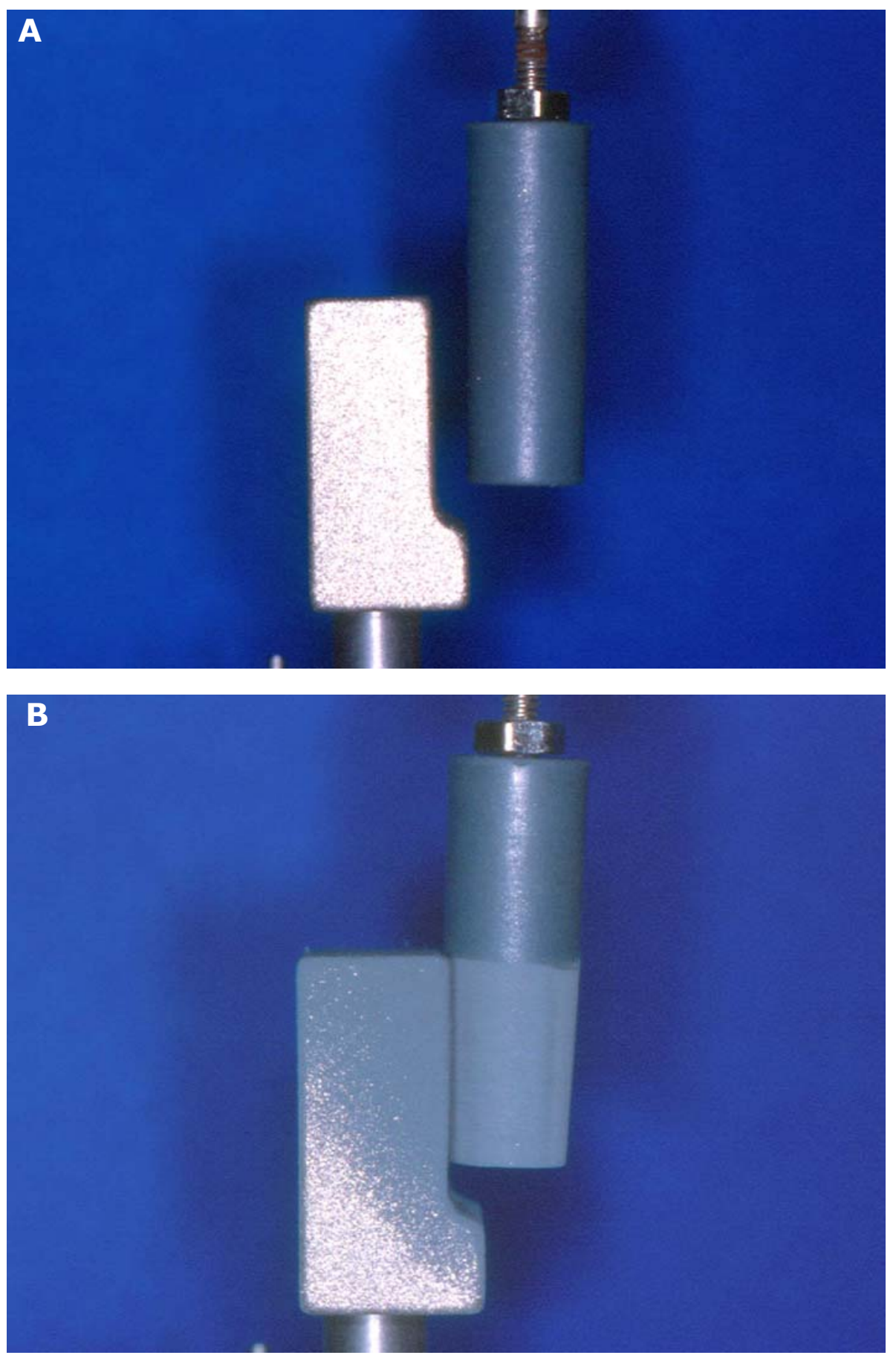
Fig. 6 - A. e B. Nova conformação da borracha de acabamento, conferindo nova conicidade de $6^{\circ}$

Após o polimento, os abutments fundidos foram parafusados sobre análogos de implantes com um torque de $32 \mathrm{~N} / \mathrm{cm}$ e reenviados ao laboratório de prótese para a confecção dos copings metálicos. Após esse torque de $32 \mathrm{~N} / \mathrm{cm}$ não foram realizados novos reapertos nos parafusos até o final do experimento.

\subsubsection{Posicionamento dos análogos de implantes}

Sessenta análogos de implantes (Conexão Sistemas de Prótese), com as mesmas dimensões dos abutments utilizados foram incluídos em resina acrílica incolor autopolimerizável Jet (Artigos Odontológicos Clássico, Lapa, SP).

Entretanto, devido a diferenças entre os equipamentos utilizados para os testes, foi necessária a confecção de diferentes formas de bases para que as mesmas fossem adaptadas a esses equipamentos. 
Para os espécimes que foram destinados aos testes de tração, os análogos foram incluídos em resina acrílica em tubos de PVC de $3 / 4$ de polegada (Tigre S.A., Joinville, SC) (Fig.7).

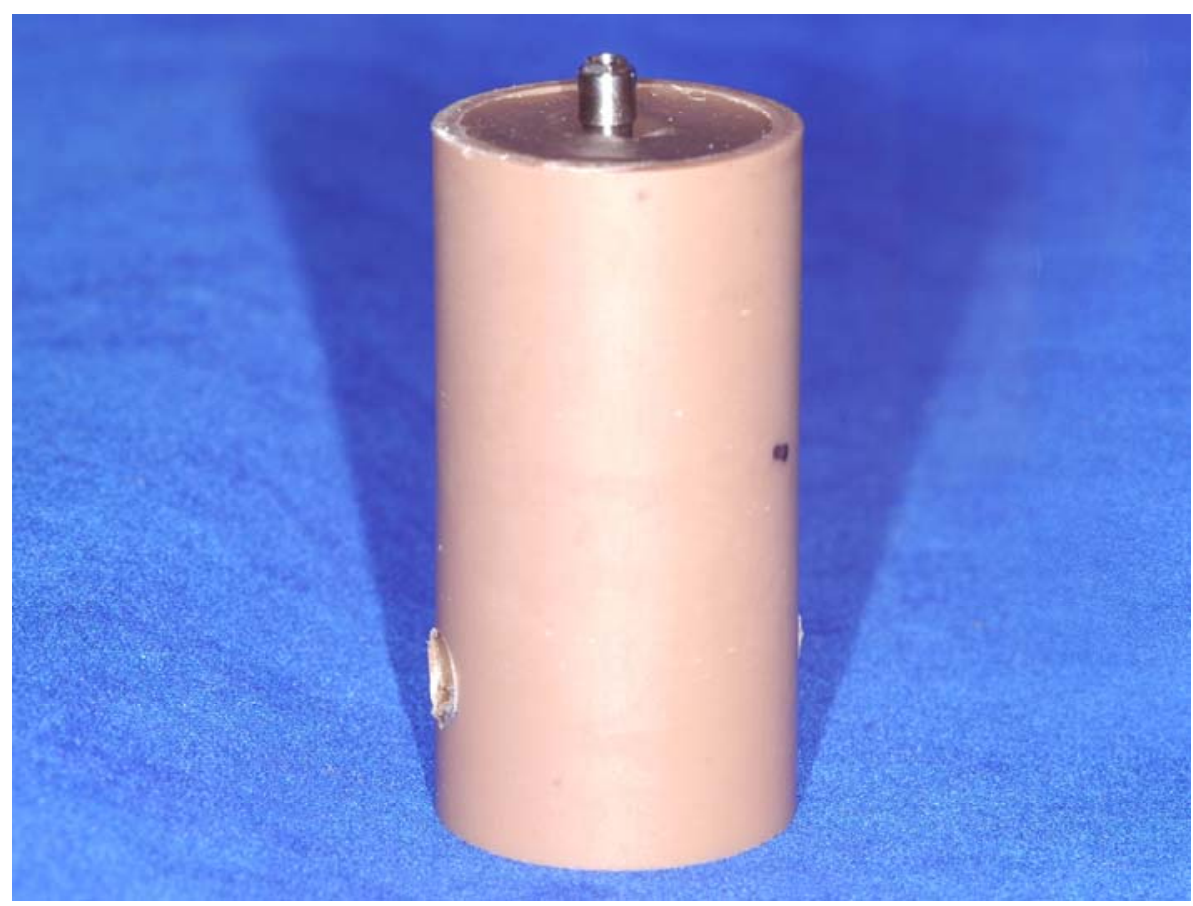

Fig.7 - Análogo de implante fixado à base para teste de tração

Para os espécimes que foram destinados aos testes de infiltração marginal, foram confeccionadas matrizes com silicone de adição laboratorial, para que as bases dos análogos tivessem a forma de um paralelepípedo (Fig.8). 
Em ambos os casos, um delineador (BioArt) foi utilizado para garantir que os análogos fossem posicionados perpendicularmente à base (Fig.9).

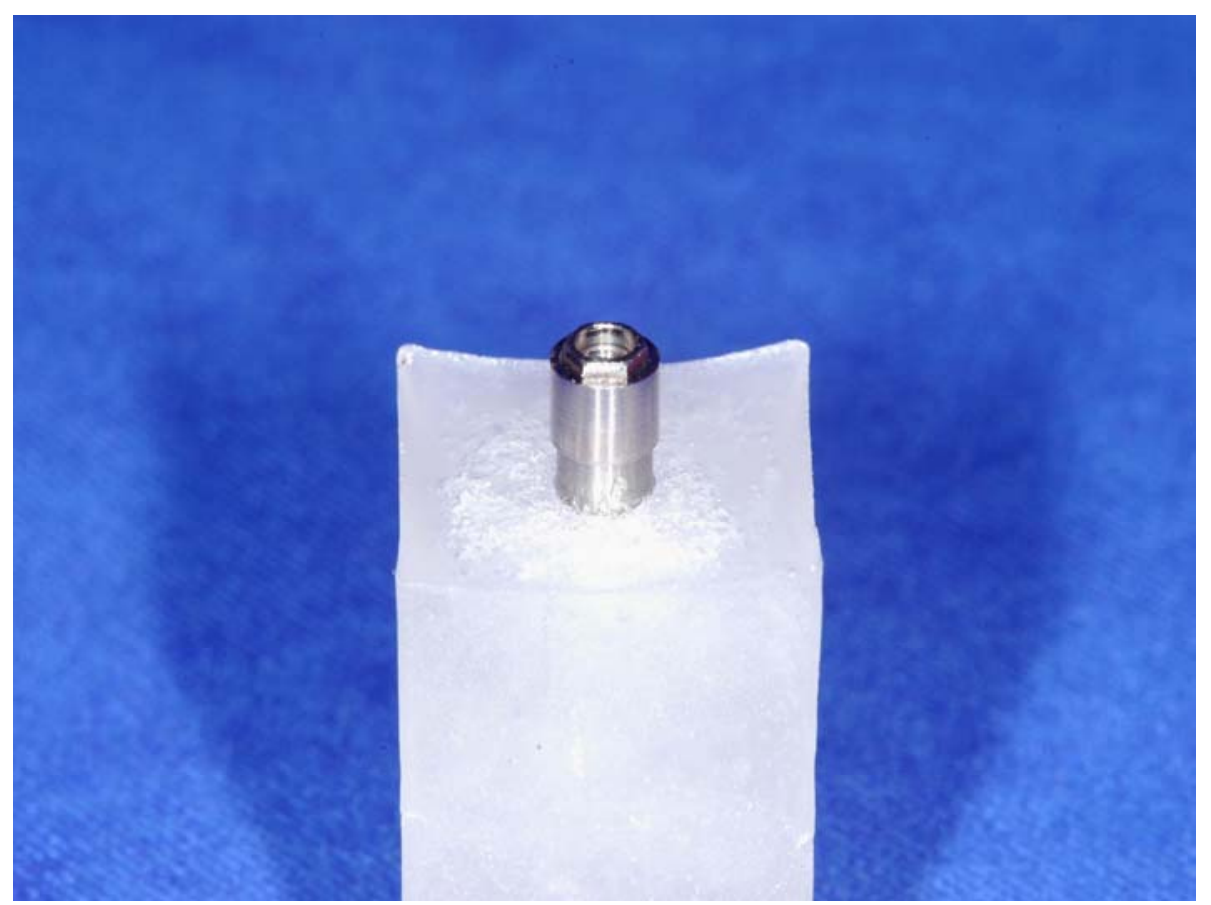

Fig. 8 - Análogo de implante fixado à base para teste de infiltração

A 


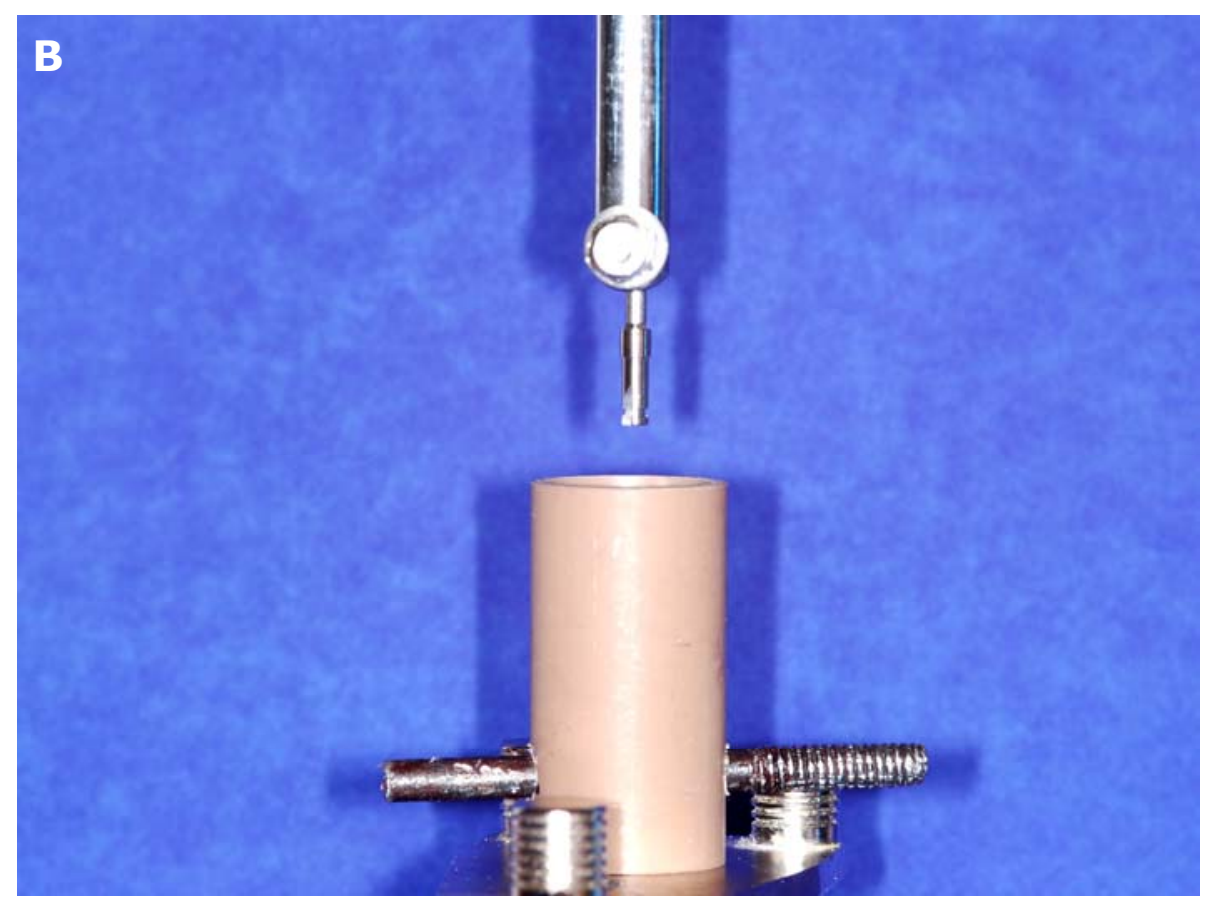

Fig.9 - A. Delineador sendo utilizado para inclusão dos análogos perpendicularmente à base; B. Vista aproximada

4.2.5. Enceramento, inclusão e fundição dos copings metálicos 
Um análogo de implante (Conexão Sistemas de Prótese) foi incluído em gesso especial tipo IV Durone (Dentsply, Petrópolis, RJ) e sobre ele foi parafusado um abutment fundido. Sobre este, foi encerado um coping para pré-molar superior (Fig.10).

Após esse procedimento, foi utilizado o silicone de adição PolyPour (GCera Lab Technologies Inc, Alsip-IL, USA) para duplicar este enceramento em posição sobre o abutment, formando assim uma matriz, que foi utilizada para o enceramento dos demais copings de modo que todos apresentassem a mesma forma e espessura (Fig.11).

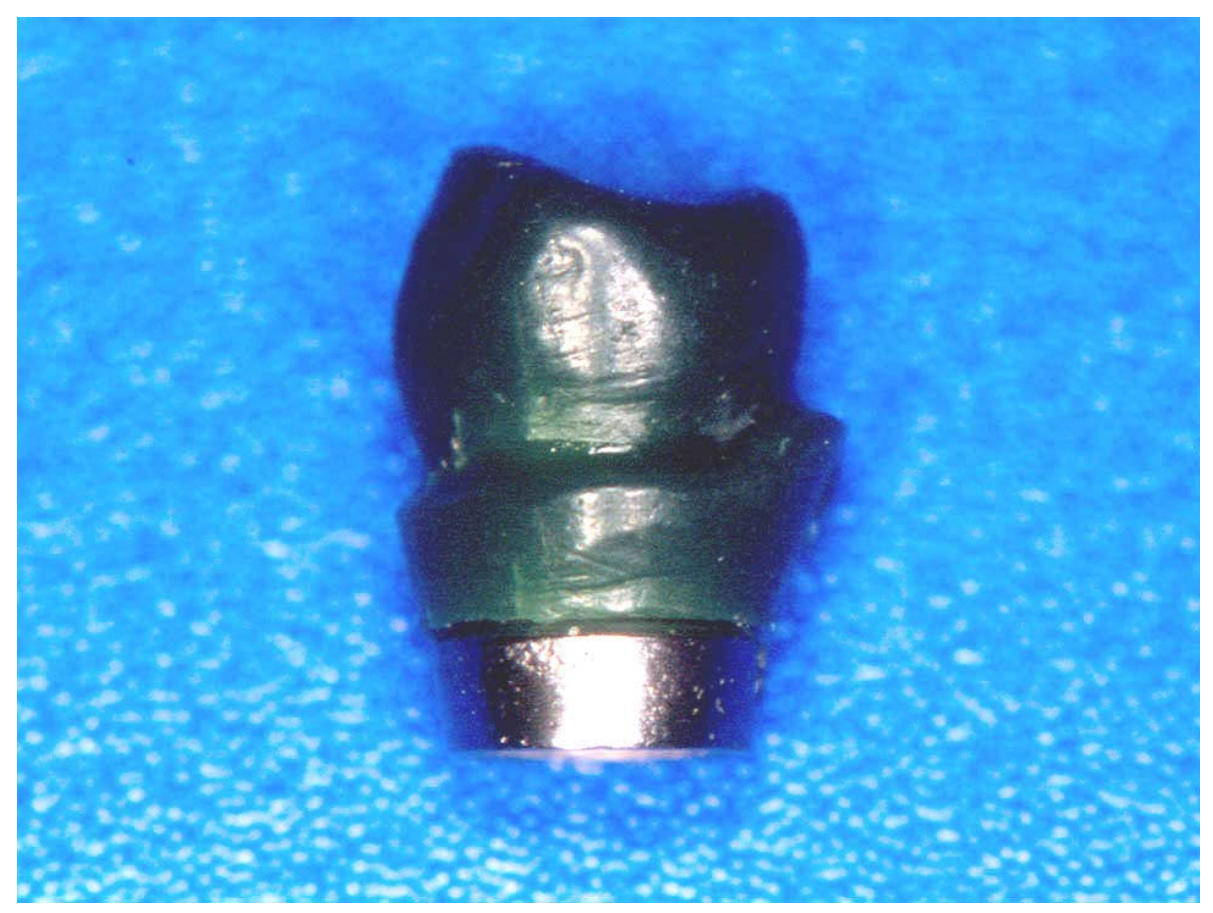

Fig.10 - Enceramento do coping em forma de pré-molar 



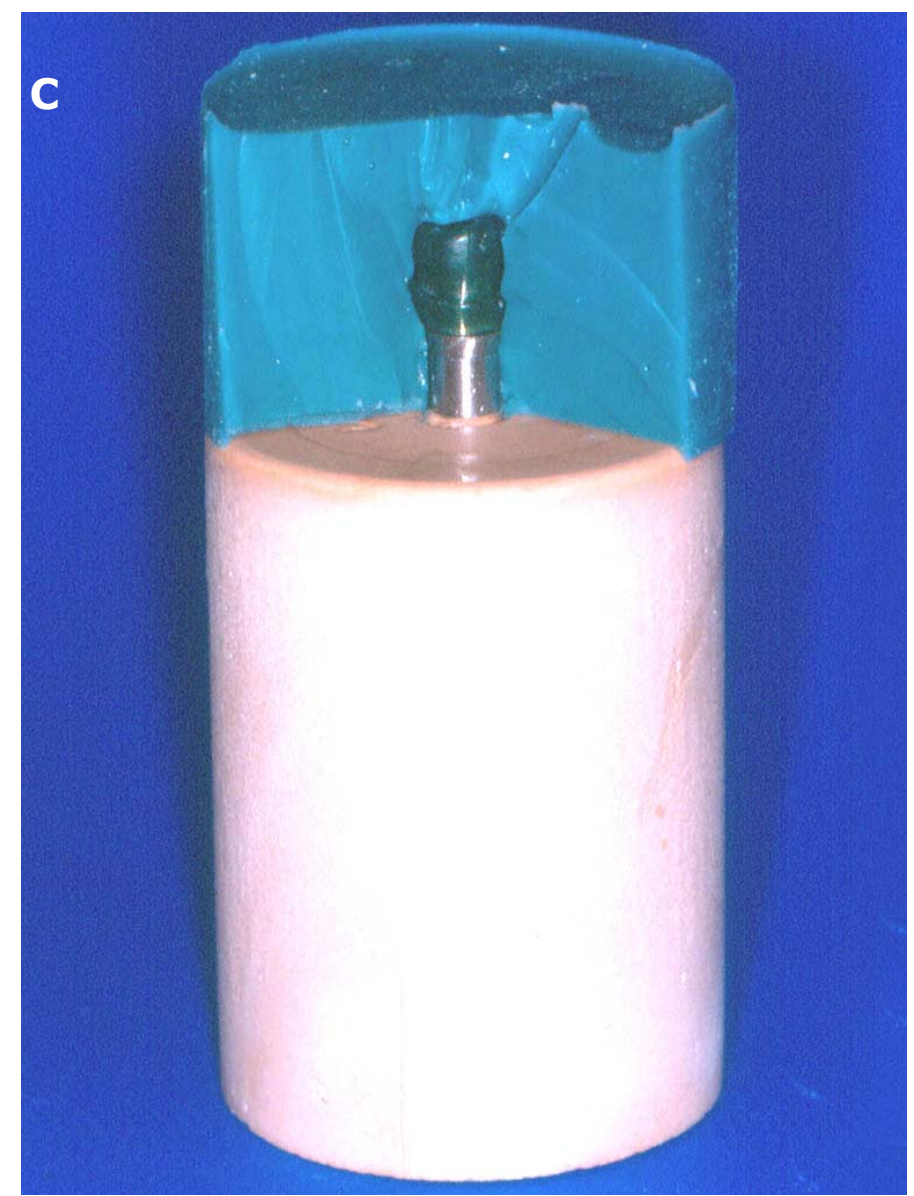

Fig.11 - A. Matriz de silicone em posição com a duplicação do enceramento; B. Matriz aberta para possibilitar a visualização do abutment em posição para a confecção do enceramento; C. Após a injeção da cera, o enceramento confeccionado 
Para os espécimes destinados ao teste de tração, foram confeccionadas alças sobre a superfície oclusal dos copings com fios de cera para permitir o tracionamento (Fig.13).

Os procedimentos de inclusão e fundição foram os mesmos utilizados para os abutments e da mesma forma, foi utilizada liga de níquel-cromo VeraBond $\mathrm{II}^{\mathrm{tm}}$.
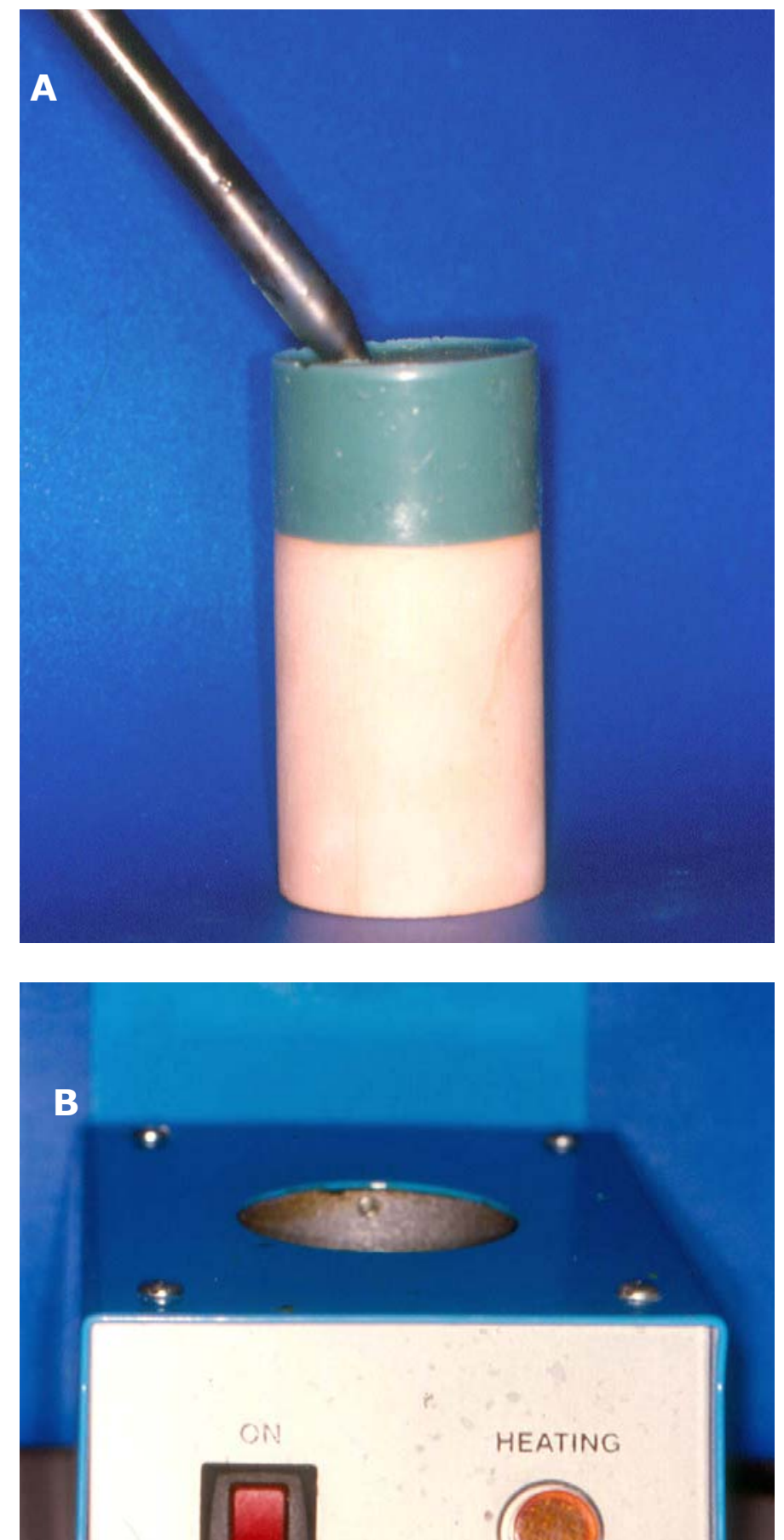
Fig.12 - A. Cera plastificada sendo injetada na matriz a partir de um conta-gotas aquecido; B - aparelho "The Pot" utilizado para a plastificação da cera

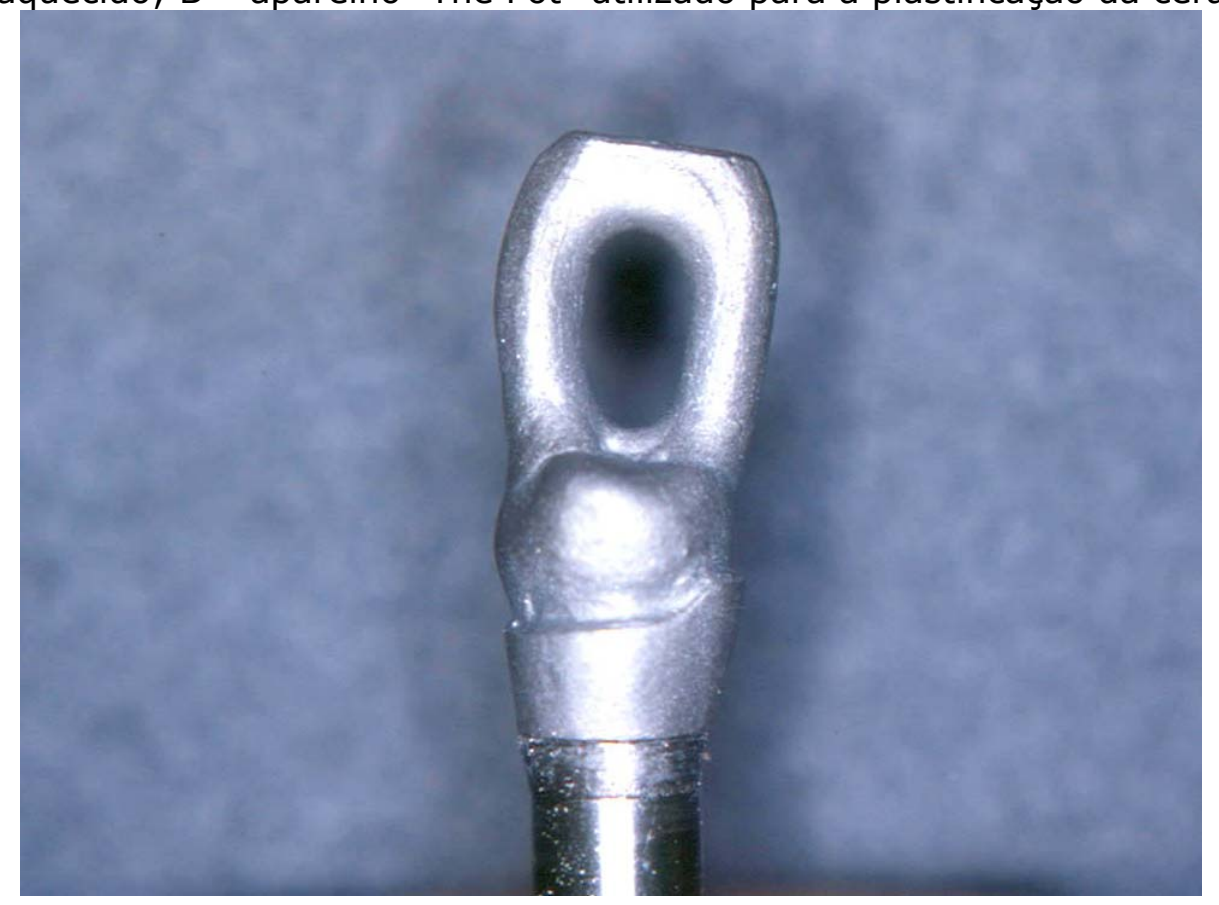

Fig.13 - Coping após fundição com alça para tracionamento

Após a remoção do revestimento, os copings receberam limpeza com jatos de micro esferas de vidro e foram adaptados a 
seus respectivos abutments, através de pequenos ajustes para remoção de pequenas bolhas que impedissem uma adaptação adequada, com auxílio de uma lupa de 4 aumentos (BioArt). Os copings os quais não se enquadrassem dentro destas condições eram descartados.

\subsubsection{Avaliação do desajuste cervical antes da} cimentação

Os copings metálicos foram posicionados sobre seus respectivos abutments e numerados aleatoriamente por sorteio. Para garantir sempre o mesmo posicionamento dos copings sobre seus respectivos abutments encaixes do tipo macho-fêmea foram confeccionados no coping e no abutment respectivamente, guiando o posicionamento (Fig.14). 
Fig.14 - Encaixe tipo macho-fêmea para guiar o posicionamento do coping sobre o abutment

Em pontos correspondentes a $0^{\circ}(\mathrm{p} 0), 90^{\circ}(\mathrm{p} 90), 180^{\circ}$ (p180) e $270^{\circ}$ (p270), foram feitas duas marcações esféricas, uma no análogo e outra no coping (Fig.15), sendo essas marcações alinhadas e confeccionadas com uma caneta permanente vermelha Lumocolor Permanent (Staedtler, Nuernberg, Germany).

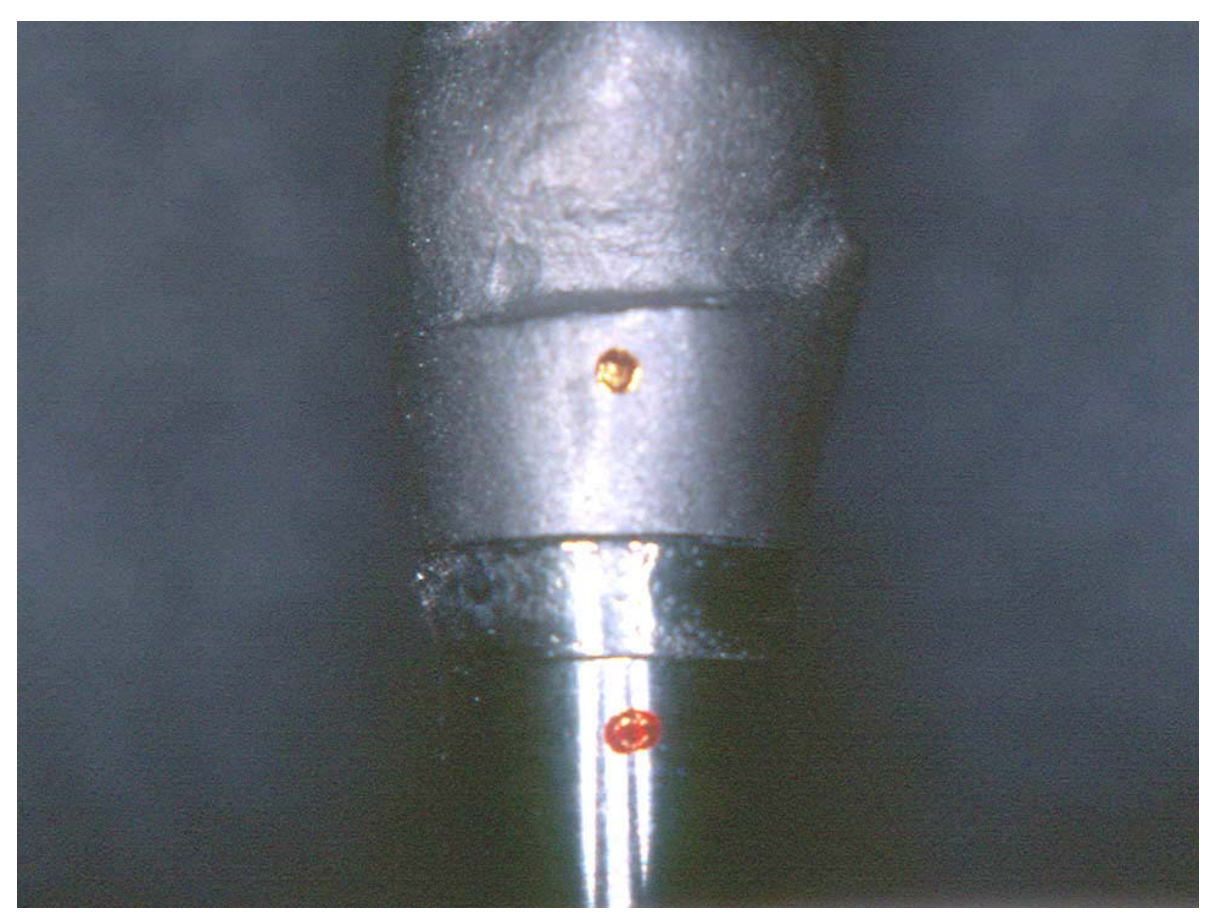

Fig.15 - Marcações esféricas para a avaliação do desajuste antes e após a cimentação 
Uma pressão vertical foi aplicada sobre cada coping com o auxílio de uma prensa para cimentação e uma carga estática de $5 \mathrm{~kg}^{4,28,35,48}$ (Fig.16).

Após esse carregamento vertical, os espécimes foram posicionados em um microscópio comparador Mitutoyo (Mitutoyo America Corporation, IL, USA) (Fig.17) e as distâncias entre as tangentes internas das marcações esféricas foram registradas (Fig.18). Foram feitas três mensurações para cada ponto de forma seqüencial e uma média foi calculada para o valor do desajuste cervical em cada ponto medido.

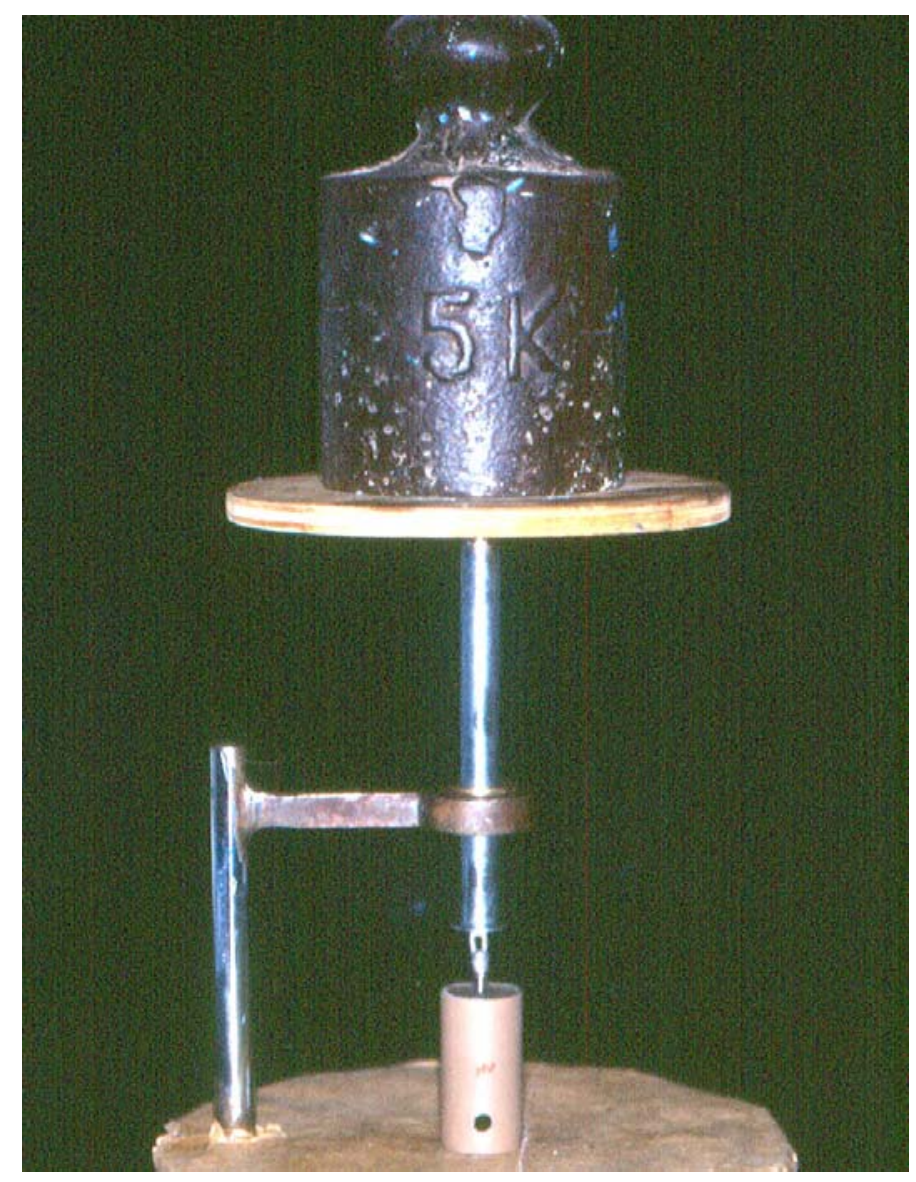

Fig.16 - Prensa para cimentação 


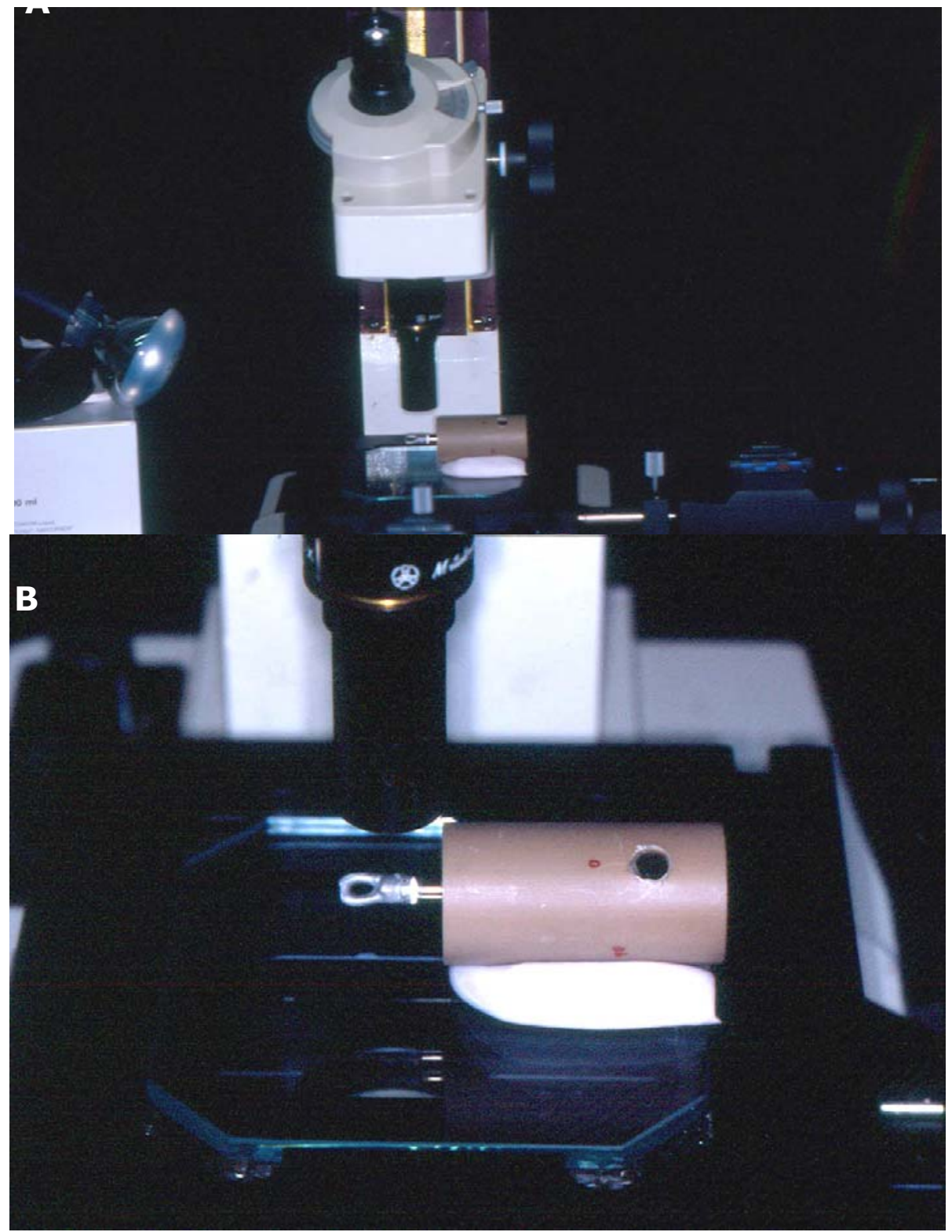

Fig.17 - A. Microscópio comparador Mitutoyo; B. Vista aproximada

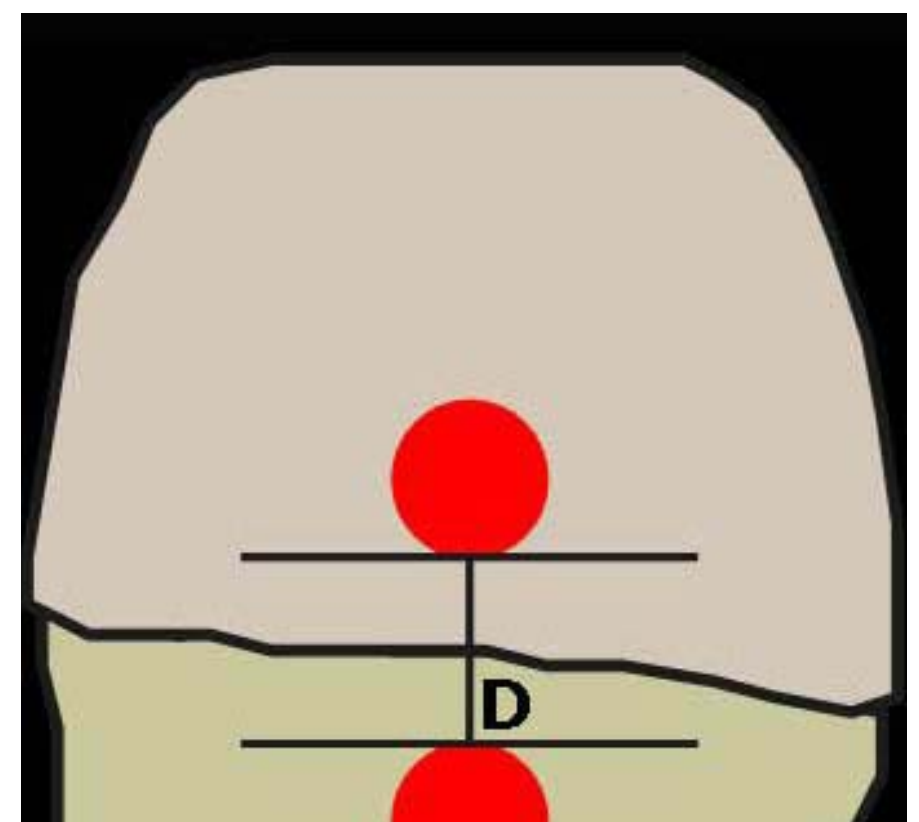


Fig.18 - Cálculo da distância entre as tangentes internas

\subsubsection{Cimentação}

Para a cimentação dos copings sobre os abutments fundidos foi utilizado o cimento temporário TempBond NE (Kerr Corporation, Orange-CA, USA).

Uma quantidade de $0,2 \mathrm{ml}$ do cimento foi aplicada às margens cervicais dos copings com o auxílio de uma seringa de insulina (Fig.19). Foi utilizada uma nova seringa para cada cimentação.

Após a aplicação do cimento, os copings foram posicionados manualmente sobre os abutments com pressão digital e novamente, um carregamento vertical, com uma carga estática de $5 \mathrm{Kg}$ foi aplicado. 


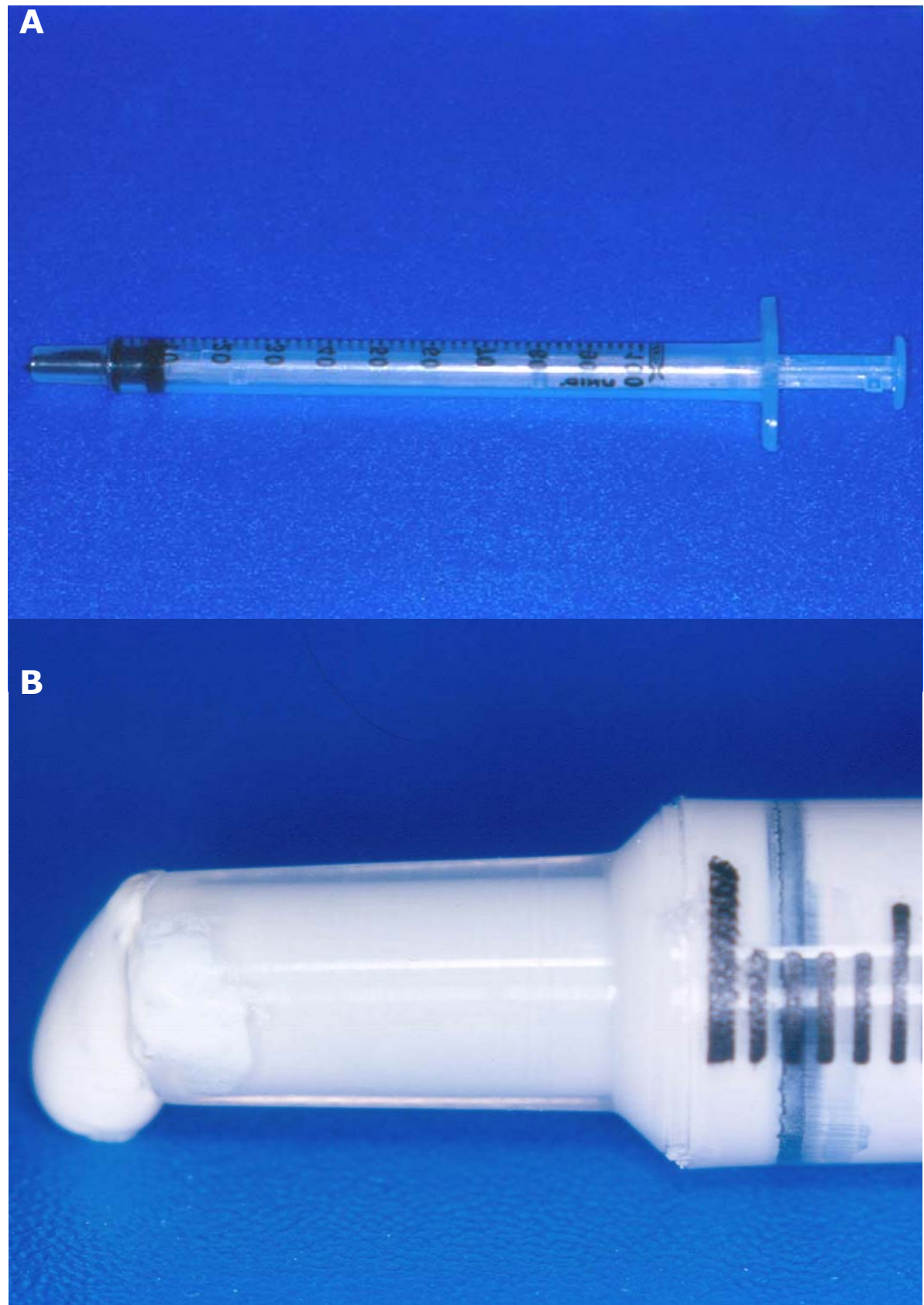

Fig.19 - A. Seringa utilizada para aplicação do cimento; B. Vista aproximada da quantidade de $0.2 \mathrm{ml}$ utilizada 
Após 6 minutos (tempo de presa do cimento recomendado pelo fabricante), os espécimes foram retirados da prensa e os excessos do cimento removidos.

\subsubsection{Avaliação do desajuste cervical após a} cimentação

Após a cimentação dos copings sobre os abutments, foram realizados, para a avaliação do desajuste cervical após a cimentação, os mesmos procedimentos utilizados para a obtenção desse desajuste antes da cimentação, assim como para o cálculo das médias em cada ponto.

\subsubsection{Cálculo do desajuste final obtido com a} cimentação

A partir do cálculo das médias em cada ponto, antes (DA) e pós (DP) cimentação, o desajuste cervical final $\left(\mathrm{DMF}_{\mathrm{p}}\right)$ obtido com a cimentação em cada ponto foi obtido pela seguinte fórmula: DPDA. 
Após a obtenção do valor de desajuste cervical final para cada ponto $\left(\mathrm{DMF}_{\mathrm{p}}\right)$, foi calculado o valor de desajuste final para cada espécime $\left(\mathrm{DMF}_{\mathrm{e}}\right)$ pela fórmula: $\mathrm{DMF}_{\mathrm{e}}=\mathrm{DMF}_{\mathrm{p} 0}+\mathrm{DMF}_{\mathrm{p} 90}+$ $\mathrm{DMF}_{\mathrm{p} 180}+\mathrm{DMF}_{\mathrm{p} 270 / 4}$ e esse valor utilizado para análise estatística.

\subsubsection{Armazenamento}

Após a cimentação e a mensuração do desajuste póscimentação, os espécimes foram mantidos em ambiente $100 \%$ úmido por 24 horas e em seguida imersos em água destilada. 0 período de imersão foi de 30 dias, sendo que a água destilada foi trocada diariamente para evitar a contaminação do meio com os produtos da solubilização, o que poderia alterar o pH.

Para os 30 espécimes destinados ao teste de infiltração marginal, o último dia de imersão foi feito em solução de fuccina básica a 2\% (Fig.20). 
Fig.20 - Espécime corado

Após o período de imersão os espécimes foram lavados em água corrente e secos em papel absorvente.

\subsubsection{I nfiltração marginal}

Para a avaliação da infiltração marginal, foi necessária a inclusão em resina acrílica da porção coronária dos espécimes, uma vez que o análogo já se encontrava incluso neste material. Esse procedimento foi necessário para que a secção vertical dos espécimes fosse realizada sem o desprendimento das partes cimentadas. Desta forma passamos a ter um cubo de resina acrílica 
com o conjunto análogo/abutment/coping incluído em seu interior (Fig.21).

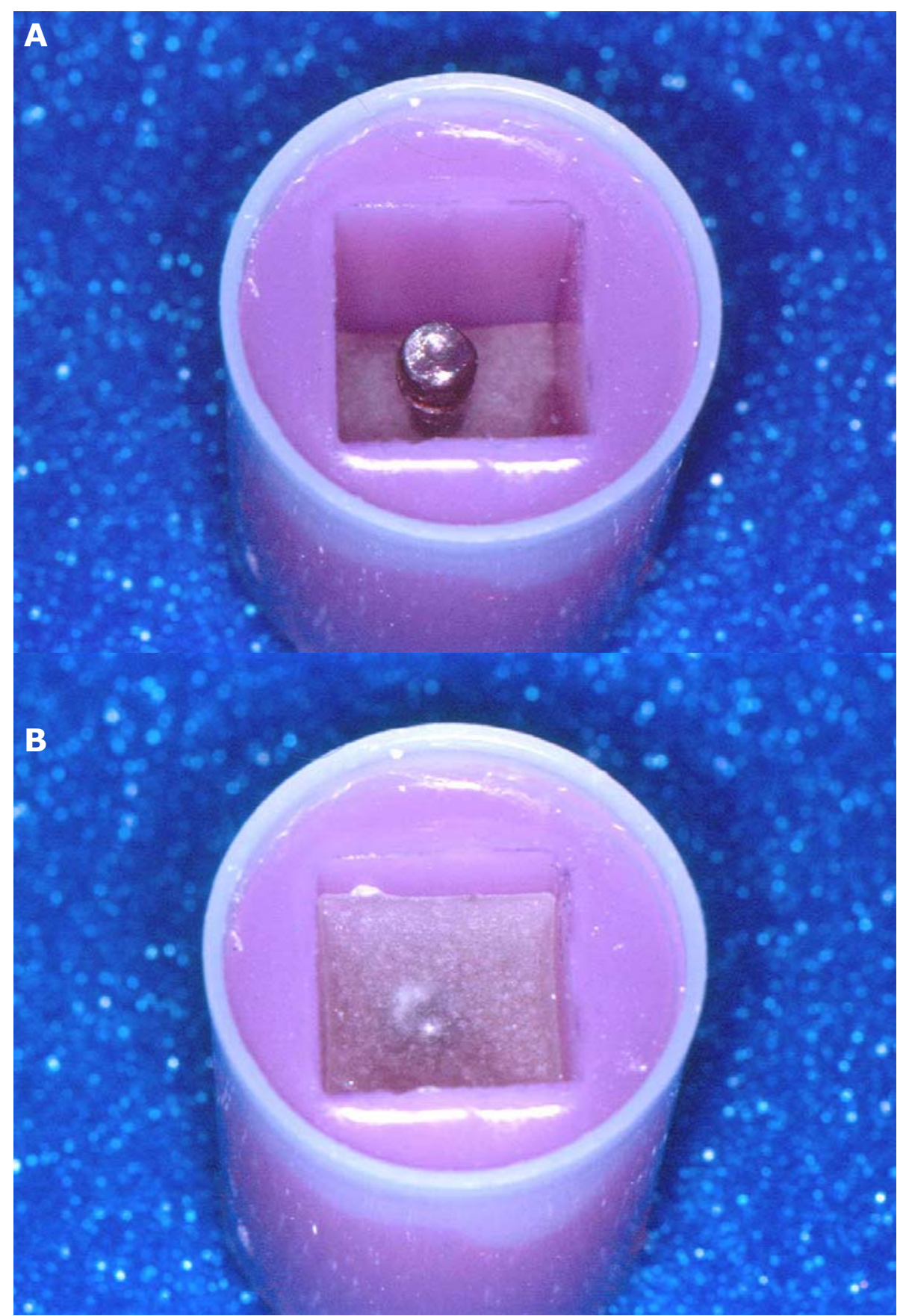

Fig.21 - A. Espécime reposicionado na matriz após período de imersão; B. Aplicação de resina acrílica para a inclusão de todo o conjunto análogo/abutment/coping 
Para a secção vertical dos espécimes foi utilizado um disco de corte Isocut para ligas de níquel-cromo (Fig.22) com dimensões de $10.2 \mathrm{~cm}$ de diâmetro x $0.3 \mathrm{~mm}$ de espessura (Buehler, Il, USA) adaptado a uma máquina de corte de precisão Isomet (Buehler) (Fig.23).

Após o corte, os espécimes foram lixados com uma lixa d'água 500 (3M) e em seguida foram avaliados sob um fotomicroscópio automático (Carl Zeiss International, Germany) (Fig.24) com um aumento de 40x.

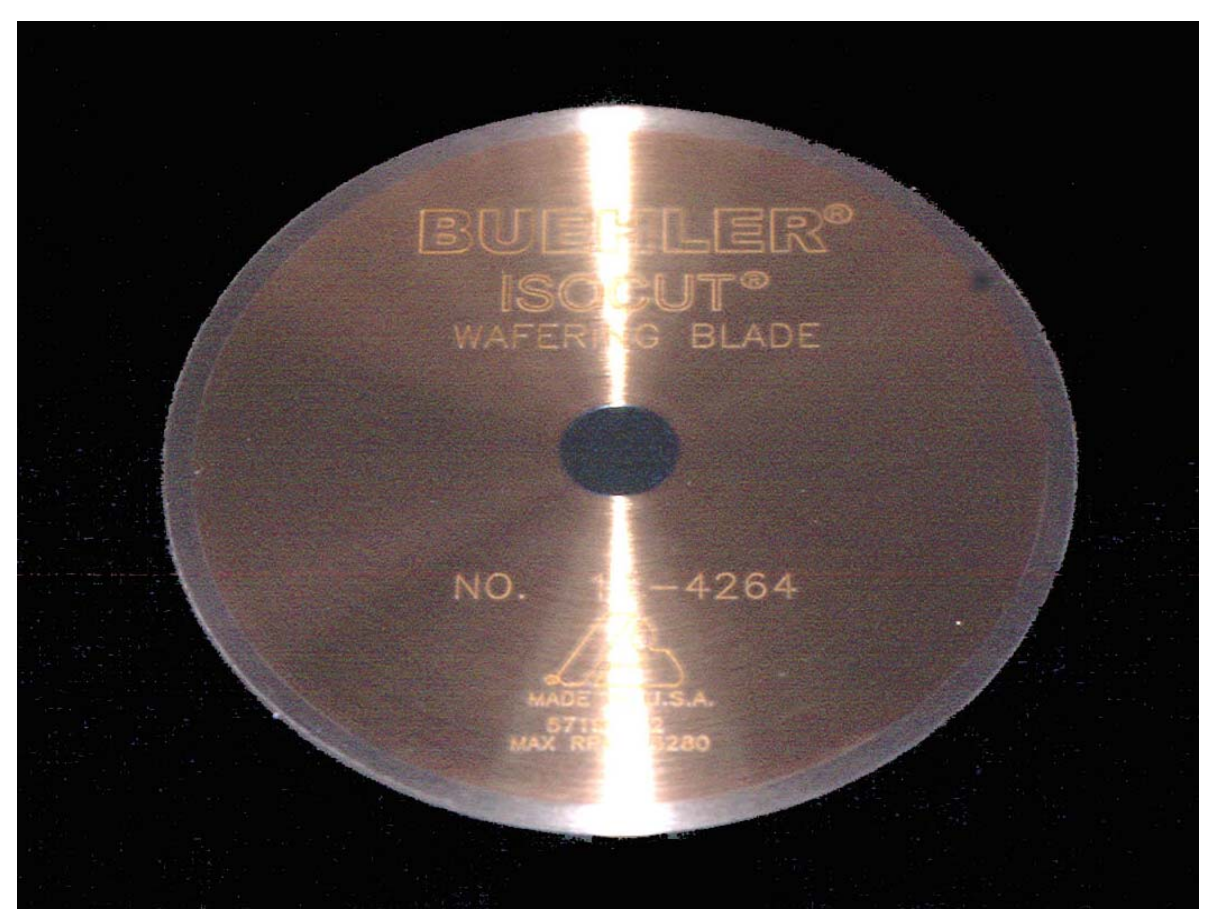

Fig.22 - Disco de corte Isocut

A 

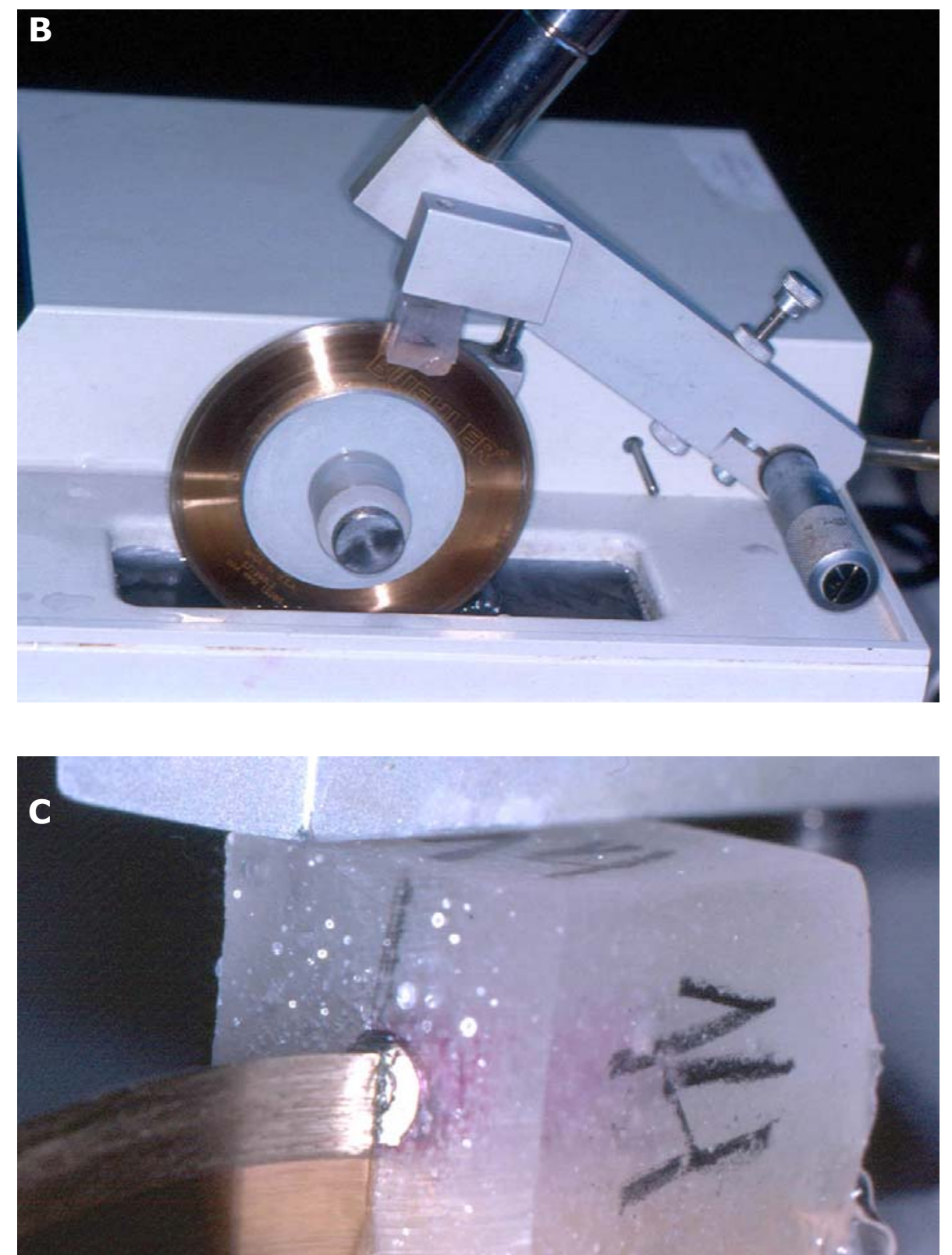
Fig.23 - A. Máquina de corte Isomet; B. Vista lateral; C. Vista aproximada

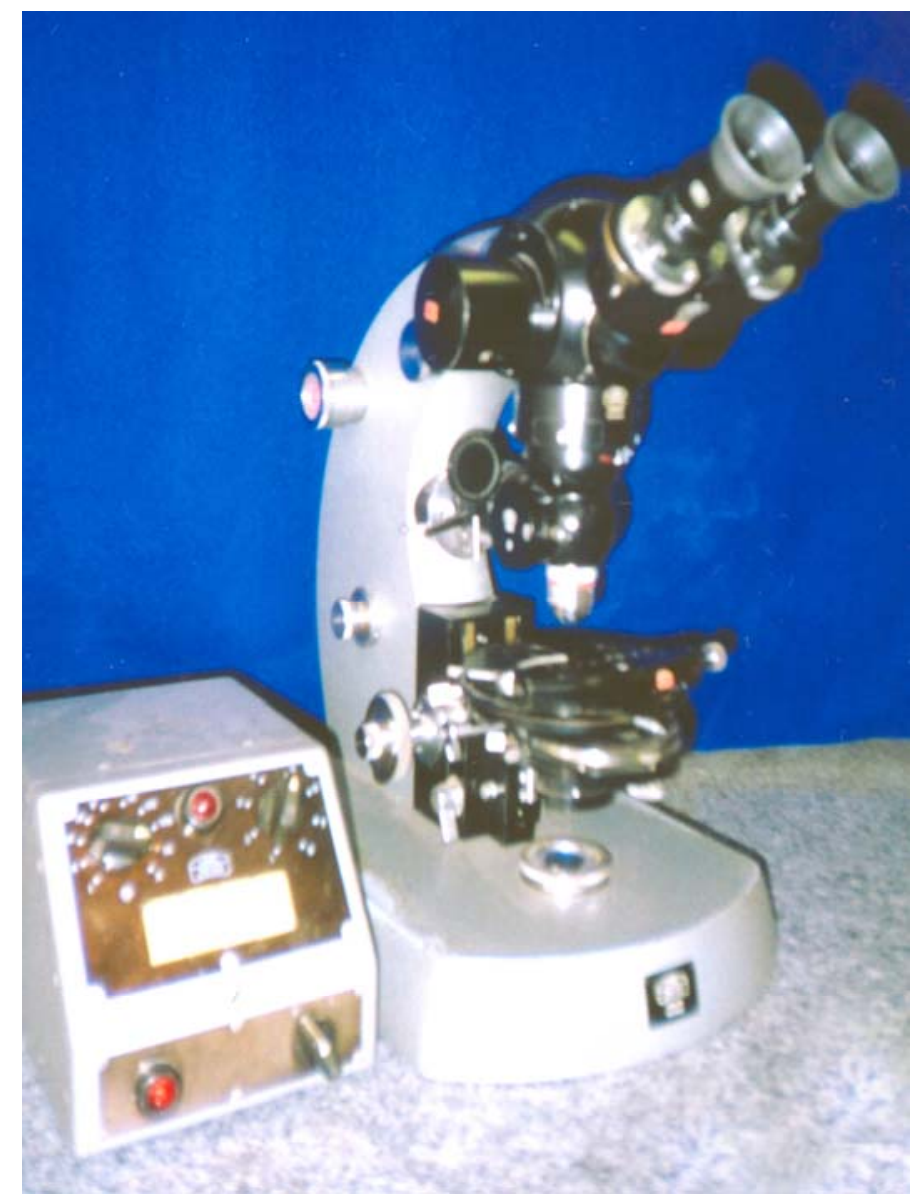

Fig.24 - Fotomicroscópio 
Foram atribuídos escores de acordo com a área da interface abutment-cimento-coping atingida pelo corante, de acordo com GU \& $\mathrm{KERN}^{20}$ para interpretação da análise estatística nãoparamétrica:

0 - nenhuma infiltração

1 - infiltração atingindo $1 / 3$ da margem cervical

2 - infiltração atingindo $2 / 3$ da margem cervical

3 - infiltração atingindo $3 / 3$ da margem cervical

4 - infiltração atingindo $1 / 3$ da parede axial

5 - infiltração atingindo $2 / 3$ da parede axial

6 - infiltração atingindo $3 / 3$ da parede axial

7 - infiltração atingindo a parede oclusal 


\subsubsection{Resistência à tração}

Para o teste de resistência à tração, os espécimes foram posicionados em uma máquina universal de ensaios (Kratos Equipamentos Industriais LTDA, São Paulo, SP), com uma velocidade de $5 \mathrm{~mm} / \mathrm{min}$ e carga de $50 \mathrm{~kg}$ (Fig.25).

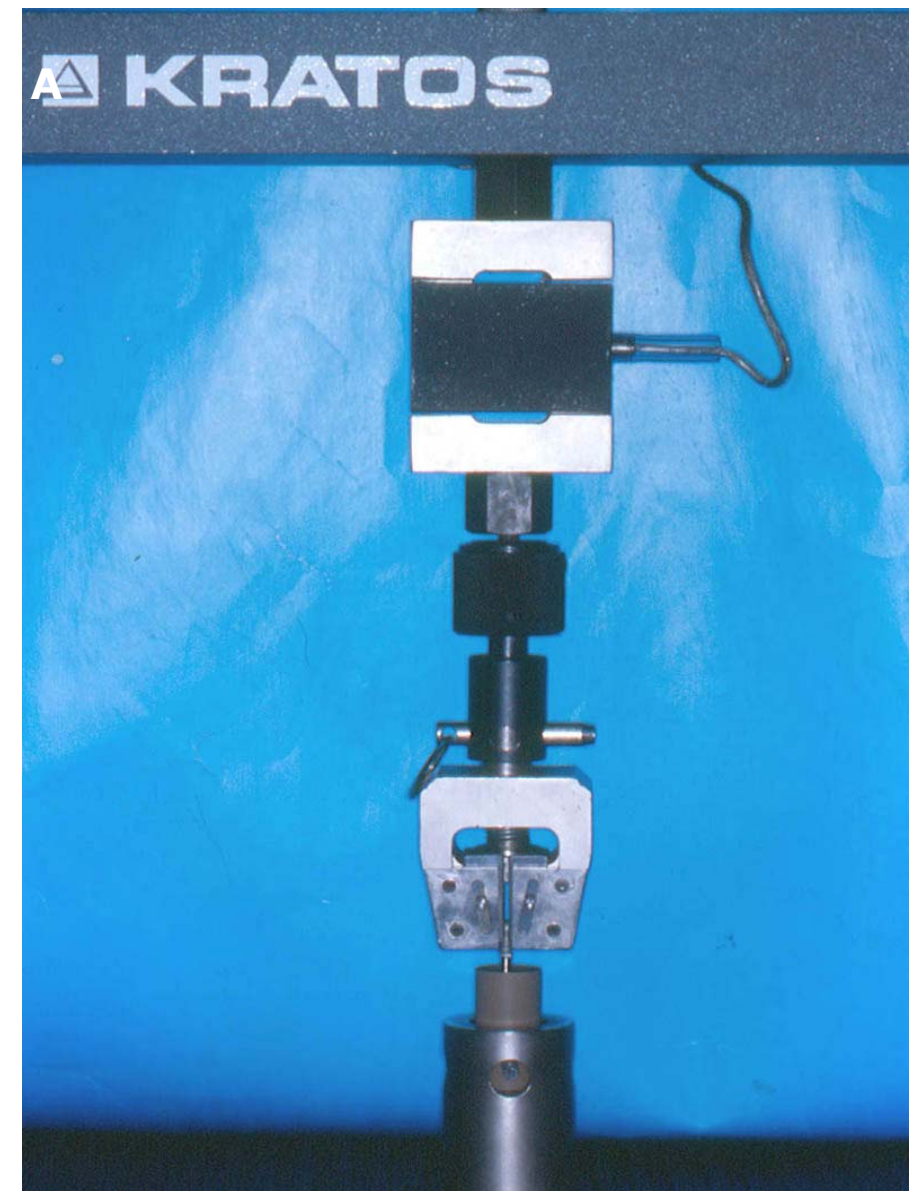




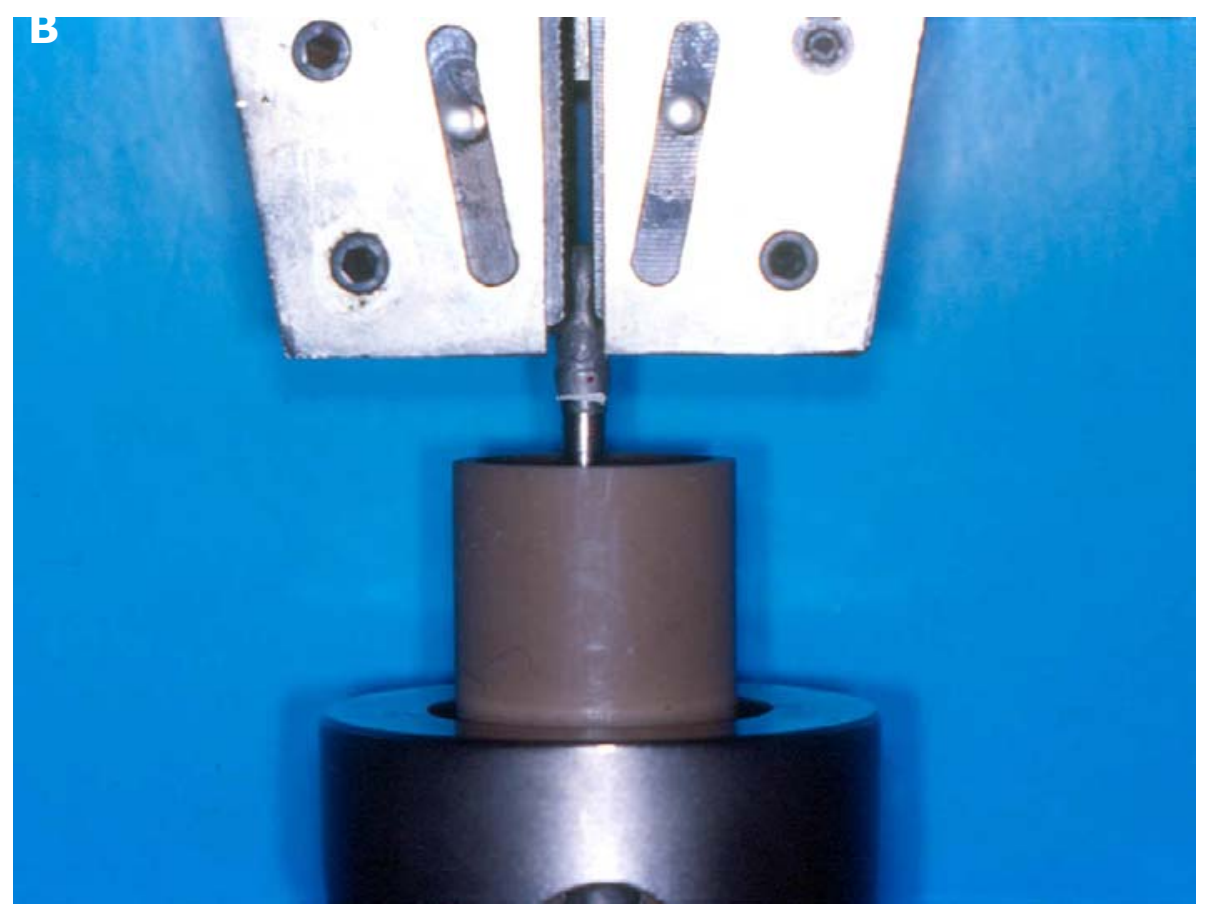

Fig.25 - A. Máquina universal de ensaios Kratos; B. Vista aproximada do teste de tração

Os valores obtidos foram registrados e utilizados na análise estatística. 
5 RESULTADOS 


\section{Resultados}

Para a análise dos resultados dos testes de desajuste cervical e resistência à tração que apresentam valores paramétricos, foi utilizado o teste ANOVA a um critério para a identificação de diferenças estatisticamente significantes entre os grupos $(p<0.05)$. Uma vez constatadas essas diferenças, foi aplicado o teste de Tukey para as comparações individuais entre os grupos.

Para o teste de infiltração marginal, onde valores não paramétricos foram utilizados (escores), o teste de Kruskal Wallis para a identificação de diferenças estatisticamente significantes entre os grupos $(p<0.05)$ foi escolhido.

Foram realizados também testes de correlação para a verificação de uma possível influência dos valores encontrados para o desajuste cervical nos valores encontrados para a infiltração marginal e para a resistência à tração. Para os valores paramétricos (desajuste $\mathrm{x}$ tração) foi utilizado $\mathrm{o}$ teste de Correlação de Pearson e na presença de valores não paramétricos (desajuste $x$ infiltração) foi utilizado o teste de Correlação de Spearman. 


\subsection{Desajuste cervical}

As medianas, médias, desvios padrão e os valores mínimos e máximos obtidos no teste de desajuste cervical são encontrados na Tabela 2.

Tabela 2: Mediana, média, desvio padrão, valores mínimo e máximo para desajuste cervical (em mm).

\begin{tabular}{cccccc}
\hline Margem & Mediana & Média & D. padrão & Mínimo & Máximo \\
\hline Chanferete & 0.004500 & 0.008300 & 0.012229 & 0.000000 & 0.040000 \\
Chanfro P. & 0.004500 & 0.005300 & 0.004398 & 0.000000 & 0.013000 \\
Ombro & 0.006000 & 0.008700 & 0.008525 & 0.002000 & 0.028000 \\
\hline
\end{tabular}

Após a aplicação do teste ANOVA sobre os valores encontrados para o desajuste cervical, não foram encontradas diferenças estatisticamente significantes entre os grupos $(p>0.05)$ (Tabela 3). 
Tabela 3: Análise de variância (ANOVA) a um critério aplicado aos valores de desajuste cervical.

\begin{tabular}{lccccc}
\hline Efeito & $\begin{array}{c}\text { Soma de } \\
\text { Quadrados }\end{array}$ & $\begin{array}{c}\text { Graus de } \\
\text { Liberdade }\end{array}$ & $\begin{array}{c}\text { Quadrado } \\
\text { médio }\end{array}$ & F & Probabilidade \\
\hline Entre & 0.00006907 & 2 & 0.00003453 & 0.428827 & $0.65563^{*}$ \\
Grupos & & & & & \\
* sem diferença estatisticamente significante $(p>0.05)$ &
\end{tabular}

\subsection{Infiltração marginal}

As medianas, médias, desvios padrão e os valores mínimos e máximos obtidos no teste de infiltração marginal são encontrados na Tabela 4.

Tabela 4: Mediana, média, desvio padrão, valores mínimo e máximo para infiltração marginal.

\begin{tabular}{cccccc}
\hline Margem & Mediana & Média & D. padrão & Mínimo & Máximo \\
\hline Chanferete & 0.000000 & 0.000000 & 0.000000 & 0 & 0 \\
Chanfro P. & 0.000000 & 0.800000 & 1.932183 & 0 & 6 \\
\hline Ombro & 0.000000 & 0.400000 & 0.966091 & 0 & 3 \\
\hline
\end{tabular}


Após a aplicação do teste Kruskal Wallis sobre os escores encontrados para infiltração marginal, não foram encontradas diferenças estatisticamente significantes entre os grupos $(p>0.05)$ (Tabela 5).

Tabela 5: Teste Kruskall Wallis aplicado aos valores de desajuste cervical.

\begin{tabular}{ccccc}
\hline Grupo & Mediana & $\begin{array}{c}\text { Soma de } \\
\text { Postos }\end{array}$ & Posto Médio & Probabilidade \\
\hline Ombro & 0.00000000 & 135.000000 & 13.5000000 & \\
Chanfro & 0.00000000 & 166.000000 & 16.6000000 & $0.328908^{*}$ \\
Profundo & & & & \\
Chanferete & 0.00000000 & 164.000000 & 16.4000000 & \\
\hline * sem diferença estatisticamente significante $(p>0.05)$
\end{tabular}

\subsection{Resistência à tração}

As medianas, médias, desvios padrão e os valores mínimos e máximos obtidos no teste de desajuste cervical são encontrados na Tabela 6. 
Tabela 6: Mediana, média, desvio padrão, valores mínimo e máximo para resistência à tração (em Kgf).

\begin{tabular}{cccccc}
\hline Margem & Mediana & Média & D. padrão & Mínimo & Máximo \\
\hline Chanferete & 4.362500 & 4.107500 & 1.933406 & 1.025000 & 6.450000 \\
Chanfro P. & 6.387500 & 6.547500 & 2.192108 & 3.600000 & 10.85000 \\
Ombro & 6.27500 & 5.557500 & 2.140322 & 0.825000 & 7.575000 \\
\hline
\end{tabular}

Após a aplicação do teste ANOVA sobre os valores encontrados para a resistência à tração, foram encontradas diferenças estatisticamente significantes entre os grupos $(p<0.05)$ (Tabela 7). Assim, o teste de Tukey foi aplicado para uma comparação individual entre os grupos, onde diferença estatisticamente significante foi encontrada apenas quando comparados os grupos chanferete $x$ chanfro profundo $(p<0.05)$. Nenhuma diferença estatisticamente significante foi encontrada quando comparados os grupos chanferete $x$ ombro e chanfro profundo $\mathrm{x}$ ombro (Tabela 8 ). 
Tabela 7: Análise de variância (ANOVA) a um critério aplicado aos valores de resistência à tração.

\begin{tabular}{lccccc}
\hline Efeito & $\begin{array}{c}\text { Soma de } \\
\text { Quadrados }\end{array}$ & $\begin{array}{c}\text { Graus de } \\
\text { Liberdade }\end{array}$ & $\begin{array}{c}\text { Quadrado } \\
\text { médio }\end{array}$ & $\mathrm{F}$ & Probabilidade \\
\hline Entre & 30.12066667 & 2 & 15.06033333 & 3.442524 & $0.04659^{*}$ \\
Grupos & & & & \\
${ }^{*}$ diferença estatisticamente significante $(p<0.05)$ & &
\end{tabular}

Tabela 8: Teste de Tukey aplicado aos valores de resistência à tração para comparação individual entre os grupos.

\begin{tabular}{cccc}
\hline Comparação & Diferença & Valor Crítico & Interpretação \\
\hline Chanferete $x$ & -2.4400000 & 2.32010787 & SIGNIFICANTE \\
Chanfro Prof. & & & \\
Chanferete $x$ & -1.4500000 & 2.32010787 & Não \\
Ombro & & & significante \\
Chanfro Prof. $x$ & 0.99000000 & 2.32010787 & Não \\
Ombro & & & significante \\
\hline
\end{tabular}




\subsection{Testes de Correlação}

Os testes de correlação de Pearson e de Spearman mostraram não haver influência $(p>0.05)$ do desajuste cervical na resistência à tração $(p=0.727858)$ e na infiltração marginal $(p=0.102068)$ respectivamente. 
6 DISCUSSÃO 


\section{Discussão}

Desde o advento da osseointegração, houve um aumento nas opções de planos de tratamento e procedimentos clínicos para a reposição de elementos perdidos.

Como já discutido anteriormente, a reabilitação de arcadas edêntulas com implantes osseointegrados foi concebida, inicialmente, para o uso exclusivo na mandíbula, com a instalação de 5 ou 6 implantes entre os forames mentuais e com a confecção de próteses fixas acopladas aos implantes por meio de abutments e parafusos, sem manter uma relação íntima com os tecidos moles subjacentes. ${ }^{51}$ Entretanto, com a introdução na Odontologia de implantes unitários para a reabilitação de arcadas parcialmente edentadas, antigos conceitos já estabelecidos na Odontologia Restauradora precisaram ser revistos e readaptados à nova realidade das próteses unitárias ou parciais retidas por implantes. Isso devido ao fato de estas próteses apresentarem um maior apelo estético do que aquelas inicialmente idealizadas por Brånemark, já que por muitas vezes substituíam elementos anteriores e até mesmo em casos de reabilitações posteriores, um cuidado maior precisava ser tomado uma vez que nas próteses parciais ou unitárias não ocorre a presença de gengiva artificial. 
Com isso, a conexão abutment/restauração que inicialmente localizava-se supragengivalmente, começou a localizar-se cada vez mais intrasulcular, levando a uma preocupação ainda maior em relação ao trabalho restaurador com os tecidos de suporte, uma vez que uma falha na adaptação dessas conexões leva inexoravelmente à formação de espaços (gaps) que por sua vez tornam-se nichos para a colonização bacteriana, causa primária na etiologia da doença periodontal e mais recentemente, da periimplantite. Pode-se também acrescentar aqui, o envolvimento mecânico decorrente também desses espaços (gaps), os quais podem determinar a fadiga, fraturas ou perda dos componentes além de acelerar processos de corrosão.

Além disso, após o estabelecimento das técnicas cirúrgicas e da alta previsibilidade atingidas pela osseointegração, novas discussões foram levantadas no que diz respeito à prótese sobre implantes. Uma dessas questões gira em torno das próteses parafusadas e cimentadas. Estudos longitudinais ${ }^{64}$ mostram que um dos maiores problemas relacionados à fase protética da reabilitação oral sobre implantes consiste no afrouxamento, perda ou fratura do parafuso de ouro que fixa a restauração ao abutment. Assim, o conceito da prótese sobre implantes cimentada foi introduzido, aproximando ainda mais esse novo conceito 
restaurador às tradicionais técnicas da odontologia restauradora sobre dentes.

Essa aproximação tornou-se ainda mais estreita com o advento dos abutments preparáveis como o UCLA (Universal Casting Long Abutment), que permitem modificações em seu desenho, em relação à altura, conicidade, inclinação e até mesmo quanto ao desenho marginal utilizado. Tudo isso para permitir que a restauração que será cimentada sobre este abutment, retomando os conceitos da prótese telescópica, alcance o máximo de adaptação, manutenção da saúde dos tecidos de suporte e estética.

Desta forma, torna-se necessária a reavaliação de conceitos por muitas vezes já estabelecidos na Odontologia, para que esses possam ser agora reaplicados à nova realidade da Implantodontia e da Prótese sobre Implantes.

Diante disso, este estudo avaliou a influência de três diferentes desenhos de margem confeccionados sobre abutments tipo UCLA calcináveis no desajuste cervical, na infiltração marginal e na resistência à tração de copings metálicos cimentados com um cimento temporário sobre esses abutments modificados. 
Em 1978, apenas 29\% dos laboratórios odontológicos usavam ligas de $\mathrm{Ni}-\mathrm{Cr}$ ou $\mathrm{Cr}$-Co para fundições de metais e para restaurações metalo-cerâmicas. Entretanto, devido ao alto custo e à instabilidade dos preços dos metais nobres, esse quadro foi revertido e já em 1980 e 1981, a porcentagem de laboratórios que faziam uso dessas ligas predominantemente de metais básicos aumentou para $66 \%$ e $70 \%$ respectivamente. Hoje, sabe-se que a grande maioria dos trabalhos que deixam os laboratórios de prótese é confeccionada em ligas não-nobres, devido não apenas ao seu baixo custo, mas também a alta dureza, menor densidade, maior rigidez (módulo de elasticidade) e comparável resistência clínica ao manchamento e à corrosão. ${ }^{1}$ Apesar de todas essas vantagens, as ligas não-nobres apresentam maior dificuldade de adaptação quando comparadas às ligas nobres, requerendo procedimentos especiais para compensar adequadamente sua contração de solidificação. ${ }^{1}$ Entretanto, devido ao uso em larga escala dessas ligas, a grande maioria dos técnicos comerciais apresenta domínio da técnica de fundição garantindo resultados satisfatórios. Dessa forma, no presente estudo, a liga de $\mathrm{Ni}-\mathrm{Cr}$ foi selecionada para a fundição dos espécimes, com o objetivo de aproximar os resultados obtidos à realidade da clínica odontológica. 
Alguns estudos $13,17,18,24,42,43,50,54$ mencionados na literatura discorrem sobre desenhos de margens em preparos dentários, mas existe uma grande lacuna sobre a discussão referente a possíveis diferentes desenhos das margens dos abutments e suas possíveis implicações no resultado final das próteses sobre eles adaptadas.

Os resultados do presente estudo mostraram valores médios semelhantes para o desajuste cervical dos copings metálicos quando cimentados sobre os três desenhos de margem avaliados (ombro $-0.009 \mathrm{~mm}$; chanferete $-0.008 \mathrm{~mm}$; chanfro profundo $0.005 \mathrm{~mm}$ ) sem diferença estatisticamente significante entre eles. Apesar de referentes a preparos sobre abutments, esses resultados estão de acordo com os achados de TJAN, MILLER e SARKISSIAN $^{56}$ que não encontraram diferença estatística do desajuste cervical promovido por coroas totais metálicas cimentadas sobre preparos em dentes com desenhos de margem em ombro ou em chanferete. Nesse estudo, os autores também incluíram o desenho em ombro biselado, que também não apresentou diferenças estatísticas com ou demais desenhos já apresentados. Estudos como os de DEDMON ${ }^{11}$ e de GAVELIS, MORENCY, RILEY e SOZIO ${ }^{18}$ também não encontraram diferença entre os términos em ombro e em chanfro, assim como outros 
autores que não encontraram influência no desenho da margem no desajuste cervical. ${ }^{6,8,44,49}$

A infiltração marginal também é discutida na literatura por GU e KERN ${ }^{20}$ e por MONDELLI, ISHIKIRIAMA e GALAN JR, ${ }^{38}$ mas no entanto, é relacionada apenas ao material de confecção das coroas, ao agente cimentante utilizado, a técnicas de proteção e ao tempo. Não foi encontrado nenhum estudo que tenha procurado avaliar a influência do desenho da margem na infiltração marginal. Essa hipótese foi levantada a partir da suposição de que um desenho de margem que causasse um maior desajuste cervical poderia levar a uma maior exposição e solubilização da linha de cimento, levando assim a infiltração marginal, uma vez que segundo MONDELLI, ISHIKIRIAMA e GALAN JR, ${ }^{38}$ a infiltração marginal é condição determinante da solubilidade e alteração dimensional do agente cimentante.

Entretanto, os presentes resultados mostraram não haver diferença estatisticamente significante quanto à infiltração marginal quando comparados os três desenhos de margem avaliados neste estudo, que apresentaram medianas idênticas para os escores atribuídos (ombro - 0.00; chanferete - 0.00; chanfro profundo $0.00)$. 
Negando a hipótese levantada nesse estudo, os testes de correlação mostraram não haver influência do desajuste cervical na infiltração marginal dos copings metálicos, com as variáveis utilizadas.

A retenção também é importante no sucesso das restaurações, pois segundo $\mathbf{P I E M J A I},{ }^{44}$ a retenção e a discrepância cervical são os fatores cruciais na longevidade das coroas metálicas. Ainda segundo esse autor, o desenho do preparo, incluindo o da margem afeta significativamente a retenção da coroa cimentada. Ele comprova em seu trabalho que o desenho de margem em ombro promove uma retenção semelhante ao desenho de ombro biselado, mas que por outro foi significativamente mais retentivo quando comparado ao chanfro. Esses resultados são diferentes dos obtidos no presente estudo onde foi encontrado que o término em ombro não foi estatisticamente diferente quanto à resistência à tração quando comparado aos términos em chanferete e chanfro profundo. Por outro lado, uma diferença estatisticamente significante foi encontrada quando o desenho em chanferete foi comparado ao desenho em chanfro profundo, sendo que esse último mostrou-se mais retentivo.

É preciso ressaltar, entretanto, que os valores retentivos apresentados pelos três grupos avaliados nesse estudo (ombro - 
$5.55 \mathrm{Kgf}$; chanferete $-4.10 \mathrm{Kgf}$; chanfro profundo $-6.54 \mathrm{Kgf}$ ) são numericamente maiores do que aquele necessário para o deslocamento de uma restauração em função no sentido de seu longo eixo que é de aproximadamente $300 \mathrm{~g}$. Dessa forma, pode-se presumir que os três desenhos de margem avaliados nesse estudo são capazes de manter a restauração em posição durante a função.

Entretanto, como o que está sendo avaliado no presente estudo é a retenção de casquetes metálicos cimentados sobre abutments de implantes, não se pode esquecer o princípio da reversibilidade, necessário nas próteses sobre implantes. Considerando este princípio, a escolha do desenho de margem nesse caso poderia ser baseada não no maior valor retentivo apresentado pelo desenho em chanfro profundo, mas pelo menor valor, representado nesse trabalho pelo desenho em chanferete. Dessa forma, no caso da necessidade da remoção da restauração retida por implantes para uma reavaliação ou reparo, ${ }^{3}$ a utilização de um término em chanferete faria com que o clínico necessitasse de uma menor força em aproximadamente $2 \mathrm{~kg}$ para a remoção da mesma, correndo assim, menos riscos de danificar essa restauração, mantendo mais facilmente o princípio da reversibilidade. 
A importância da manutenção da reversibilidade justifica a utilização de um cimento temporário para a cimentação definitiva das restaurações implanto-suportadas..$^{2-4,7,10,25,31,37,47}$ Por isso, seleção do cimento temporário Temp Bond NE utilizado neste estudo foi baseada nos achados de AKASHI, FRANCISCHONE, TOKUTSUNE e SILVA JR $^{2}$ e de REgO e SANTIAGO ${ }^{48}$ que comprovam que este cimento apresenta os menores valores retentivos quando comparados a outros disponíveis no mercado odontológico.

Novamente, testes de correlação foram utilizados nesse estudo para testar a hipótese da influência do desenho da margem na resistência à tração dos casquetes metálicos cimentados. Apesar da diferença estatisticamente significante encontrada entre os grupos avaliados com relação à resistência à tração, os resultados não foram estatisticamente significantes para essa correlação, negando, portanto, esta hipótese. Novamente, esses resultados estão de acordo com os achados de PIEMJAI ${ }^{44}$ que apesar de encontrar diferenças significativas no que diz respeito à força retentiva quando comparados os desenhos em chanfro e em ombro, também não encontrou relação entre a adaptação e a retenção das restaurações testadas em seu estudo. 
Alguns fatores devem ser levados em consideração na avaliação dos resultados do presente estudo.

Muito embora se tenha consciência absoluta dos aspectos relacionados à fundição e sua condição de dificuldade de padronização, mesmo cercando-se de todos os cuidados, estas variáveis poderiam ser aqui consideradas, porém, elas são as mesmas que aconteceriam em procedimentos clínicos semelhantes. Além disso, pequenas alterações existentes, inerentes aos processos de fundição podem ser compensadas com a cimentação dos copings metálicos, garantindo uma adaptação passiva das peças.

Além disso, nesse estudo foram utilizados análogos e abutments de $3.75 \mathrm{~mm}$ de diâmetro. Nesse caso, as dimensões disponíveis para o preparo e desenho do término cervical são diminutas, o que não permite uma extrapolação para outras dimensões de implantes e abutments, onde um maior espaço para a confecção do preparo poderia alterar as relações entre restauração/abutment.

Por essas razões e devido à escassez de estudos que relacionem os princípios básicos da Odontologia Restauradora sobre dentes à Prótese sobre Implantes, novos estudos tornam-se 
necessários, para que se avaliem novas variáveis em novas dimensões, pois a falta de estudos que correlacionem estes fenômenos nos leva a aferir condições e baseá-las em extrapolações coerentes. Além disso, dão margem a uma busca científica interessante na área dos desajustes marginais, visto que se situam muitas vezes dentro de tecidos gengivais com características diferentes dos quais circundam os dentes, podendo causar distúrbios teciduais, imediatos ou tardios, como doença peri-implantar inflamatória ou recessões gengivais as quais teriam uma implicação estética imediata.

Dessa forma, será possível a manutenção de uma estabilidade entre os componentes implante/restauração/tecidos de suporte, garantindo a longevidade do tratamento reabilitador, além de permitir o desenvolvimento de novas técnicas restauradoras baseadas nas próteses telescópicas cimentadas, com estruturas pré-fabricadas que apresentem o melhor design baseado em relatos científicos, garantindo saúde, função e estética e conseqüentemente, a satisfação do paciente e do profissional. 
7 CONCLUSÃO 


\section{Conclusão}

Com base nos resultados obtidos neste trabalho, podemos concluir que:

1. Não há diferença significativa no desajuste cervical de copings metálicos cimentados sobre abutments metálicos de $4.1 \mathrm{~mm}$ de diâmetro preparados com desenhos de margem em chanferete, chanfro profundo ou ombro;

2. Não há diferença significativa quanto à infiltração marginal de copings metálicos cimentados sobre abutments metálicos de $4.1 \mathrm{~mm}$ de diâmetro preparados com desenhos de margem em chanferete, chanfro profundo ou ombro;

3. Com relação à resistência à tração, foram necessárias forças significativamente maiores para o tracionamento de copings metálicos cimentados sobre abutments metálicos de $4.1 \mathrm{~mm}$ de diâmetro preparados com desenho de margem em chanfro profundo quando comparados àqueles cimentados sobre abutments preparados com desenho de margem em chanferete; 
4. Não há diferença significativa na resistência à tração de copings metálicos cimentados sobre abutments metálicos de $4.1 \mathrm{~mm}$ de diâmetro preparados com desenhos de margem em chanfro profundo quando comparados àqueles cimentados sobre abutments com preparos em ombro ou quando o ombro foi comparado ao chanferete;

5. Não há influência do desajuste cervical na resistência à tração dos copings metálicos cimentados sobre abutments metálicos de $4.1 \mathrm{~mm}$ de diâmetro até o nível de desajuste encontrado e;

6. Não há influência do desajuste cervical na infiltração marginal dos copings metálicos cimentados sobre abutments metálicos de $4.1 \mathrm{~mm}$ de diâmetro até o nível de desajuste encontrado. 
ANEXOS 


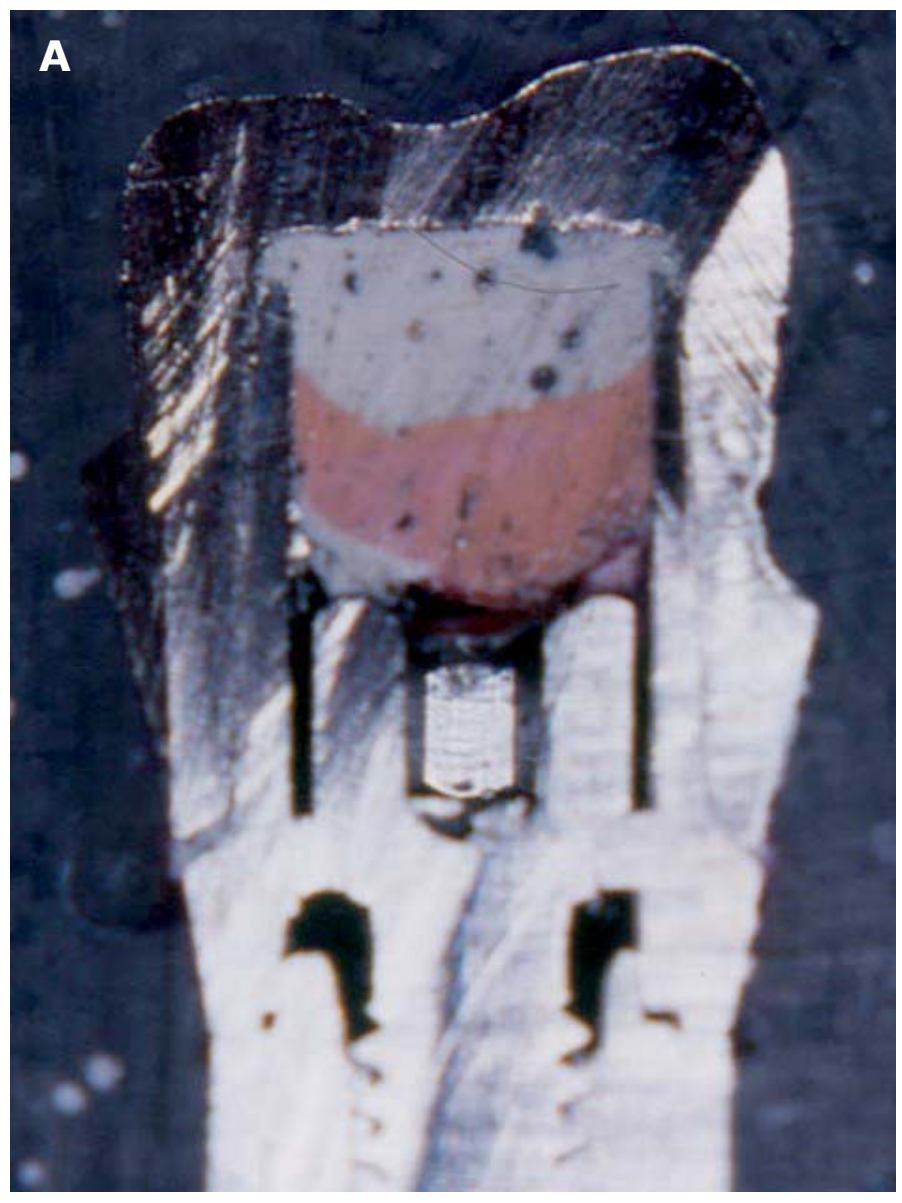

Fig. 26 - A. Corte longitudinal do espécime para teste de infiltração marginal; B. 1,2 e 3 -áreas avaliadas, $\mathrm{C}$ - coping metálico, U - UCLA, I - implante, P parafuso

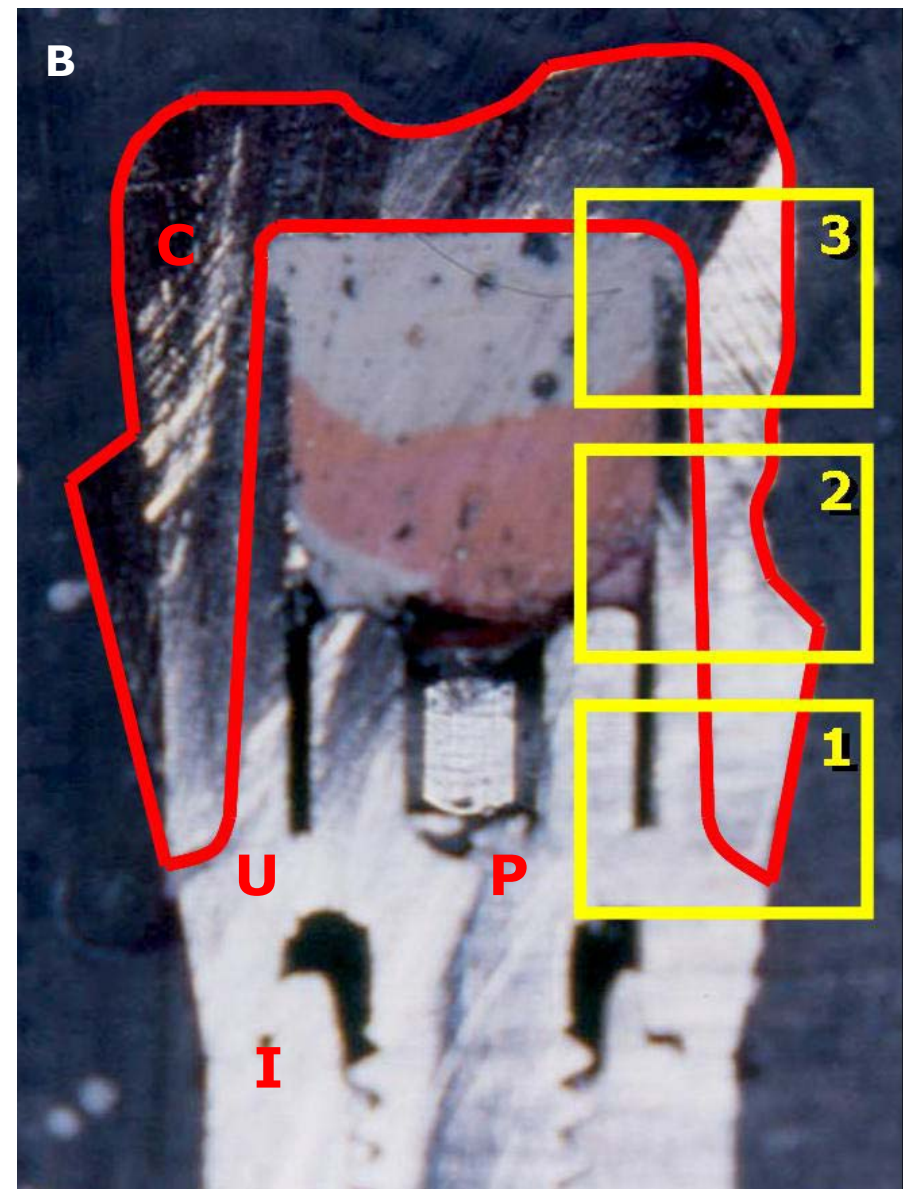




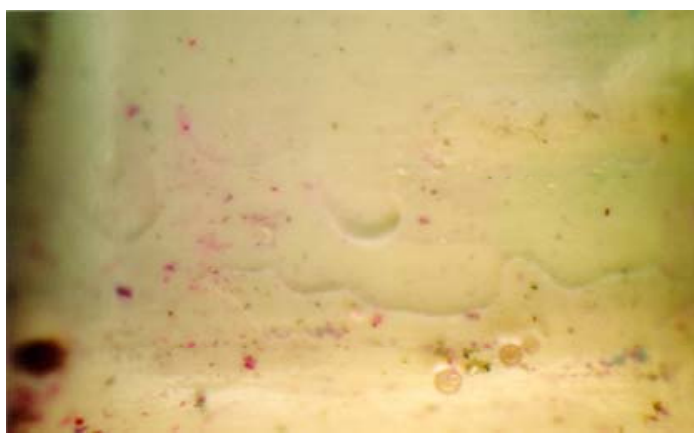

Fig.27 - pigmentação do cimento pela fuccina $(40 \mathrm{X})$

$(40 \mathrm{X})$

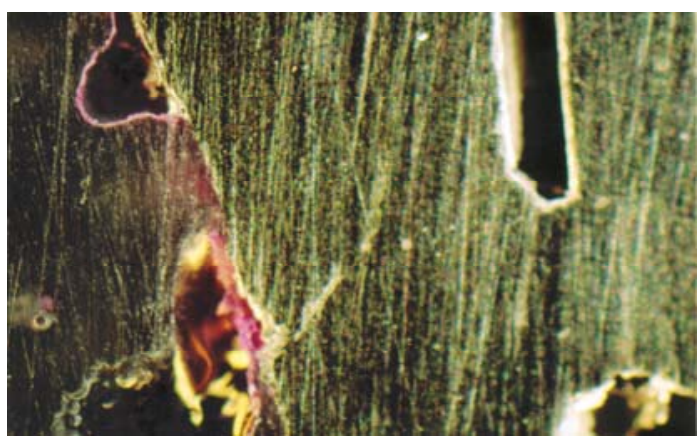

Fig.29 - adaptação adequada em término em chanferete (40X) Área - 1
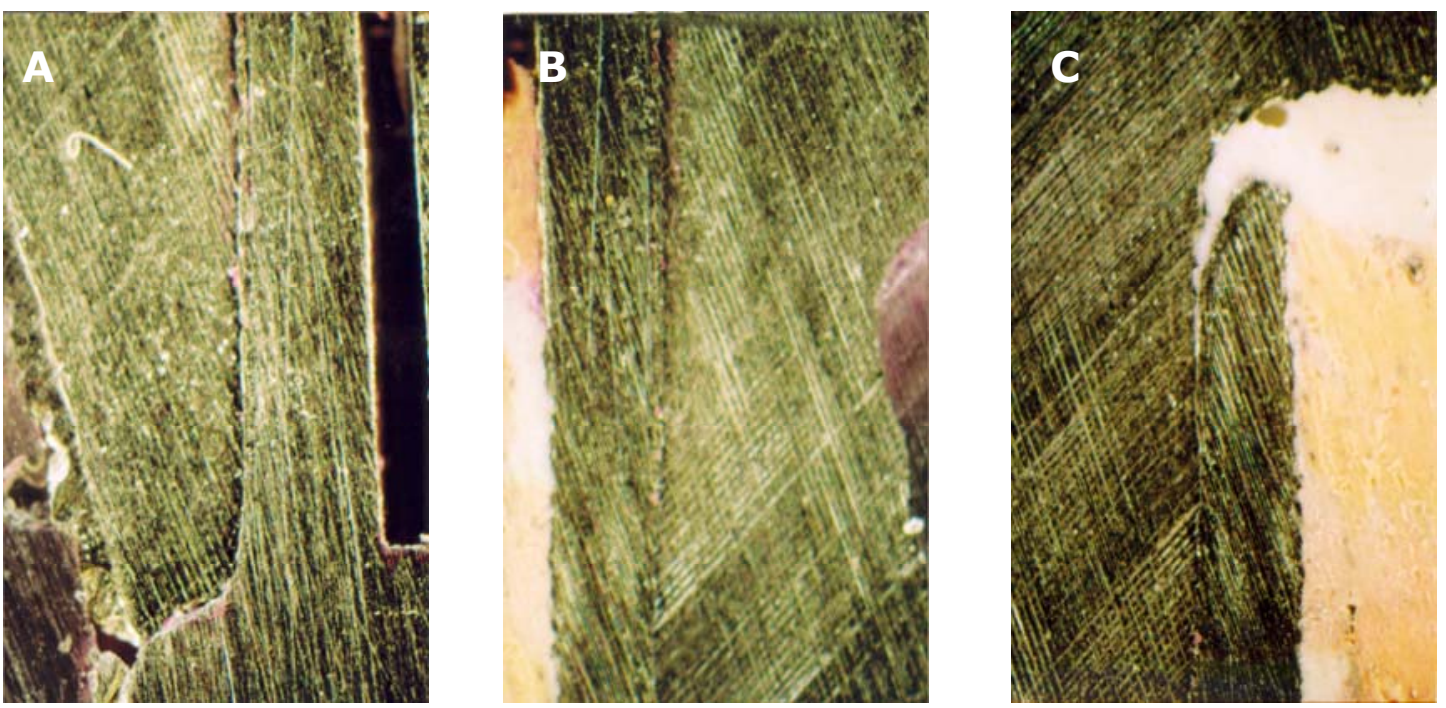

Fig.31 - espécime com desenho em chanfro profundo com escore 6 por apresentar infiltração em A. na região cervical (Área - 1); B. no meio da parede axial (Área - 2); C. na parede axial, próximo a oclusal (Área - 3) (40X) 


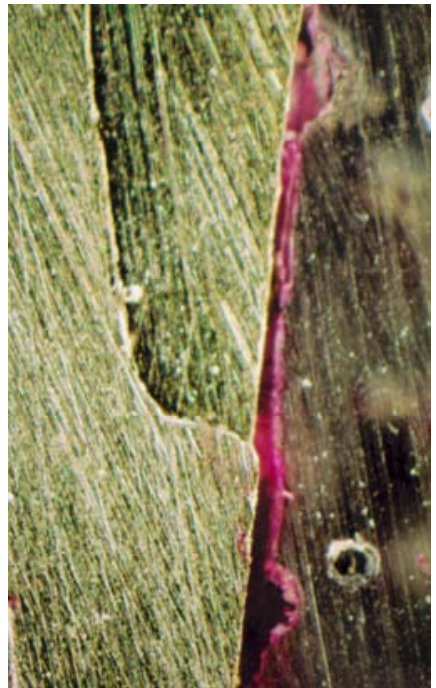

Fig.32 - desenho em

chanfro profundo (40X)

Área - 1

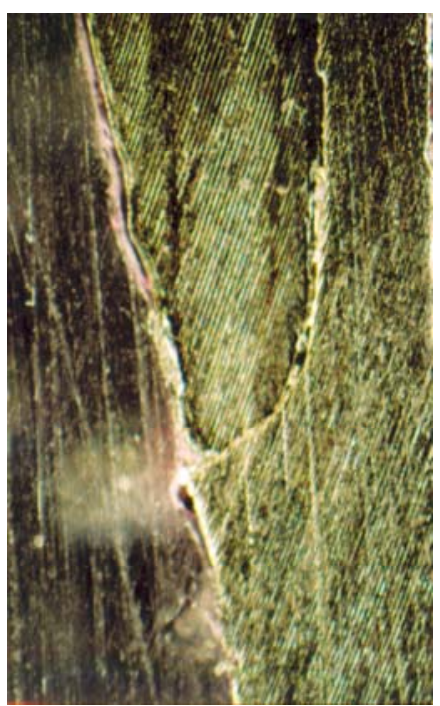

Fig.35 - chanferete (40X) Área - 1

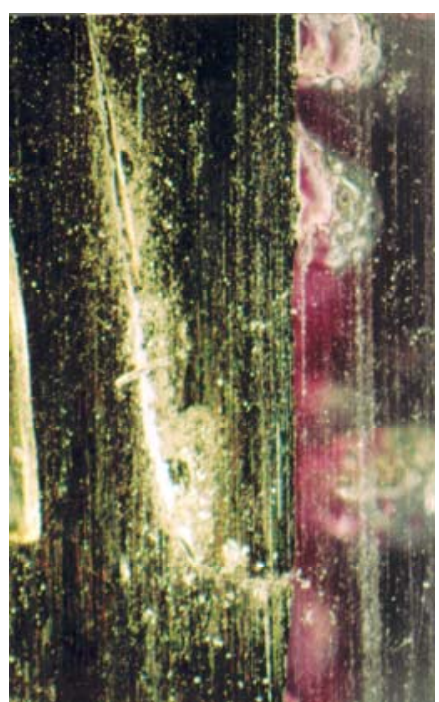

Fig.33 - linha de cimento bem evidente (40X)

Área - 1

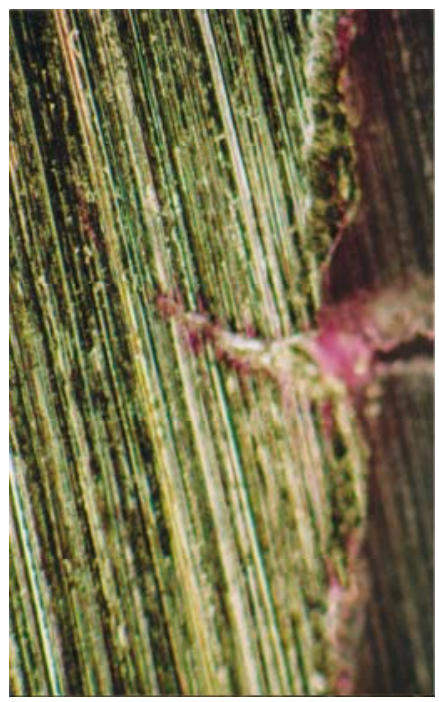

Fig. 36 - escore 3 (80X) Área - 1

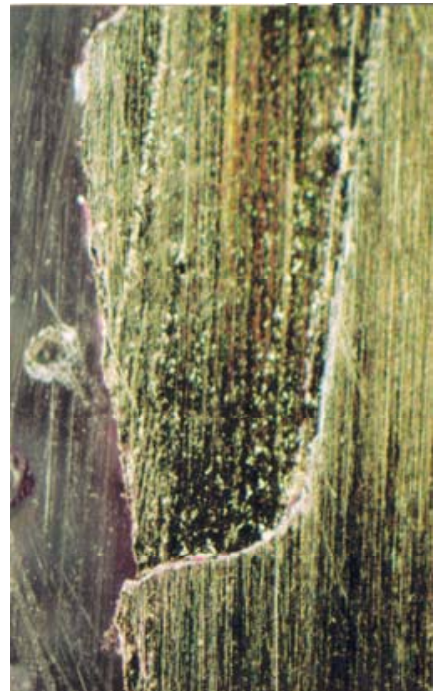

Fig.34 - espécime com escore 3 (40X)

Área - 1

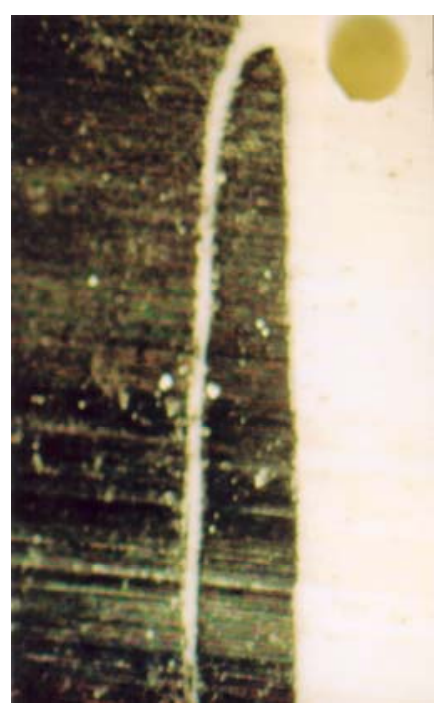

Fig. 37 - linha de cimento espessa (40X) Área - 3

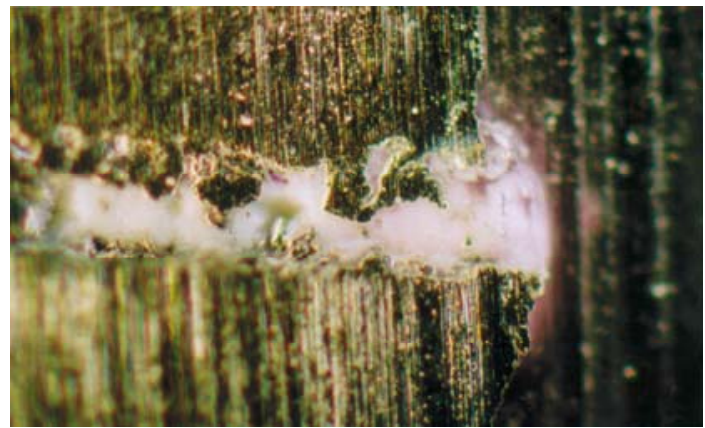

Fig.38 - infiltração escore 1 (160X)

Área - 1 
Tabela 9 - Valores absolutos para o desajuste cervical obtidos com a cimentação temporária (em $\mathrm{mm}$ ) para cada espécime (G1 ombro; G2 - chanfro profundo; G3 - chanfro).

\begin{tabular}{cccc}
\hline GRUPO & DESAJUSTE & GRUPO & DESAJUSTE \\
\hline 1 & 0,002 & 1 & 0,020 \\
1 & 0,023 & 1 & 0,003 \\
\hline 1 & 0,028 & 1 & 0,008 \\
\hline 1 & 0,005 & 1 & 0,009 \\
\hline 1 & 0,005 & 1 & 0,006 \\
\hline 1 & 0,007 & 1 & 0,006 \\
\hline 1 & 0,002 & 1 & 0,007 \\
\hline 1 & 0,005 & 1 & 0,008 \\
\hline 1 & 0,003 & 1 & 0,006 \\
\hline 1 & 0,002 & 1 & 0,025 \\
\hline 2 & 0,000 & 2 & 0,003 \\
\hline 2 & 0,002 & 2 & 0,009 \\
\hline 2 & 0,002 & 2 & 0,004 \\
\hline 2 & 0,005 & 2 & 0,008 \\
\hline 2 & 0,005 & 2 & 0,011 \\
\hline 2 & 0,006 & 2 & 0,005 \\
\hline 2 & 0,000 & 2 & 0,009 \\
\hline 2 & 0,007 & 2 & 0,003 \\
\hline 2 & 0,003 & 2 & 0,013 \\
\hline 2 & 0,004 & 2 & 0,001 \\
\hline 3 & 0,005 & 3 & 0,009 \\
\hline 3 & 0,009 & 3 & 0,005 \\
\hline 3 & 0,000 & 3 & 0,004 \\
\hline 3 & 0,008 & 3 & 0,007 \\
\hline 3 & 0,010 & 3 & 0,040 \\
\hline 3 & 0,000 & 3 & 0,009 \\
\hline 3 & 0,013 & 3 & 0,012 \\
\hline 3 & 0,008 & 3 & 0,007 \\
\hline 3 & 0,009 & 3 & 0,000 \\
\hline & 0,000 & 3 & 0,005 \\
\hline 3 & & & \\
\hline
\end{tabular}


Tabela 10 - Escores para infiltração marginal obtidos para cada espécime (G1 - ombro; G2 - chanfro profundo; G3 - chanfro).

\begin{tabular}{|c|c|}
\hline GRUPO & ESCORE \\
\hline 1 & 3 \\
\hline 1 & 0 \\
\hline 1 & 1 \\
\hline 1 & 0 \\
\hline 1 & 0 \\
\hline 1 & 0 \\
\hline 1 & 0 \\
\hline 1 & 0 \\
\hline 1 & 0 \\
\hline 1 & 0 \\
\hline 2 & 0 \\
\hline 2 & 0 \\
\hline 2 & 0 \\
\hline 2 & 6 \\
\hline 2 & 2 \\
\hline 2 & 0 \\
\hline 2 & 0 \\
\hline 2 & 0 \\
\hline 2 & 0 \\
\hline 2 & 0 \\
\hline 3 & 2 \\
\hline 3 & 0 \\
\hline 3 & 0 \\
\hline 3 & 0 \\
\hline 3 & 0 \\
\hline 3 & 0 \\
\hline 3 & 0 \\
\hline 3 & 0 \\
\hline 3 & 0 \\
\hline 3 & 0 \\
\hline
\end{tabular}


Tabela 11 - Valores absolutos para resistência à tração obtidos (em Kgf) para cada espécime (G1 - ombro; G2 - chanfro profundo; G3 - chanfro).

\begin{tabular}{|c|c|}
\hline GRUPO & RESISTÊNCIA À TRAÇÃO \\
\hline 1 & 0,825 \\
\hline 1 & 6,325 \\
\hline 1 & 6,225 \\
\hline 1 & 7,050 \\
\hline 1 & 4,800 \\
\hline 1 & 3,375 \\
\hline 1 & 7,575 \\
\hline 1 & 7,225 \\
\hline 1 & 4,900 \\
\hline 1 & 7,275 \\
\hline 2 & 7,825 \\
\hline 2 & 5,425 \\
\hline 2 & 8,125 \\
\hline 2 & 5,100 \\
\hline 2 & 6,900 \\
\hline 2 & 4,000 \\
\hline 2 & 10,850 \\
\hline 2 & 5,875 \\
\hline 2 & 7,775 \\
\hline 2 & 3,600 \\
\hline 3 & 4,650 \\
\hline 3 & 1,150 \\
\hline 3 & 4,400 \\
\hline 3 & 3,925 \\
\hline 3 & 6,175 \\
\hline 3 & 6,450 \\
\hline 3 & 1,025 \\
\hline 3 & 6,050 \\
\hline 3 & 4,325 \\
\hline 3 & 2,925 \\
\hline
\end{tabular}




\section{REFERÊNCIAS BIBLIOGRÁFICAS}


1. ANUSAVICE, K.J. Ligas Odontológicas para Fundição. In: - Philips Materiais Dentários. $10^{a}$ ed. Rio de Janeiro, Guanabara Koogan, 1998, Cap. 20, p.24870.

2. AKASHI, A.E.; FRANCISCHONE, C.E.; TOKUTSUNE, E.; SILVA JR, W. Effects of different types of temporary cements on the tensile strength and marginal adaptation of crowns on implants. J Adhes Dent, v.4, n.4, p.309-15, Winter 2002.

3. AKÇA, K.; İPLIKÇIOĞLU, H.; ÇEHRELI, M.C. Comparison of uniaxial resistance forces of cements used with implantsupported crowns. Int J Oral Maxillofac Implants, v.17, n.4, p.536-42, Jul/Aug 2002.

4. ALFARO, M.A.; PAPAZOGLOU, E.; McGLUMPHY, E.A.; HOLLOWAY, J.A. Short-term retention properties of cements for retrievable implant-supported prostheses. Eur J Prosthodont Restor Dent, v.12, n.1, p.33-37, Mar 2004.

5. ANDERSSON, B.; ÖDMAN, P.; LINDVALL, A-M.; BRÅNEMARK, P-I. Cemented single crowns on osseointegrated implants after 5 years: Results from a prospective study on CeraOne. Int J Prosthodont, v.11, n.3, p.212-18, May/Jun 1998.

6. BELSER, U.C.; MacENTEE, M.I.; RICHTER, W.A. Fit of three porcelain-fused-to-metal marginal designs in vivo: $A$ scanning electron microscope study. J Prosthet Dent, v.53, n.1, p.24-9, Jan 1985.

7. BREEDING, L.C.; DIXON, D.L.; BOGACKI, M.T.; TIETGE, J.D. Using of luting agents with an implant system: Part I. J Prosthet Dent, v.68, n.5, p.737-41, Nov 1992.

8. BYRNE, G. Influence of finish-line form on crown cementation. Int J Prosthodont, v.5, n.2, p.137-44, 1992. 
9. CLAYTON, G.H.; DRISCOLL, C.F.; HONDRUM, S.O. The effect of lutting agents on the retention and marginal adaptation of the CeraOne implant system. Int J Oral Maxillofac Implants, v.12, n.5, p.660-5, Sep-Oct 1997.

10. COVEY, D.A.; KENT, D.K.; GARMAIN JR, H.A.S.; KOKA, S. Effects of abutment size and luting cement type on the uniaxial retention force of implant-supported crowns. J Prosthet Dent, v.83, n.3, p.344-8, Mar 2000.

11. DEDMON, H.W. The relationship between open margins and margin designs on full cast crowns made by commercial dental laboratories. J Prosthet Dent, v.53, n.4, p.463-66, Apr 1985.

12. DIXON, D.L.; BREEDING, L.C.; LILLY, K.R. Use of luting agents with an implant system: Part II. J Prosthet Dent, v.68, n.6, p.885-90, Dec 1992.

13. FAUCHER, R.R.; NICHOLLS, J.I. Distortion related to margin design in porcelain-fused-to-metal restorations. J Prosthet Dent, v.43, n.2, p.149-55, Feb 1980.

14. FELTON, D.A.; KANOY, M.A.; BAYNE, M.S.; WIRTHMAN, G.P. Effect of in vivo crown margins discrepancies on periodontal health. J Prosthet Dent, v.65, n.3, p.357-64, Mar 1991.

15. FUSAYAMA, T.; IDE, K.; HOSODA, H. Relief of resistance of cement on full cast crowns. J Prosthet Dent, v.14, n.1, p.95-106, Jan-Feb 1964.

16. GANOR, Y.; INDIG, B.; GROSS, M. Retrievable cemented crown options on implant-supported angled abutments: A case report. Quintessence Int, v.27, n.10, p.679-84, Oct 1996.

17. GARDNER, F.M. Margins of complete crowns-Literature review. J Prosthet Dent, v.48, n.4, p.396-400, Oct 1982. 
18. GAVELIS, J.R.; MORENCY, J.D.; RILEY, E.D.; SOZIO, R.B. The effect of various finish line preparations on the marginal seal and occlusal seat of full crown preparations. J Prosthet Dent, v.15, n.2, p.138-45, Feb 1981.

19. GORODOVSKY, S.; ZIDAN, O. Retentive strength, disintegration, and marginal quality of luting cements. J Prosthet Dent, v.68, n.2, p.269-74, Aug 1992.

20. GU, X.; KERN, M. Marginal discrepancies and leakage of all-ceramic crowns: Influence of lutting agents and aging conditions. Int J Prosthodont, v.16, n.2, p.109-16, MarApr 2003.

21. GUALINI, F.; BERGLUNDH, T. Immunohistochemical characteristics of inflammatory lesions at implants. J Clin Periodontol, v.30, n.1, p.14-18, Jan 2003.

22. GUICHET, D.L.; CAPUTO, A.A.; CHOI, H.; SORENSEN, J.A. Passivity of fit and marginal opening in screw- or cementretained implant fixed partial denture designs. Int J Oral Maxillofac Implants, v.15, n.2, p.239-46, Mar-Apr 2000.

23. GULKER, I. Margins. N Y State Dent J, v.51, p.213-17, Apr 1985.

24. HAMAGUCHI, H.; CACCIATORE, A.; TUELLER, V.M. Marginal distortion of the porcelain-bonded-to-metal complete crown: A SEM study. J Prosthet Dent, v.47, n.2, p.146-53, Feb 1982.

25. HEBEL, K.S.; GAJJAR, R.C. Cement-retained versus screwretained implant restorations: Achieving optimal occlusion and esthetics in implant dentistry. J Prosthet Dent, v.11, n.1, p.28-35, Jan 1997.

26. HOLMES, J.R.; BAYNE, S.C.; HOLLAND, G.A.; SULIK, W.D. Considerations in measurement of marginal fit. J Prosthet Dent, v.62, n.4, p.405-8, Oct 1989. 
27. HUNTER, A.J.; HUNTER, A.R. Gingival margins for crowns: A review and discussion. Part II: Discrepancies and configurations. J Prosthet Dent, v.64, n.6, p.636-42, Dec 1990.

28. ISHIKIRIAMA, A.; BUSATO, A.L.S.; NAVARRO, M.F.L.; MONDELLI, J. Temporary cementation of acrylic resin and cast complete crowns. J Prosthet Dent, v.51, n.5, p.63741, May 1984.

29. KAY, G.W.; JABLONSKI, D.A.; DOGON, I.L. Factors affecting seating and fit of complete crowns: A computer simulation study. J Prosthet Dent, v.55, n.1, p.13-8, Jan 1986.

30. KEITH, S.E.; MILLER, B.H.; WOODY, R.D.; HIGGINBOTTOM, F.L. Marginal discrepancy of screwretained and cemented metal-ceramic crowns on implant abutments. Int J Oral Maxillofac Implants, v.14, n.3, p.369-78, 1999.

31. KENT, D.K.; KOKA, S.; BANKS, S.B.; BEATTY, M.W. Factors influencing retention of a CeraOne gold cylinder. Implant Dent, v.5, n.2, p.96-9, 1996.

32. KOKA, S.; EWOLDSEN, N.O.; DANA, C.L.; BEATTY, M.W. The effect of cementing agent and technique on the retention of a CeraOne gold cylinder: A pilot study. Implant Dent, v.4, n.1, p.32-5, 1995.

33. KOYANO, E.; IWAKU, M.; FUSAYAMA, T. Pressuring techniques and cement thickness for cast restorations. J Prosthet Dent, v.40, n.5, p.544-48, Nov 1978.

34. LEWIS, S.; AVERA, S.; ENGLEMAN, M.; BAUMER, J. The restoration of improperly inclined osseointegrated implants. Int J Oral Maxillofac Implants, v.4, n.2, p.147-52, Summer 1989. 
35. MARKER, V.A.; MILLER, A.W.; MILLER, B.H.; SWEPSTON, J.H. Factors affecting the retention and fit of gold castings. J Prosthet Dent, v.57, n.4, p.425-30, Apr 1987.

36. MICHALAKIS, K.X.; HIRAYAMA, H.; GAREFIS, P.D. Cemented-retained versus screw-retained implant restorations: A critical review. Int J Oral Maxillofac Implants, v.18, n.5, p.719-28, Sep/Oct 2003.

37. MICHALAKIS, K.X.; PISSIOTIS, A.L.; HIRAYAMA, $H$. Cement failure loads of 4 provisional luting agents used for the cementation of implant-supported fixed partial denture. Int J Oral Maxillofac Implants, v.15, n.4, p.545-49, 2000.

38. MONDELLI, J.; ISHIKIRIAMA, A.; GALAN JÚNIOR, J. Marginal microleakage in cemented complete crowns. J Prosthet Dent, v.40, n.5, p.632-36, Dec 1978.

39. MOORE, J.A.; BARGHI, N.; BRUKL, C.E.; KAISER, D.A. Marginal distortion of cast restorations induced by cementation. J Prosthet Dent, v.54, n.3, p.336-40, Sep 1985.

40. OLIVEIRA, J.F.; ISHIKIRIAMA, A.; VIEIRA, D.F.; MONDELLI, J. Influence of pressure and vibration during cementation. J Prosthet Dent, v.41, n.2, p.173-77, Feb 1979.

41. OSTLUND, L.E. Cavity design and mathematics: Their effect on gaps at the margin of cast restorations. Oper Dent, v.10, p.122-37, 1985.

42. PARDO, G.I. A full cast restoration design offering superior marginal characteristics. J Prosthet Dent, v.48, n.5, p.539-43, Nov 1982.

43. PASCOE, D.F. An evaluation of the marginal adaptation of extracoronal restorations during cementation. J Prosthet Dent, v.49, n.5, p.657-62, May 1983. 
44. PIEMJAI, M. Effect of seating force, margin design, and cement on marginal seal and retention of complete metal crowns. Int J Prosthodont, v.14, n.5, p.412-6, Sep-Oct 2001.

45. PREISKEL, H.W.; TSOLKA, P. Telescopic prostheses for implants. Int J Oral Maxillofac Implants, v.13, n.3, p.352-57, May/Jun 1998.

46. PREISKEL, H.W.; TSOLKA, P. Cement- and screw-retained implant-supported prostheses: Up to 10 years follow-up of a new design. Int J Oral Maxillofac Implants, v.19, n.1, p.87-91, Jan/Feb 2004.

47. RAMP, M.H.; DIXON, D.L.; RAMP, L.C.; BREEDING, L.C.; BARBER, L.L. Tensile bond strengths of provisional luting agents used with an implant system. J Prosthet Dent, v.81, n.5, p.510-4, May 1999.

48. REGO, R.M.R.; SANTIAGO, L.C. Retention of provisional crowns cemented with eight provisional cements. Comparative study. J Appl Oral Sci, v.12, n.13, p.20912, Jul/Sep 2004.

49. RICHTER-SNAPP, K.; AQUILINO, S.A.; SVARE, C.W.; TURNER, K.A. Change in marginal fit as related to margin design, alloy type, and porcelain proximity in porcelainfused-to-metal restorations. J Prosthet Dent, v.60, n.4, p.435-9, Oct 1988.

50. SHILLINGBURG, H.T.; HOBO, S.; FISHER, D.W. Preparation design and margin distortion in porcelainfused-to-metal restorations. J Prosthet Dent, v.29, n.3, p.276-84, Mar 1973.

51. SINGER, A.; SERFATY, V. Cement-retained implant supported fixed partial dentures: A 6-month to 3-year follow up. Int J Oral Maxillofac Implants, v. 11, n.5, p.645-49, 1996. 
52. SORENSEN, J.A. A standardized method for determination of crown margin fidelity. J Prosthet Dent, v.64, n.1, p.18-24, Jul 1990.

53. SORENSEN, S.E.; LARSEN, I.B.; JÖRGENSEN, K.D. Gingival and alveolar bone reaction to marginal fit of subgingival crown margins. Scand J Dent Res, v.94, p.109-14, 1986.

54. STRATING, H.; PAMEIJER, C.H.; GILDENHUYS, R.R. Evaluation of the marginal integrity of ceramometal restorations. Part I. J Prosthet Dent, v.46, n.1, p.59-65, Jul 1981.

55. SUTHERLAND, J.K.; LONEY, R.W.; JAROTSKIC, T.J. Marginal discrepancy of ceramic crowns with redesigned implant components. J Prosthet Dent, v.75, n.5, p.5404, May 1996.

56. TJAN, A.H.L.; MILLER, G.D.; SARKISSIAN, R. Internal scape channel to improve the seating of full crowns with various marginal configurations: A follow up study. J Prosthet Dent, v.53, n.6, p.759-63, June, 1985.

57. TORRADO, E.; ERCOLI, C.; MARDINI, M.A.; GRASER, G.N.; TALLENTS, R.H.; CORDARO, L. A comparison of the porcelain fracture resistance of screw-retained and cement-retained implant-supported metal-ceramic crowns. J Prosthet Dent, v.91, n.6, p.532-37, Jun 2004.

58. VALBAO, F.P.B.; PEREZ, E.G.; BREDA, M. Alternative method for retention and removal of cement-retained implant prostheses. J Prosthet Dent, v.86, n.2, p.181-3, Aug 2001.

59. VAN NORTWICK, W.T.; GETTLEMAN, L. Effect of internal relief, vibration and venting on the vertical seating of cemented crowns. J Prosthet Dent, v.45, n.4, p.395-9, Apr 1981. 
60. VIGOLO, P.; GIVANI, A.; MAJZOUB, Z.; CORDIOLI, G. Cemented versus screw-retained implant-supported single-tooth crowns: A 4-year prospective clinical study. Int J Oral Maxillofac Implants, v.19, n.2, p.260-65, Mar/Apr 2004.

61. WANG, C.; MILLSTEIN, P.L.; NATHANSON, D. Effects of cement, cement space, marginal design, seating aid materials, and seating force on crown cementation. J Prosthet Dent, v.67, n.6, p.786-90, Jun 1992.

62. WILSON, P.R. Effect of increasing cement space on cementation of artificial crowns. J Prosthet Dent, v.71, n.6, p.560-64, June 1994.

63. WILSON, P.R.; GOODKIND, R.J.; SAKAGUCHI, R. Deformation of crowns during cementation. J Prosthet Dent, v.64, n.5, p.601-9, Nov 1990.

64. ZARB, G.A.; SCHMITT, A. The longitudinal clinical effectiveness of osseointegrated dental implants: The Toronto study. Part III: Problems and complications encountered. J Prosthet Dent, v.64, n.2, p.185-94, Aug 1990. 
ABSTRACT 


\section{Abstract}

The aim of this study was to evaluate the cervical disadjustment, the marginal leakage and the tensional strength of metalic supra-structures wich were cemented on UCLA abutments with three different margin designs: shoulder, chamfer and deep chamfer. For that, three UCLA abutments received standardized full crown preparations, where only the margin designs varied. Sixty reproductions of these abutments were custom-made, 20 of each margin design, forming the three experimental groups. These abutments were casted and over them, metalic supra-structures were waxed and casted. The cervical disadjustment was evaluated in a travelling microscope, before and after the cementation with TempBond NE. By the subtraction of these values, the final cervical disadjustment values were obtained for each specimen. The specimens were reorganized in two groups of thirty specimens each, with 10 of each margin design. One of these groups was subjected to tensional tests, while the other to marginal leakage test after a period of water imersion of thirty days. The obtained values were subjected to statistic tests. About the cervical disadjustment, the ANOVA showed no statistically significant difference $(p>0.05)$ among the evaluated groups. The same was found by Kruskal-Wallis test, related to marginal leakage. Concerning the tensional strength, ANOVA test showed statistically 
significant difference among the groups $(p<0.05)$. The Tukey test was aplied for multiple comparisons, and statistic difference was found when chamfer and deep chamfer margin designs were compared, where the last one showed higher retentive values. Correlation tests were conducted to evaluate whether the cervical disadjustment could influence the marginal leakage or the tensional strength. However, these correlations were not confirmed $(p>0.05)$. Thus, it can be concluded that the different margin designs had no influence either on the cervical disadjustment or on the marginal leakage of the metallic supra-structures. Yet, with regard to tensile strength, the deep chamfer margin design showed higher values then the chamfer margin design, with no differences when compared to the shoulder margin design. No correlation between the cervical disadjustment and the marginal leakage or the tensile strength was found.

Key-words: cervical disadjustment, marginal leakage, tensile strength, implant, full crown restoration 